\title{
CBP PHASE I CODE INTEGRATION
}

\section{Cementitious Barriers Partnership}

September 2011

CBP-TR-2011-009-1, Rev. 0 



\title{
CBP PHASE I CODE INTEGRATION
}

\author{
Frank G. Smith, III \\ Savannah River National Laboratory \\ Aiken, SC 29808 \\ Kevin G. Brown \\ Vanderbilt University, School of Engineering \\ Consortium for Risk Evaluation with Stakeholder Participation III \\ Nashville, TN 37235 \\ Greg P. Flach \\ Savannah River National Laboratory \\ Aiken, SC 29808 \\ Sohini Sarkar \\ Vanderbilt University, School of Engineering \\ Consortium for Risk Evaluation with Stakeholder Participation III \\ Nashville, TN 37235
}

September 2011

CBP-TR-2011-009-1, Rev. 0 


\title{
ACKNOWLEDGEMENTS
}

This report was prepared for the United States Department of Energy in part under Contract No. DE-AC0908SR22470 and is an account of work performed in part under that contract. Reference herein to any specific commercial product, process, or service by trademark, name, manufacturer, or otherwise does not necessarily constitute or imply endorsement, recommendation, or favoring of same by Savannah River Nuclear Solutions or by the United States Government or any agency thereof. The views and opinions of the authors expressed herein do not necessarily state or reflect those of the United States Government or any agency thereof.

and

This report is based on work supported by the U. S. Department of Energy, under Cooperative Agreement Number DE-FC01-06EW07053 entitled 'The Consortium for Risk Evaluation with Stakeholder Participation III' awarded to Vanderbilt University. The opinions, findings, conclusions, or recommendations expressed herein are those of the author(s) and do not necessarily represent the views of the U.S. Department of Energy or Vanderbilt University.

\section{DISCLAIMER}

This work was prepared under an agreement with and funded by the U. S. Government. Neither the U.S. Government or its employees, nor any of its contractors, subcontractors or their employees, makes any express or implied: 1. warranty or assumes any legal liability for the accuracy, completeness, or for the use or results of such use of any information, product, or process disclosed; or 2. representation that such use or results of such use would not infringe privately owned rights; or 3. endorsement or recommendation of any specifically identified commercial product, process, or service. Any views and opinions of authors expressed in this work do not necessarily state or reflect those of the United States Government, or its contractors, or subcontractors.

\section{Printed in the United States of America}

United States Department of Energy Office of Environmental Management Washington, DC

\author{
This document is available on the U.S. DOE Information Bridge and on the \\ CBP website: http://cementbarriers.org/ \\ An electronic copy of this document is also available through links on the following \\ website: http://srnl.doe.gov/
}




\title{
FOREWORD
}

The Cementitious Barriers Partnership (CBP) Project is a multi-disciplinary, multi-institutional collaboration supported by the United States Department of Energy (US DOE) Office of Waste Processing. The objective of the CBP project is to develop a set of tools to improve understanding and prediction of the long-term structural, hydraulic, and chemical performance of cementitious barriers used in nuclear applications.

A multi-disciplinary partnership of federal, academic, private sector, and international expertise has been formed to accomplish the project objective. In addition to the US DOE, the CBP partners are the Savannah River National Laboratory (SRNL), Vanderbilt University (VU) / Consortium for Risk Evaluation with Stakeholder Participation (CRESP), Energy Research Center of the Netherlands (ECN), and SIMCO Technologies, Inc. The Nuclear Regulatory Commission (NRC) is providing support under a Memorandum of Understanding. The National Institute of Standards and Technology (NIST) is providing research under an Interagency Agreement. Neither the NRC nor NIST are signatories to the Cooperative Research and Development Agreement (CRADA).

The periods of cementitious performance being evaluated are up to or longer than 100 years for operating facilities and longer than 1000 years for waste management. The set of simulation tools and data developed under this project will be used to evaluate and predict the behavior of cementitious barriers used in nearsurface engineered waste disposal systems, e.g., waste forms, containment structures, entombments, and environmental remediation, including decontamination and decommissioning analysis of structural concrete components of nuclear facilities (spent-fuel pools, dry spent-fuel storage units, and recycling facilities such as fuel fabrication, separations processes). Simulation parameters will be obtained from prior literature and will be experimentally measured under this project, as necessary, to demonstrate application of the simulation tools for three prototype applications (waste form in concrete vault, high-level waste tank grouting, and spent-fuel pool). Test methods and data needs to support use of the simulation tools for future applications will be defined.

The CBP project is a five-year effort focused on reducing the uncertainties of current methodologies for assessing cementitious barrier performance and increasing the consistency and transparency of the assessment process. The results of this project will enable improved risk-informed, performance-based decision-making and support several of the strategic initiatives in the DOE Office of Environmental Management Engineering \& Technology Roadmap. Those strategic initiatives include 1) enhanced tank closure processes; 2) enhanced stabilization technologies; 3) advanced predictive capabilities; 4) enhanced remediation methods; 5) adapted technologies for site-specific and complex-wide D\&D applications; 6) improved SNF storage, stabilization and disposal preparation; 7) enhanced storage, monitoring and stabilization systems; and 8) enhanced long-term performance evaluation and monitoring.

\author{
Christine A. Langton, PhD \\ Savannah River National Laboratory \\ David S. Kosson, PhD \\ Vanderbilt University / CRESP
}




\section{CONTENTS}

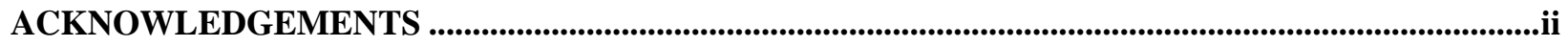

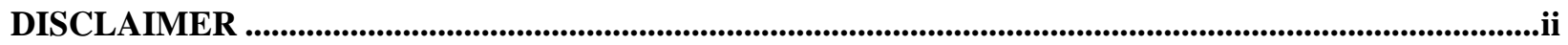

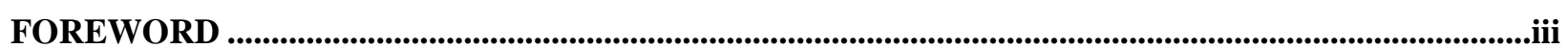

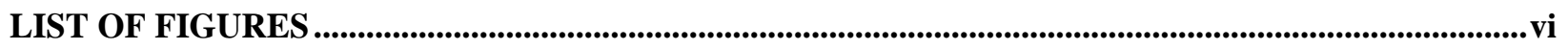

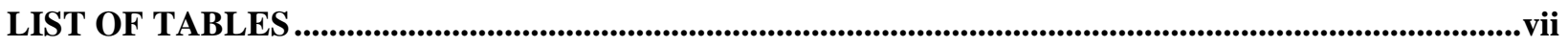

LIST OF ACRONYMS AND ABBREVIATIONS ..................................................................................

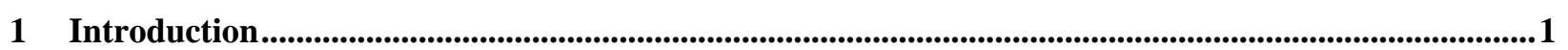

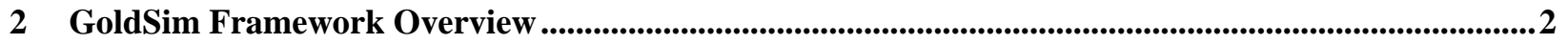

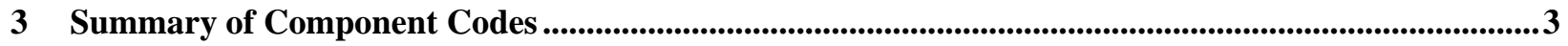

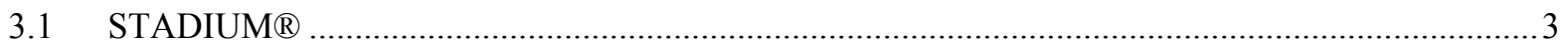

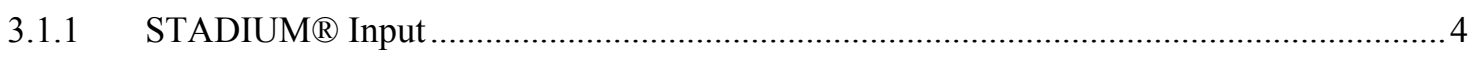

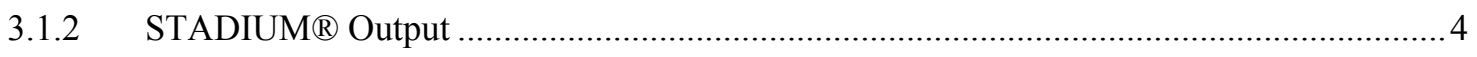

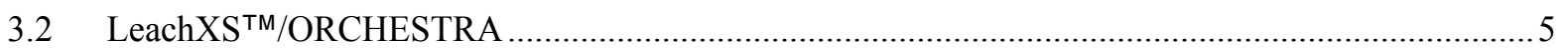

3.2.1 LeachXS T⿳亠丷厂犬RCHESTRA Chemical Equilibrium Input ....................................................

3.2.2 LeachXS ${ }^{\text {TM}} /$ ORCHESTRA Chemical Equilibrium Output ................................................ 6

3.2.3 LeachXS TM/ORCHESTRA Reactive Transport Input ..................................................... 6

3.2.4 LeachXS TM/ORCHESTRA Reactive Transport Output..................................................... 7

4 Phase I Code Integration Model Description and User Guide......................................................................8

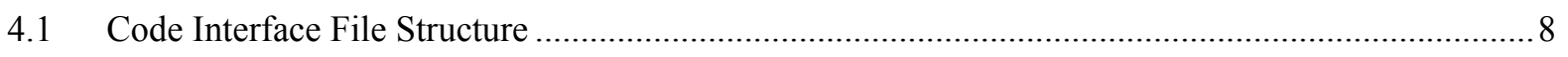

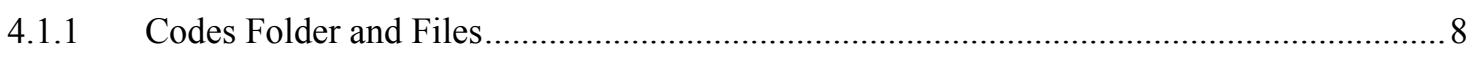

4.1.2 Auxiliary Folders and Files ............................................................................... 9

4.1.3 Template Working Folder and Files...............................................................................

4.2 GoldSim Model Dashboard Controls .......................................................................................... 12

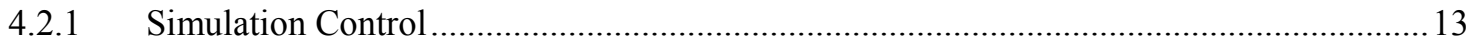

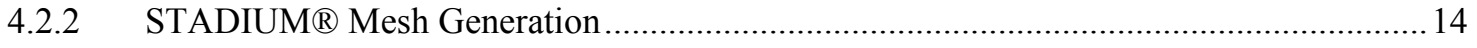

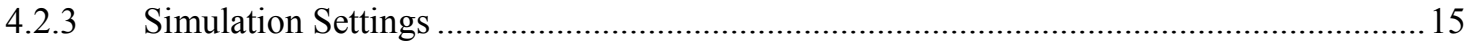

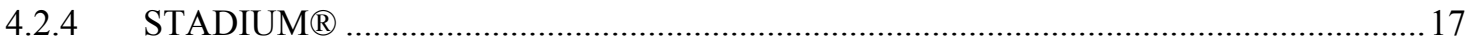

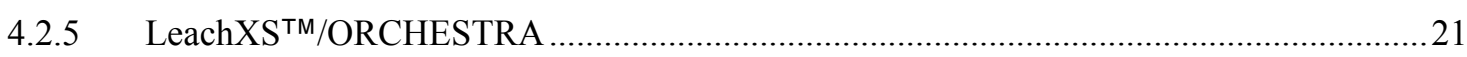

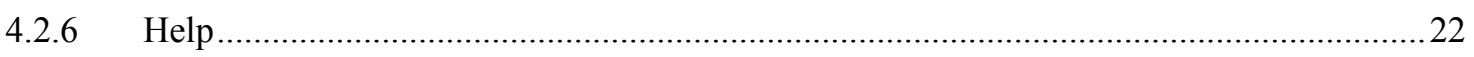

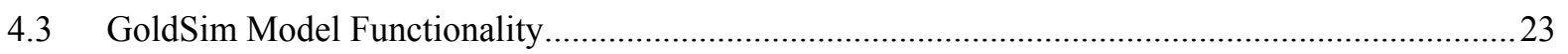

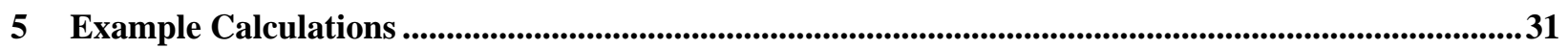

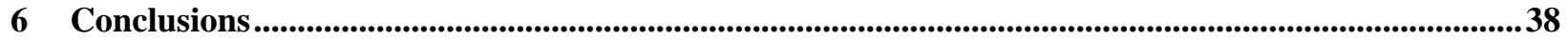




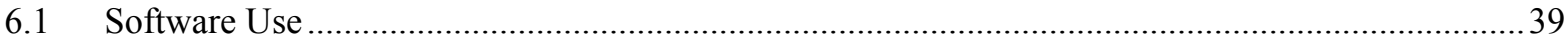

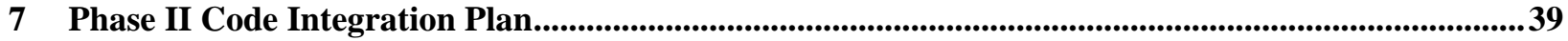

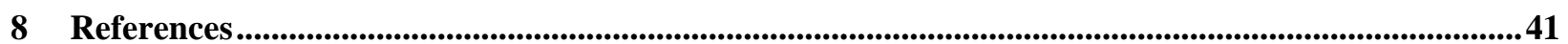
APPENDIX

A Grid Generator Design and Use..................................................................................................43

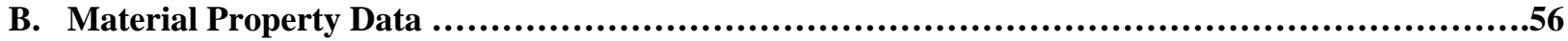




\section{LIST OF FIGURES}

Figure 2-1. Schematic representation of Phase I CBP code integration framework........................................ 3

Figure 4-1. Top-level file structure for CBP code integration application. ................................................. 8

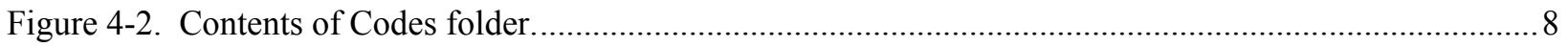

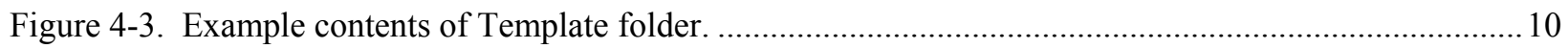

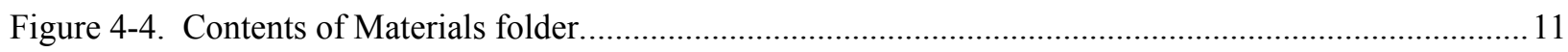

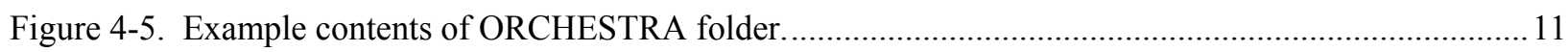

Figure 4-6. Example contents of Runs folder for a STADIUM ${ }^{\circledR}$ simulation................................................ 12

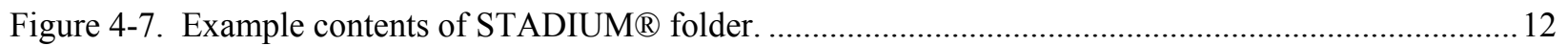

Figure 4-8. Top-level dashboard in GoldSim CBP code integration model. ................................................. 13

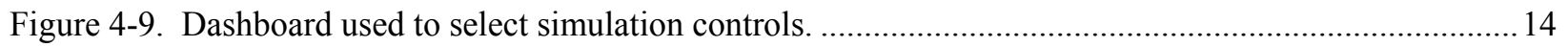

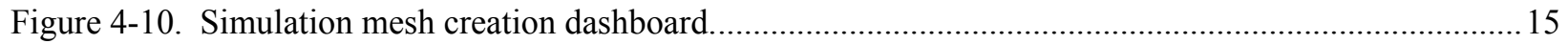

Figure 4-11. GoldSim simulation settings window for time control.............................................................. 16

Figure 4-12. GoldSim simulation settings window for Monte Carlo control. ............................................... 17

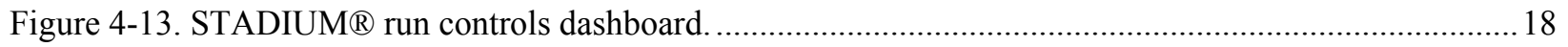

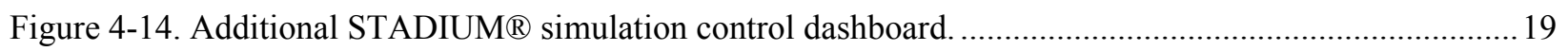

Figure 4-15. Dashboard for selecting a plot of STADIUM ${ }^{\circledR}$ results.............................................................2 20

Figure 4-16. Example GoldSim results display plot for chloride. ….................................................................20

Figure 4-17. LeachXS ${ }^{\mathrm{TM}} /$ ORCHESTRA run controls dashboard..................................................................21

Figure 4-18. Dashboard for selecting a plot of LeachXSTM/ORCHESTRA results...........................................22

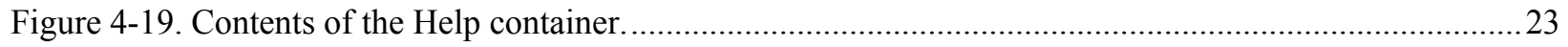

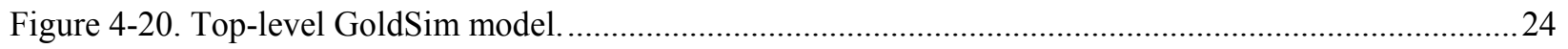

Figure 4-21. Contents of Simulation_Parameters container. ……..................................................................25

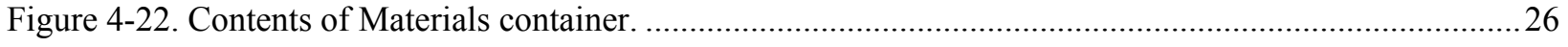

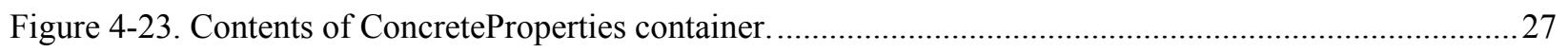

Figure 4-24. Contents of ConcreteComposition container. .............................................................................28

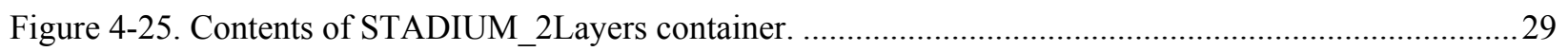

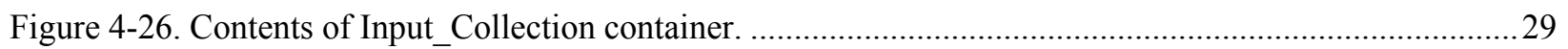

Figure 4-27. Contents of STADIUM_Output_Sorting container................................................................... 30

Figure 5-1. Input file used to generate the one-dimensional STADIUM ${ }^{\circledR}$ mesh for test cases.........................32

Figure 5-2. DLL_STADIUM_2Layers.dat file used in Stadium test cases ......................................................33

Figure 5-3. Ion concentrations at end of Saltstone domain ....................................................................... 34

Figure 5-4. Ion concentrations at Saltstone-concrete interface........................................................................ 34 
Figure 5-5. Nitrate concentration at Saltstone-concrete interface from deterministic calculation and 50 Monte Carlo realizations.

Figure 5-6. Calcium concentration at Saltstone-concrete interface from deterministic calculation and 50 Monte Carlo realizations.

Figure 5-7. Sulfate concentration at Saltstone-concrete interface from deterministic calculation and 50 Monte Carlo realizations.

Figure 5-8. Nitrate concentration at end of Saltstone domain from deterministic calculation and 50 Monte Carlo realizations.

Figure 5-9. Sodium concentration at end of Saltstone domain from deterministic calculation and 50 Monte Carlo realizations.

Figure 5-10. Ettringite concentration (mols / L) computed by LeachXSTM/ORCHESTRA for the nodes in a 3-layer system for single realization. The results for a single realization can be displayed using the built-in GoldSim Array View Element. .38

Figure 7-1. Proposed Phase II CPB code integration framework. .................................................................. 40

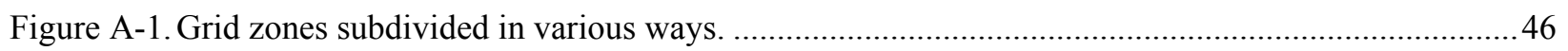

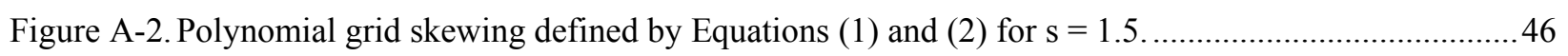

Figure A-3. Example two-dimensional grid generated by Mesh2d............................................................52

\section{LIST OF TABLES}

Table A-1. Superfile format. .47

Table A-2. File format for specifying the $x(i)$ grid coordinates. . .48

Table A-3. File format for specifying the $y(i, j)$ grid coordinates. . .49

Table A-4. File format for specifying the mtyp(i,j) material assignments....................................................50

Table A-5. superfile for example two-dimensional mesh. .............................................................................53

Table A-6. xMesh.dat file for example two-dimensional mesh......................................................................53

Table A-7. yMesh.dat file for example two-dimensional mesh...................................................................5

Table A-8. mtypMesh.dat file for example two-dimensional mesh...............................................................5

Table A-9. example.ply file referenced in mtypMesh.dat for example two-dimensional mesh. ......................55

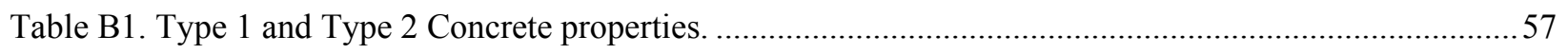

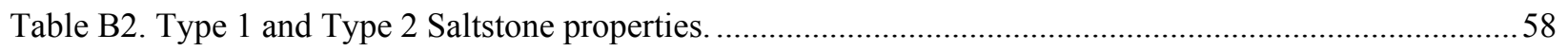

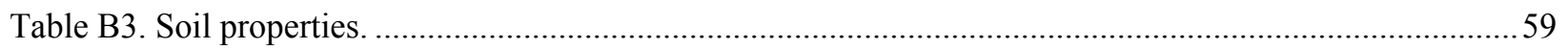




\section{LIST OF ACRONYMS AND ABBREVIATIONS}

CBP Cementitious Barriers Partnership

cpu central processing unit

CRESP Consortium for Risk Evaluation with Stakeholder Participation

DLL Dynamic-link library

DOE Department of Energy

ECN Energy Research Centre of the Netherlands

GTG GoldSim Technology Group

NIST National Institute of Standards and Technology

NRC Nuclear Regulatory Commission

ORCHESTRA Objects Representing CHEmical Speciation and TRAnsport

SRNL Savannah River National Laboratory

SRS Savannah River Site

STADIUM ${ }^{\circledR} \quad$ Software for Transport and Degradation in Unsaturated Materials

THAMES Thermodynamic Hydration And Microstructure Evolution Simulator

VTK Visualization ToolKit

viii 


\title{
CBP Phase I Code Integration
}

\author{
Frank G. Smith, III \\ Savannah River National Laboratory \\ Aiken, SC 29808 \\ Kevin G. Brown \\ Vanderbilt University, School of Engineering \\ Consortium for Risk Evaluation with Stakeholder Participation III \\ Nashville, TN 37235 \\ Greg P. Flach \\ Savannah River National Laboratory \\ Aiken, SC 29808 \\ Sohini Sarkar \\ Vanderbilt University, School of Engineering \\ Consortium for Risk Evaluation with Stakeholder Participation III \\ Nashville, TN 37235
}

\section{INTRODUCTION}

The goal of the Cementitious Barriers Partnership (CBP) is to develop a reasonable and credible set of software tools to predict the structural, hydraulic, and chemical performance of cement barriers used in nuclear applications over extended time frames (greater than 100 years for operating facilities and greater than 1000 years for waste management). The simulation tools will be used to evaluate and predict the behavior of cementitious barriers used in near surface engineered waste disposal systems including waste forms, containment structures, entombments, and environmental remediation. These cementitious materials are exposed to dynamic environmental conditions that cause changes in material properties via (i) aging, (ii) chloride attack, (iii) sulfate attack, (iv) carbonation, (v) oxidation, and (vi) primary constituent leaching. A set of state-of-the-art software tools has been selected as a starting point to capture these important aging and degradation phenomena.

Integration of existing software developed by the CBP partner organizations was determined to be the quickest method of meeting the CBP goal of providing a computational tool that improves the prediction of the longterm behavior of cementitious materials. The CBP partner codes selected for the Phase I integration effort were

- LeachXSTM/ORCHESTRA developed by the Energy Research Centre of the Netherlands (ECN) (ECN 2007, Meeussen 2003) and

- $\quad$ STADIUM® developed by SIMCO Technologies, Inc. (SIMCO 2008). 
These partner codes were selected based on their maturity and ability to address the problems outlined above. The GoldSim Monte Carlo simulation program (GTG 2010a, GTG 2010b) was chosen as the code integration platform (Brown \& Flach 2009b). GoldSim (current Version 10.5) is a Windows based graphical objectoriented computer program that provides a flexible environment for model development (Brown \& Flach 2009b). The linking of GoldSim to external codes has previously been successfully demonstrated (Eary 2007, Mattie et al. 2007). GoldSim is capable of performing deterministic and probabilistic simulations and of modeling radioactive decay and constituent transport.

As part of the CBP project, a general Dynamic Link Library (DLL) interface was developed to link GoldSim with external codes (Smith III et al. 2010). The DLL uses a list of code inputs provided by GoldSim to create an input file for the external application, runs the external code, and returns a list of outputs (read from files created by the external application) back to GoldSim. In this way GoldSim provides: 1) a unified user interface to the applications, 2) the capability of coupling selected codes in a synergistic manner, and 3) the capability of performing probabilistic uncertainty analysis with the codes. GoldSim is made available by the GoldSim Technology Group as a free "Player" version that allows running but not editing GoldSim models. The player version makes the software readily available to a wider community of users that would wish to use the CBP application but do not have a license for GoldSim.

\section{GOLDSIM FRAMEWORK OVERVIEW}

The Phase I CBP code integration work has produced a GoldSim model linked to the STADIUM ${ }^{\circledR}$ and LeachXSTM/ORCHESTRA codes through a custom DLL interface (Smith III et al. 2010). The interface passes input augments from GoldSim to the codes and extracts output from the code-generated result files. In the Phase I interface, the two codes are run independently with no coupling between the codes. The GoldSim interface allows the user to create a one- or two-dimensional mesh for use in the computations and provides limited capabilities for plotting simulation results. Figure 2-1 shows a schematic diagram of the Phase I code integration structure.

GoldSim provides a framework for performing probabilistic analysis with the interfaced codes by including stochastic distributions of model parameters within GoldSim. The analysis is accomplished by utilizing builtin GoldSim capabilities to create and sample stochastic distributions and make repeated model runs (realizations) in conjunction with the code interface's ability to send random values from the distributions as input to the linked codes. This approach is demonstrated by the example calculations presented in Section 5. The standard version of GoldSim allows the user to run up to four realizations simultaneously. If the GTG distributed processing module is licensed, an essentially unlimited number of realizations can be run simultaneously to enhance productivity. 


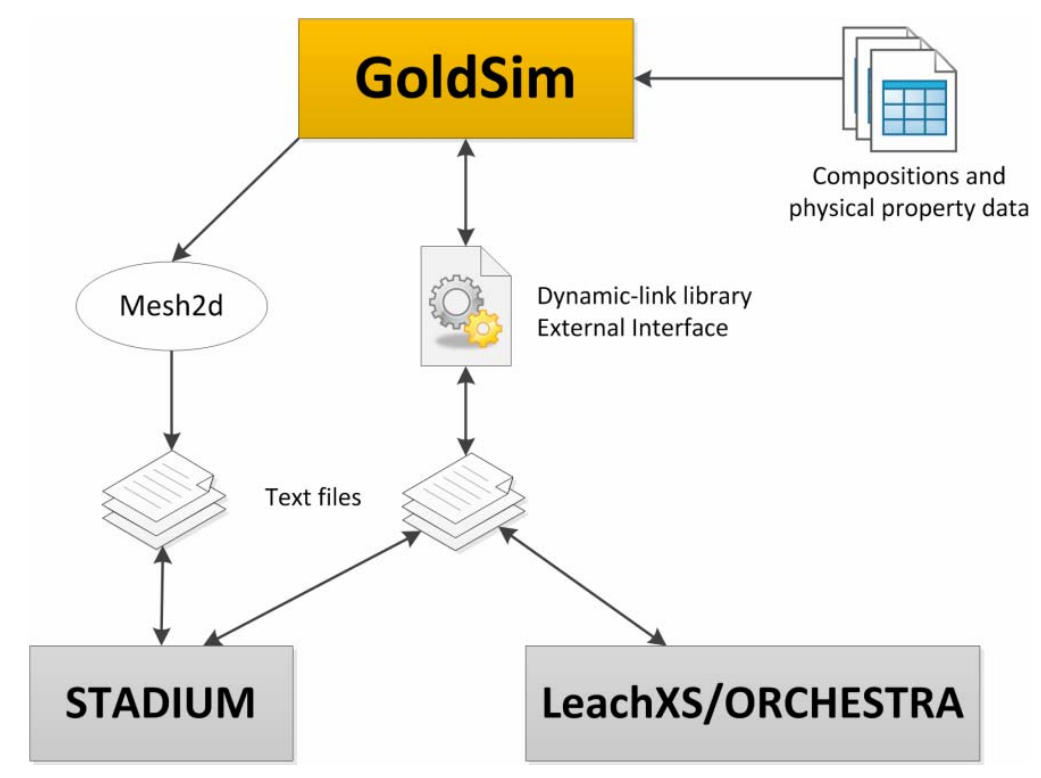

Figure 2-1. Schematic representation of Phase I CBP code integration framework.

\section{SUMMARY OF COMPONENT CODES}

STADIUM and LeachXS ${ }^{\text {TM} / O R C H E S T R A ~ w e r e ~ s e l e c t e d ~ f o r ~ i n c l u s i o n ~ w i t h i n ~ t h e ~ P h a s e ~ I ~ G o l d S i m ~ i n t e g r a t i o n ~}$ framework because the two codes collectively provide more capability than either code alone. A brief description of the selected component codes is provided in this section. This material was summarized from the CBP Task 3 report where more detailed code descriptions are available (Brown \& Flach 2009a).

\subsection{STADIUM®}

SIMCO Technologies, Inc. has developed a numerical model called Software for Transport and Degradation in Unsaturated Materials (STADIUM ${ }^{\circledR}$ ) that can be used to predict the transport of ions and liquids in reactive porous media (SIMCO 2008). The model has been used to predict the degradation of unsaturated concrete structures exposed to chemically aggressive environments. The results provided by STADIUM ${ }^{\circledR}$ have been validated through laboratory test results and field exposure observations. The model has been used to predict the behavior of numerous existing structures exposed to various forms of chemical degradation phenomena. In particular, the model has been used to estimate the service life of concrete under attack from chloride and sulfate ions.

Calculations in the STADIUM ${ }^{\circledR}$ model are divided into two primary modules. The first module accounts for coupled transport of ions and water without considering chemical reactions (e.g., dissolution and precipitation). Transport is modeled using a finite-element version of the extended Nernst-Planck equation, which accounts for the electrical coupling between the ions as well as for the chemical activity of the species in solution. Terms are included to account for the impact of fluid flow and temperature gradients on ionic fluxes. The transport equations are coupled to Poisson's equation, which gives the electrical potential in the material as a function of the ionic distribution and with equations for moisture conservation and heat conduction. 
The second STADIUM ${ }^{\circledR}$ module is a chemical equilibrium code. After each transport step, this module equilibrates the concentrations at each node of the finite element mesh with the phases present. Solid phases can be formed as a result of the penetration of species into the porous network of the material. The variation of solid phases will lead to local variations in porosity. These variations will likely affect the transport properties of the material locally. STADIUM $®$ takes this locally varying phenomenon into account in the transport module described above.

\subsubsection{STADIUM® Input}

The input information needed to run STADIUM ${ }^{\circledR}$ consists of the following information entered into a text file (SIMCO 2008):

- Geometry and Time. STADIUM® performs separate sets of calculations for ionic transport and chemistry. The ionic transport model consists of a set of partial differential equations that are solved using a finite element method. The user must provide the space and time discretization parameters needed for the numerical algorithm.

- Material Properties. The characteristics of the material to be modeled, some of which can be modified by the user through the code integration interface, must be entered. The properties to be entered for the material fall into the following categories: mixture proportions, transport properties, binder chemical composition, and initial state.

- Exposure Conditions (Boundary Conditions). STADIUM® can simulate many different types of exposure conditions for concrete structures. The exposure conditions include information describing the ionic species and temperature and humidity boundary conditions. The user can modify some parameters (e.g., average temperature and relative humidity of the environment, the salinity of seawater, or the concentration of the ionic contaminant). When chloride or sulfate attack is selected, the user enters the initial composition of the solution at the surface.

- Initial Values. Initial values must be provided for each variable in the model including data on the initial composition of the hydrated cement paste. The initial values are divided into three main sections: moisture and temperature, concentration, and solid phases. In the Moisture and Temperature section, the user provides the initial degree of the material saturation and the initial temperature of the material at the beginning of the simulation. In the Concentration section, the user provides the initial (neutral) composition of the pore solution. Finally, the initial content of the solid phases forming the hydrated cement paste of the material must be entered.

- Corrosion and Printing Options. These options control how various output files will be generated. The output frequency (step) is defined. How and where corrosion results are to be computed are also defined. A frequency and number of rebar positions to be analyzed can be entered. The model calculates total chloride content and the chloride/hydroxide ratio in the pore solution at each rebar position at the defined frequency.

\subsubsection{STADIUM ${ }^{\circledR}$ Output}

At the end of a simulation, output text files are created containing the results. Three series of output results are generated by STADIUM ${ }^{(S I M C O ~ 2008): ~}$

- Content versus depth (i.e., species concentrations over the material thickness as a function of time), 
- Content versus time (i.e., corrosion related quantities, in total chloride or chloride/hydroxide ratio at specific locations as a function of time), and

- Corrosion initiation results.

\subsection{LeachXS ${ }^{\text {TM }}$ /ORCHESTRA}

The Leaching eXpert System (LeachXSTM) is a database coupled with an expert system for material characterization and environmental impact assessment based on estimated contaminant release rates derived from leaching tests. Databases used by LeachXSTM include leaching data for over 600 materials, scenarios, and regulations to allow comparisons of test data against specific utilization or disposal conditions. The expert system assists in evaluation and laboratory guidance, data management and evaluation, source term description, impact evaluation, and decision analysis. Applicable materials for assessment using LeachXS ${ }^{\mathrm{TM}}$ include:

- Treated Wastes

- Stabilized Waste

- Construction Materials

- Cement Mortars and Concrete

- Soils and Contaminated Soil

- Sludge
- Compost

- Sediments

- Municipal Wastes

- Industrial and Hazardous Wastes

- Mining Wastes

- Preserved Wood

Geochemical speciation and chemical reaction/transport modeling capabilities are integrated into LeachXS ${ }^{\mathrm{TM}}$ using the Objects Representing CHEmical Speciation and TRAnsport (ORCHESTRA) modeling environment. ORCHESTRA is a modeling framework for defining geochemical equilibrium models and combining these models with mass transport (including diffusion, convection, etc.) and other user defined processes (Meeussen 2003). The ORCHESTRA chemical module can calculate chemical thermodynamic equilibrium in a similar way to other speciation codes, but is internally organized very differently. Instead of defining all model equations within the source code, equations are defined in a separate user accessible text file in ORCHESTRA. ORCHESTRA has been used in practice for a wide range of applications that include aqueous speciation, precipitation, different forms of surface complexation, ion exchange, diffusion (including radial and electroneutral), convection, solid solutions, colloid adsorption, and biota uptake.

\subsubsection{LeachXS ${ }^{\mathrm{TM}}$ /ORCHESTRA Chemical Equilibrium Input}

All models contain one (or more) chemical equilibrium modules that describe the chemical reactions and distribution of elements over different physical-chemical forms in a material. These chemical models require as input:

- A set of chemical equilibrium reactions representative for the material under consideration. LeachXS ${ }^{\mathrm{TM}}$ contains predefined sets for several typical materials (e.g., different soil types and cementitious materials) in the database; however, alternative sets may be provided by users.

- A set of total (or available) element concentrations (i.e., maximum leached concentrations) that can be estimated from total composition measurements or from $\mathrm{pH}$ dependent leaching test results. 
- The amounts of adsorbing surfaces (including organic matter, hydrous ferric oxide, aluminum hydroxide, and clay) that can be estimated by determining oxalate extractable Fe and Al.

- Liquid to solid ratio.

\subsubsection{LeachXS ${ }^{\mathrm{TM}}$ /ORCHESTRA Chemical Equilibrium Output}

The main result of a chemical equilibrium calculation is the distribution of elements over the different physical and chemical forms (including different dissolved, adsorbed, precipitated, and gaseous species) according to the set of thermodynamic equilibrium reactions provided as input. For each element, the distribution over the possible forms is calculated. Other generated outputs include: $\mathrm{pH}$, REDOX potential, ionic strength, and electrical conductivity.

ORCHESTRA generates the basic numerical results of these calculations, while LeachXSTM processes this output and presents the results in graphical form. For a reactant of interest, pe, dissolved humic acid (HA), conductivity, acid/base neutralization capacity, and REDOX capacity can be displayed graphically as a function of $\mathrm{pH}$. The geochemical speciation results from ORCHESTRA can also be viewed and exported. Possible ORCHESTRA results include:

- Solubility prediction results. These results provide a comparison of measured test results and modeled solution composition.

- Solid and liquid phase partitioning. This selection allows visualization of partitioning of the constituent among free, dissolved organic carbon associated, clay bound, Fe-oxide bound, particulate organic matter bound, and mineral precipitate or incorporated in a solid solution.

- A combination of solubility prediction and partitioning for a specific reactant in the selected reactant series. Additional graphs including solid phase partitioning and liquid phase partitioning can be shown.

\subsubsection{LeachXS ${ }^{\mathrm{TM}}$ /ORCHESTRA Reactive Transport Input}

The transport modules calculate mass transport based upon the information provided by the chemical modules on the mobility of elements. These transport modules keep track of how much of each element is present as a function of time and space. The modules need to be initialized with the chemical conditions of the system at the start of the simulation. This is exactly the same information required for a single chemical equilibrium calculation; however, it is also required for each material layer or cell in the transport system. Apart from the chemical information, the transport model also needs a set of physical input parameters of which the most important ones are:

- Physical dimensions of the system,

- Porosity of the material(s),

- Density of solid material(s),

- Effective tortuosity of the material(s),

- Flow rates (for column simulation),

- Refresh rates (for tank test), 
- Water saturation/gas volume, and

- Chemical composition of each solid material and each solution that is used in the simulation, including amounts of adsorbing surfaces.

\subsubsection{LeachXS ${ }^{\mathrm{TM}}$ /ORCHESTRA Reactive Transport Output}

The ORCHESTRA reactive transport model generates a chemical composition that provides basically the same output as that for a single chemical equilibrium reaction, but as a function of time and space. Outputs include:

- Chemical composition of the system as a function of time and space (i.e., concentration profiles) including distribution of elements (over mineral, aqueous, gaseous, and other phases), $\mathrm{pH}$, and REDOX conditions.

- Total fluxes of elements over chosen internal or external system boundaries.

As in the case of a single chemical equilibrium calculation, the numerical outputs are generated by ORCHESTRA, while LeachXS ${ }^{\mathrm{TM}}$ uses these results to generate output in graphical form. For a reactant of interest, $\mathrm{pH}$, pe, dissolved humic acid (HA), conductivity, acid/base neutralization capacity, and REDOX capacity can be displayed graphically as a function of liquid to solid ratio (ECN 2007). For percolation or lysimeter test results, geochemical speciation predictions from ORCHESTRA can be viewed and exported including:

- Leachate concentrations. The measured percolation or lysimeter test concentrations and the predicted concentrations are graphed as functions of liquid to solid (L/S) ratio as well as the concentrations predicted for the collected fractions.

- Cumulative release. The cumulative leached amount (as derived from the percolation or lysimeter test data) is compared with the predicted cumulative release as a function of liquid to solid (L/S) ratio.

- Concentration profiles at a specified time. The partitioning between dissolved and solid phases is represented as a function of the depth in the column at the specified time.

- Concentration profiles at a specified depth. The partitioning between dissolved and solid phases is represented at a specified depth in the column as a function of time.

- Animated time profiles for a single reactant. An animation can be generated of the partitioning of a constituent between dissolved and solid phases as a function of depth in the column over the time span of the percolation test. 


\section{PHASE I CODE INTEGRATION MODEL DESCRIPTION AND USER GUIDE}

\subsection{Code Interface File Structure}

The code integration application is supplied with the top level file structure shown in Figure 4-1. The two folders Codes and Template contain executable versions (subject to user licensing constraints) of the CBP partner codes used for this project and the code integration software. Template is the local folder where the user performs a simulation. The Codes folder and the other three auxiliary folders, briefly described below, would normally be of secondary interest to the user.

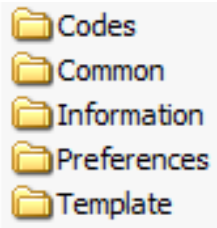

Figure 4-1. Top-level file structure for CBP code integration application.

\subsubsection{Codes Folder and Files}

The Codes folder substructure is shown in Figure 4-2.

DLLExternalCode
Mes440rc1_win
MTAdiuM
TecplotViewer
TestCode
IaunchGnuplot.bat

Figure 4-2. Contents of Codes folder.

Subfolders in the Codes folder contain the software that can be run using the GoldSim code integration interface. The subfolder names are largely self-explanatory:

1. DLLExternalCode contains the source code and compiled DLL files for the DLL interface. Details of the DLL interface and instructions for its use are described by Smith et al. (2010).

2. gp440rc1_win and its subfolders contain files for the open source plotting software Gnuplot (http://www.gnuplot.info/).

3. Mesh2d contains the source code and executable for the grid generation software used in the code interface application. A complete description of the functionality of the grid generation software is provided in Appendix A. The user can access this software and associated files through the GoldSim interface. 
4. STADIUM ${ }^{\circledR}$ contains a STADIUM ${ }^{\circledR}$ executable file and two input files, CHM-DB-STADIUM . $t x t$ and PITZER-STADIUM . dat required by STADIUM ${ }^{\circledR}$. STADIUM ${ }^{\circledR}$ must be licensed to use.

5. TecplotViewer contains the Tecplot viewer executable and associated files which can be used to view a computational grid or plot data external to the GoldSim interface. Tecplot Viewer is free software (http://tecplottalk.com/addons/viewer/) that can be used to view a file in Tecplot format but cannot edit the display.

6. TestCode contains source files and an executable program that was used to verify code interface DLL input and output operations.

The free software contained in these subfolders is neither supported nor promoted by the CBP.

\subsubsection{Auxiliary Folders and Files}

Three auxiliary folders shown in Figure 4-1 perform the following functions:

1. Common is currently unused and is intended for future use as a folder to store data common to all CBP partner codes (e.g., in common databases called by the GoldSim interface).

2. Information contains:

a. A copy of the DLL documentation,

b. A shortcut to the current GoldSim Player executable,

c. A batch file to run the STADIUM ${ }^{\circledR}$ code for testing independent of the code integration interface,

d. An Excel workbook containing a macro that can be used to test the DLL independently of the GoldSim code integration interface.

3. Preferences contains shortcuts to text editors and plotting programs that the user can modify for use as desired. For example, the shortcut MyTextEditor points to the default text editor, which is currently specified as Microsoft WordPad.

While source code is provided for the DLL interface and the Mesh2d software, it is expected that the user would not normally modify this code. In that case, the user could work entirely in the Template folder as described below.

\subsubsection{Template Working Folder and Files}

The expectation is that the code interface user would typically work almost exclusively in the Template folder. The contents of the Template folder are shown in Figure 4-3. The full Phase I GoldSim model is provided in the file GoldSim_CPB_Phase_I.gsm. A player version of the same model is provided for users that do not have a GoldSim license in the file GoldSim_CPB_Phase_I .gsp. The free player version of GoldSim allows users to run but not edit GoldSim models. Using the dashboards explained in Section 4.2, the player version can be used to modify code inputs and run CBP simulations. 


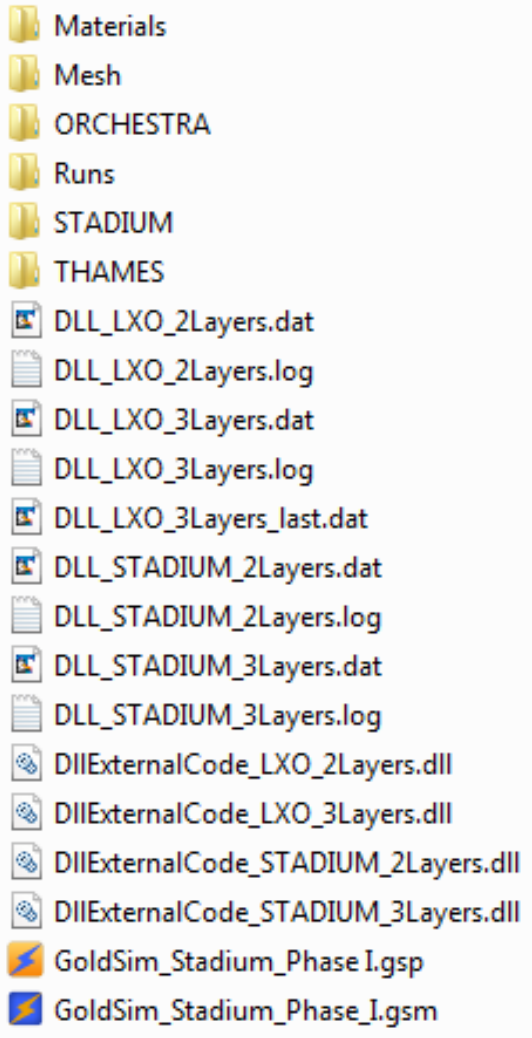

Figure 4-3. Example contents of Template folder.

The Template folder also contains four versions of the DLL code interface: two-layer STADIUM ${ }^{\circledR}$, threelayer STADIUM ${ }^{\circledR}$, two-layer LeachXSTM/ORCHESTRA, and three-layer LeachXSTM/ORCHESTRA. The primary difference between these four DLLs is the dimensioning of the input and output arrays used to exchange data between GoldSim and the DLLs. The corresponding data specification and log files are also contained in this folder.

The six subfolders in the Template directory perform the following functions:

1. The Materials folder (Figure 4-4) currently contains three Microsoft Excel spreadsheets that contain composition and physical property data for concrete, the SRS Saltstone waste form, and soil. The spreadsheets, at a minimum, hold data for Type 1 and Type 2 concrete, Type 1 and Type 2 Saltstone, and Type 1 soil. Type 1 concrete composition and properties are representative of the concrete used to make SRS Saltstone Vault 2 while the Type 2 concrete properties are representative of the concrete used to make SRS Saltstone Vaults 1 and 4. The Type 1 and Type 2 Saltstone differ only in the initial composition of chemicals and minerals. The properties used for these materials were taken directly from the SIMCO Technologies, Inc. CBP Task 7 report (SIMCO 2010). Full details of the material properties are available in the SIMCO Technologies, Inc. CBP Task 7 report. Property values are tabulated in Appendix B for convenience. 


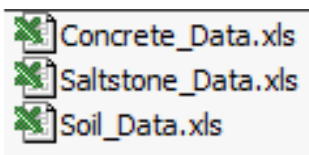

Figure 4-4. Contents of Materials folder.

2. The Mesh folder contains the data files used to define the computational grid and output files created from running the mesh generation process from the GoldSim interface. Creating a grid using the GoldSim interface also generates files that can be used to view the grid formatted for Tecplot Viewer, Gnuplot, and as a Visualization Tool Kit (VTK) graphics file suitable for viewing with VisIt and Paraview plotting software. Mesh files formatted for use by STADIUM ${ }^{\circledR}$ and PORFLOW are also created in this folder.

3. The ORCHESTRA folder (Figure 4-5) contains the four batch files used to run LeachXSTM/ORCHESTRA and duplicates of the folders containing the LeachXSTM/ORCHESTRA models to be run. The batch files bincopyII . bat and bincopyIII . bat are called from the DLL to copy the necessary LeachXS ${ }^{\mathrm{TM}} /$ ORCHESTRA files for subsequent execution ${ }^{1}$. The batch files noscreenII . bat and noscreenIII . bat are then called from the GoldSim DLL interface to make either two- and three-layer LeachXSTM/ORCHESTRA calculations, respectively ${ }^{2}$. The LXS_2LAYER and LXS_3LAYER folders contain copies of the ORCHESTRA model files for the two- and three-layer models, respectively ${ }^{3}$. Selected input files (e.g., initial_solid_composition.dat and leachxs_parameters.txt) are updated by the DLL at run time and then copied to the appropriate LeachXSTM/ORCHESTRA realization folder (described below) for execution. The results files (e.g., output_profiles.dat) are also copied to the Runs directory (described below) for subsequent processing by the GoldSim DLL.

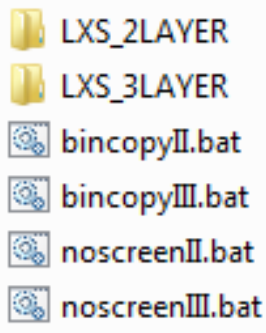

Figure 4-5. Example contents of ORCHESTRA folder.

4. The Runs folder contains subfolders where simulation results are stored. The DLL interface automatically creates subfolders in Runs for each realization when the Save Output option is selected. For a deterministic calculation, a subfolder named realization_0 is created as shown in Figure 4-6.

1 The copying of LeachXSTM/ORCHESTRA program files to the ORCHESTRA folder is consistent with how LeachXS ${ }^{\mathrm{TM}}$ manages ORCHESTRA execution for a given scenario.

2 These batch files are typically configured to suppress the normal LeachXS ${ }^{\mathrm{TM}}$ /ORCHESTRA GUI interface (that requires user interaction) to allow a series of runs to be made through the GoldSim code interface.

3 LeachXSTM/ORCHESTRA files are found in the \Application DatalLeachXS\Orchestralprojects folder in the user's directory in Windows XP or the corresponding \AppData\RoamingLeachXS\Orchestralprojects folder in Windows 7. 
The contents of this folder with input and output files from an example STADIUM® run are also shown in Figure 4-6.

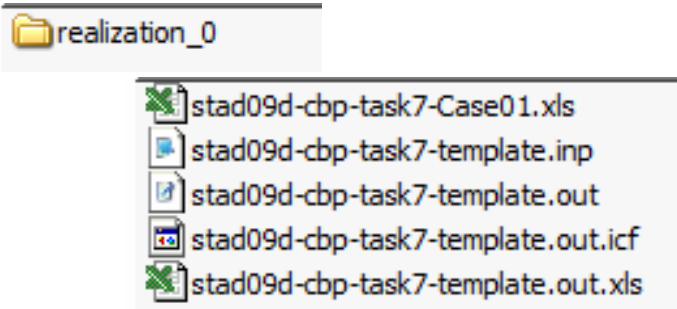

Figure 4-6. Example contents of Runs folder for a STADIUM® simulation.

5. The STADIUM ${ }^{\circledR}$ folder contains an input template file (stad@9d-cbp-task7-

template. inp) used by the DLL interface as shown in Figure 4-7. The line and column numbers referenced in the DLL . dat input instructions (Smith III et al. 2010) must conform to the data locations in this template file. The DLL interface uses this template and the instructions in the appropriate DLL . dat file to create a STADIUM ${ }^{\circledR}$ input file that will be placed in the corresponding realization folder in Runs (Figure 4-6). The STADIUM ${ }^{\circledR}$ folder also contains the appropriate mesh coordinate and element files (e.g., $20 \mathrm{~cm}-50 \mathrm{~cm}$ - mesh. cor and $20 \mathrm{~cm}-50 \mathrm{~cm}-\mathrm{mesh}$. ele, respectively, as illustrated in Figure 4-7) that are required as input to STADIUM ${ }^{\circledR}$. This folder also contains the Excel workbook STADIUM_Summary. xls that is linked to the GoldSim model.

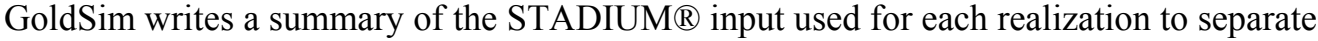
spreadsheets in this workbook. This workbook saves the input values used for later analysis and is particularly valuable for stochastic runs where the input values are randomly assigned. In the Phase I version, blank spreadsheets must already exist for each realization in the STADIUM_Summary .xls workbook.

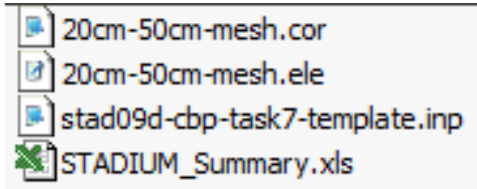

Figure 4-7. Example contents of STADIUM® folder.

6. The THAMES folder is currently not used but is included as a place holder for planned Phase II development work that will, in part, create an interface to this CBP partner code.

\subsection{GoldSim Model Dashboard Controls}

The Phase I GoldSim CBP code integration model provides an interface to the STADIUM ${ }^{\circledR}$ and

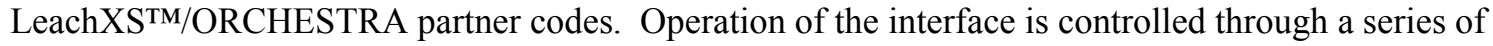
dashboards (i.e., screens with simulation control and display functions) that have been created within the GoldSim software. When the user first opens the GoldSim model, the top level dashboard shown in Figure 4-8 appears. Dashboards have been created so that the user can set up and run a simulation and view the results without having to interact directly with the underlying GoldSim model or linked codes. The dashboard functions will be explained in the following sections followed by a description of the GoldSim model. 


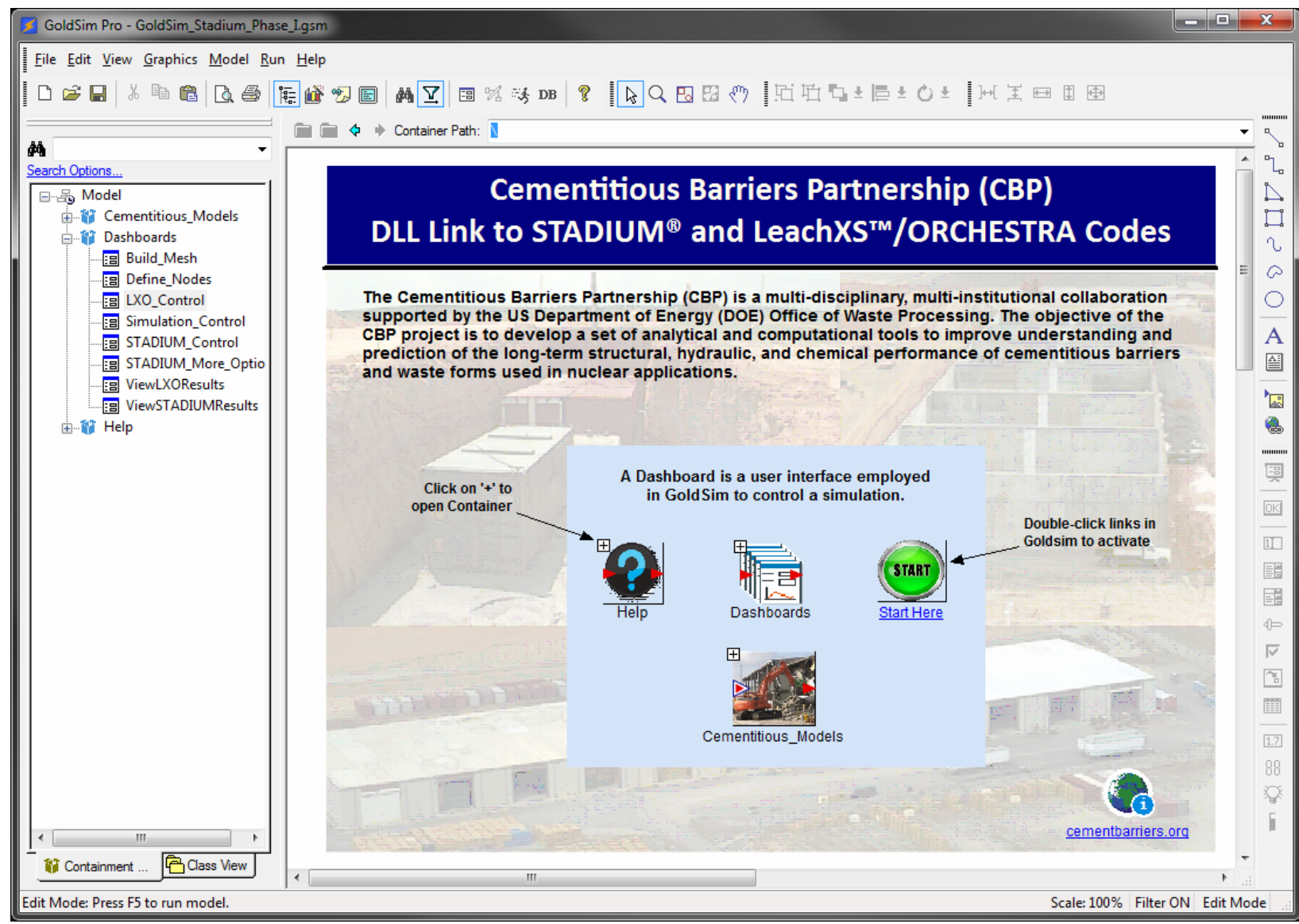

Figure 4-8. Top-level dashboard in GoldSim CBP code integration model.

\subsubsection{Simulation Control}

Double clicking on the START button shown in Figure 4-8 opens the dashboard shown in Figure 4-9, where the user can access simulation controls for the partner codes. These top level controls, consisting of five buttons and two checkboxes used to select either a STADIUM ${ }^{\circledR}$ or LeachXSTM/ORCHESTRA simulation, allow the user to open dashboards that can then be used to create a simulation mesh, modify the GoldSim simulation settings, setup and run STADIUM ${ }^{\circledR}$, and setup and run LeachXS ${ }^{\mathrm{TM}} / \mathrm{ORCHESTRA}$. In general, the color blue corresponds to STADIUM ${ }^{\circledR}$ information and the color green to LeachXSTM/ORCHESTRA. 


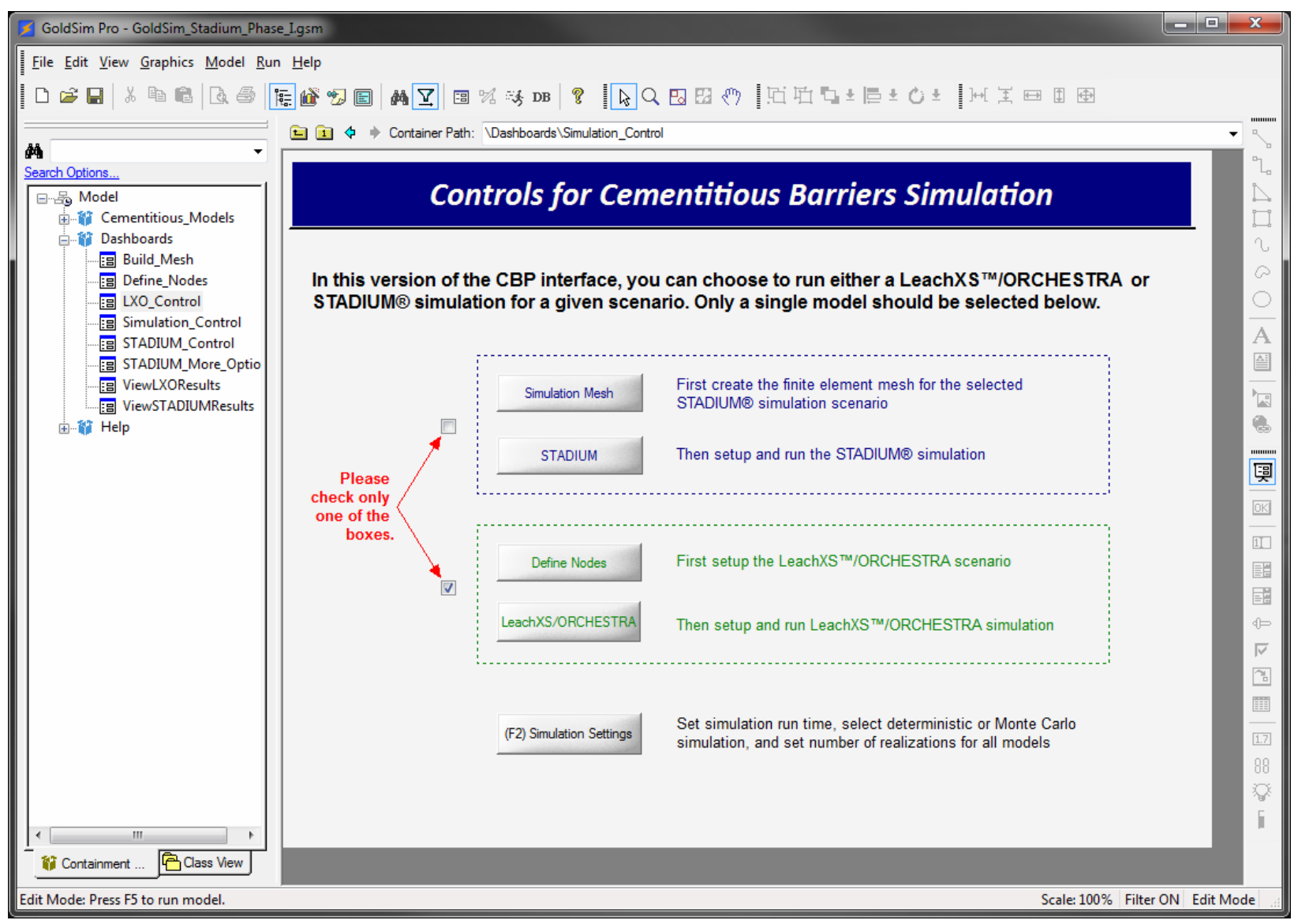

Figure 4-9. Dashboard used to select simulation controls.

\subsubsection{STADIUM® Mesh Generation}

Clicking on the Simulation Mesh button in the simulation control dashboard takes the user to the dashboard shown in Figure 4-10. A full explanation of the Mesh2d software used to generate computational grids is given in Appendix A. The simulation mesh dashboard allows the user to create input files for Mesh2d, run Mesh2d, and view the resulting grid.

Selecting any of the four buttons on the line labeled "1. Define mesh" opens the indicated text file that the user can then edit. The buttons are linked to the default text editor specified in the top level Preferences folder. Each button is linked to a particular file in the Mesh folder in Template (superMesh . dat, xMesh. dat, yMesh. dat and mtypMesh. dat). These files contain instructions read by the Mesh2d code to create the computational grid. Examples of these files are shown in Figures A-5 through A-8 in Appendix A. The user must also enter the number of layers for the model, and the layer dimensions in the input blocks on the STADIUM ${ }^{\circledR}$ Run Controls Dashboard (Figure 4-13) so this information is available to the GoldSim model. This information is reproduced on this Dashboard for reference. Similar controls are being developed to 
modify scenario geometry for LeachXS CBP code integration model.

Clicking on the Make mesh button on the line labeled "2. Build mesh" runs the Mesh2d executable file contained in a subfolder within the Codes folder. The executable will read the input files edited in Step 1 and creates the computational grid used in the simulation. The functions in the highlighted box on the line labeled "3. View mesh" can be used to view the computational grid either in a text file or graphically. Tecplot viewer and Gnuplot plotting software are provided as graphics programs for plotting the mesh. These programs were included because they do not require licensing and would therefore be of general use. The mesh is also written as a VTK graphics file suitable for viewing in VisIt and Paraview, which are also available at no cost. The text output uses the default text editor to view the mesh file formatted for Tecplot viewing.

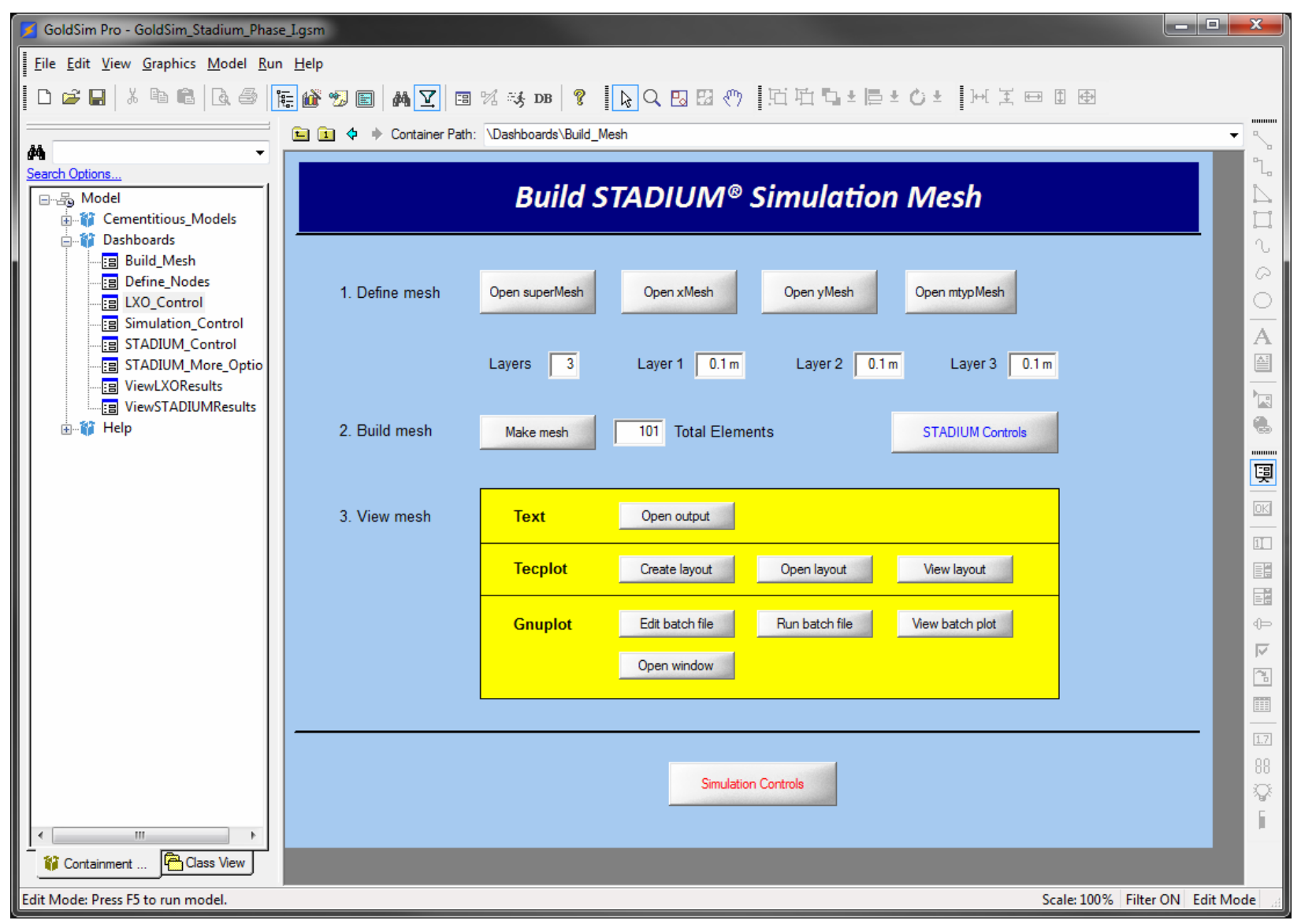

Figure 4-10. Simulation mesh creation dashboard.

\subsubsection{Simulation Settings}

Selecting either the F2 key or the (F2) Simulation Settings button on the simulation control dashboard shown in Figure 4-9 opens the GoldSim Simulation Settings... window (Figure 4-11). The first tab (Time) on this window is used to control the total simulation time and the time steps used by GoldSim. The simulation duration is passed to STADIUM ${ }^{\circledR}$ as the simulation time; however, the STADIUM ${ }^{\circledR}$ time step control is 
specified separately as discussed in Section 4.2.4 below. A single GoldSim time step is specified so that the DLL will only run the codes linked to GoldSim one time. In future work, it is expected that the codes would be run multiple times for shorter durations during the course of the overall simulation and information exchanged between the codes using the GoldSim interface. For the Phase I calculations, there is no coupling between the codes so, for demonstration purposes, the codes are run separately and a single GoldSim time step is used.

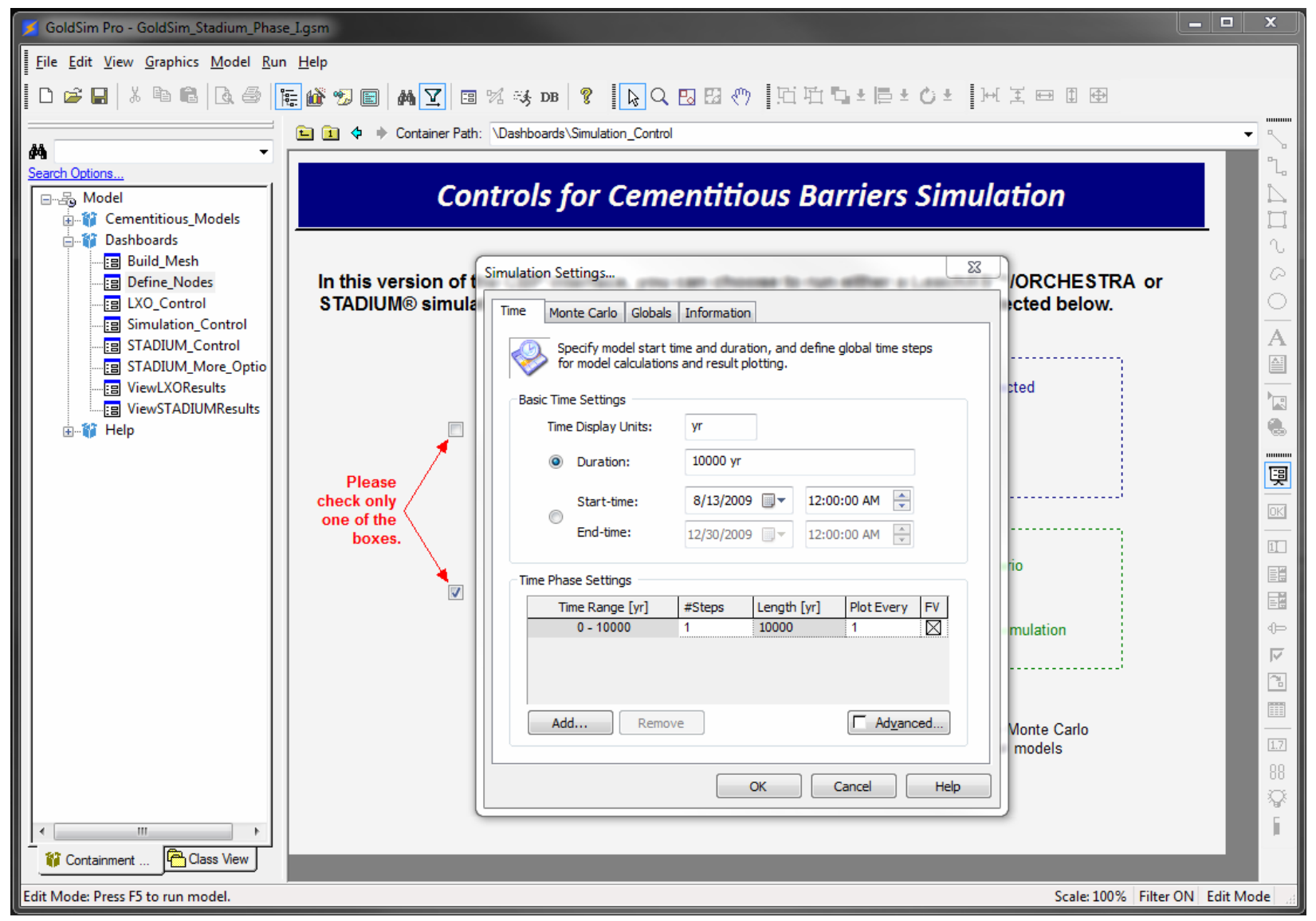

Figure 4-11. GoldSim simulation settings window for time control.

The second tab on the GoldSim Simulation Settings... window (Monte Carlo) is used to specify whether a deterministic or Monte Carlo simulation is to be made. For Monte Carlo simulations, this window is also used to set the number of realizations made, which results are saved in memory, and stochastic sampling parameters. An example of the Monte Carlo simulation settings panel is shown in Figure 4-12. The settings shown in Figure 4-12 were used to run the STADIUM ${ }^{\circledR}$ example problem presented in Section 5.1. 


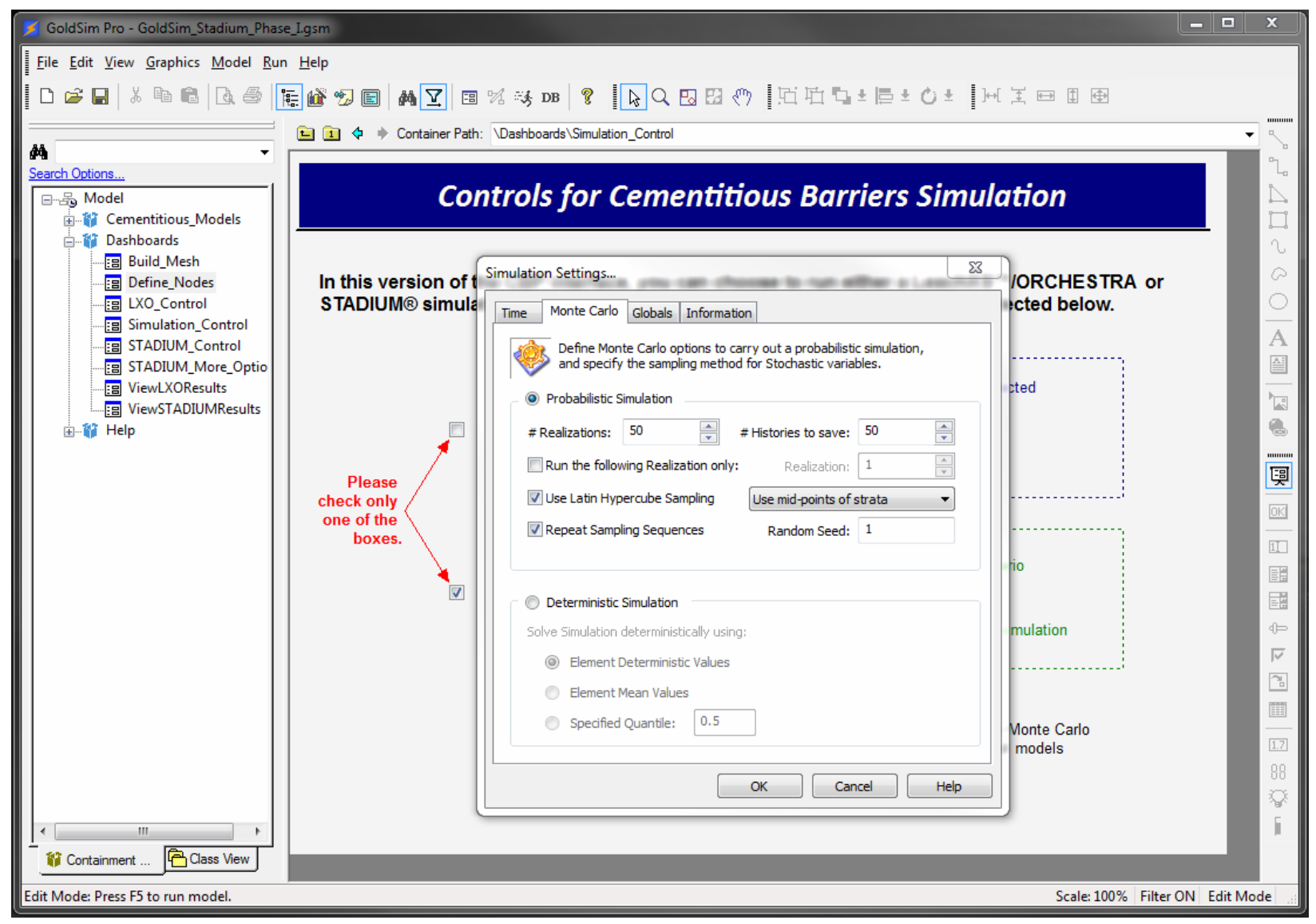

Figure 4-12. GoldSim simulation settings window for Monte Carlo control.

\subsubsection{STADIUM®}

Clicking the STADIUM button on the simulation control dashboard shown in Figure 4-9 opens the STADIUM ${ }^{\circledR}$ run controls dashboard shown in Figure 4-13. This dashboard allows the user to enter some basic data used for a STADIUM® simulation. Using the group of inputs labeled "Scenario Options" on the left hand side of the dashboard, the user selects whether a two- or three-layer system is modeled by checking the appropriate option box. The materials present in each layer are selected from a list of available materials (see Section 4.1.2) and the layer thicknesses in meters are entered. In the final input box for each layer, the user specifies the standard deviation applied to the initial compositions for use in probabilistic calculations. For probabilistic calculations, it is assumed that the nominal compositions provided in the materials property spreadsheets are the mean values of normal distributions with the standard deviations specified by the concentration RSD entries.

The section of the STADIUM ${ }^{\circledR}$ run control dashboard labeled "General Run Settings" contains four boxes that allow the user to enter time step control parameters for the STADIUM ${ }^{\circledR}$ simulation and a box where the number of nodes in the mesh can be modified. A check box is located below these entries where the user selects whether or not to save the output from STADIUM ${ }^{\circledR}$ calculations. When the save option is checked, the integration software will create files saving output from each realization during a stochastic simulation as noted in Section 4.1.3 above. 


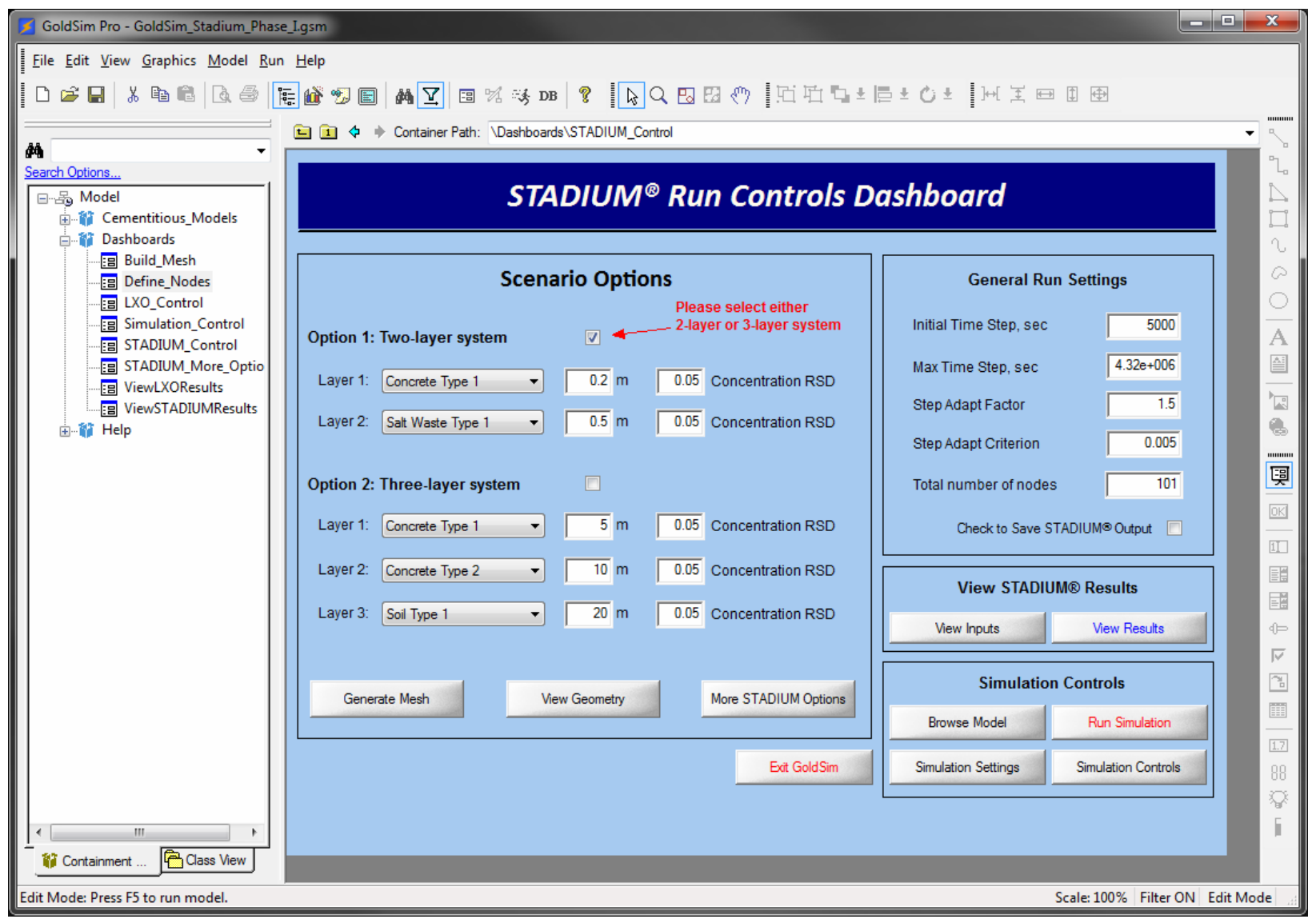

Figure 4-13. STADIUM® run controls dashboard.

Below the Scenario Option entries, buttons are provided that allow the user to create the computational mesh (Section 4.2.2), view the mesh geometry, and enter more STADIUM® options. Clicking the More STADIUM Options button opens the Dashboard shown in Figure 4-14 that allows the user to enter or select seven additional parameters that control STADIUM ${ }^{\circledR}$ solution methods. The STADIUM ${ }^{\circledR}$ documentation (SIMCO 2008) should be consulted for an explanation of these additional features. 


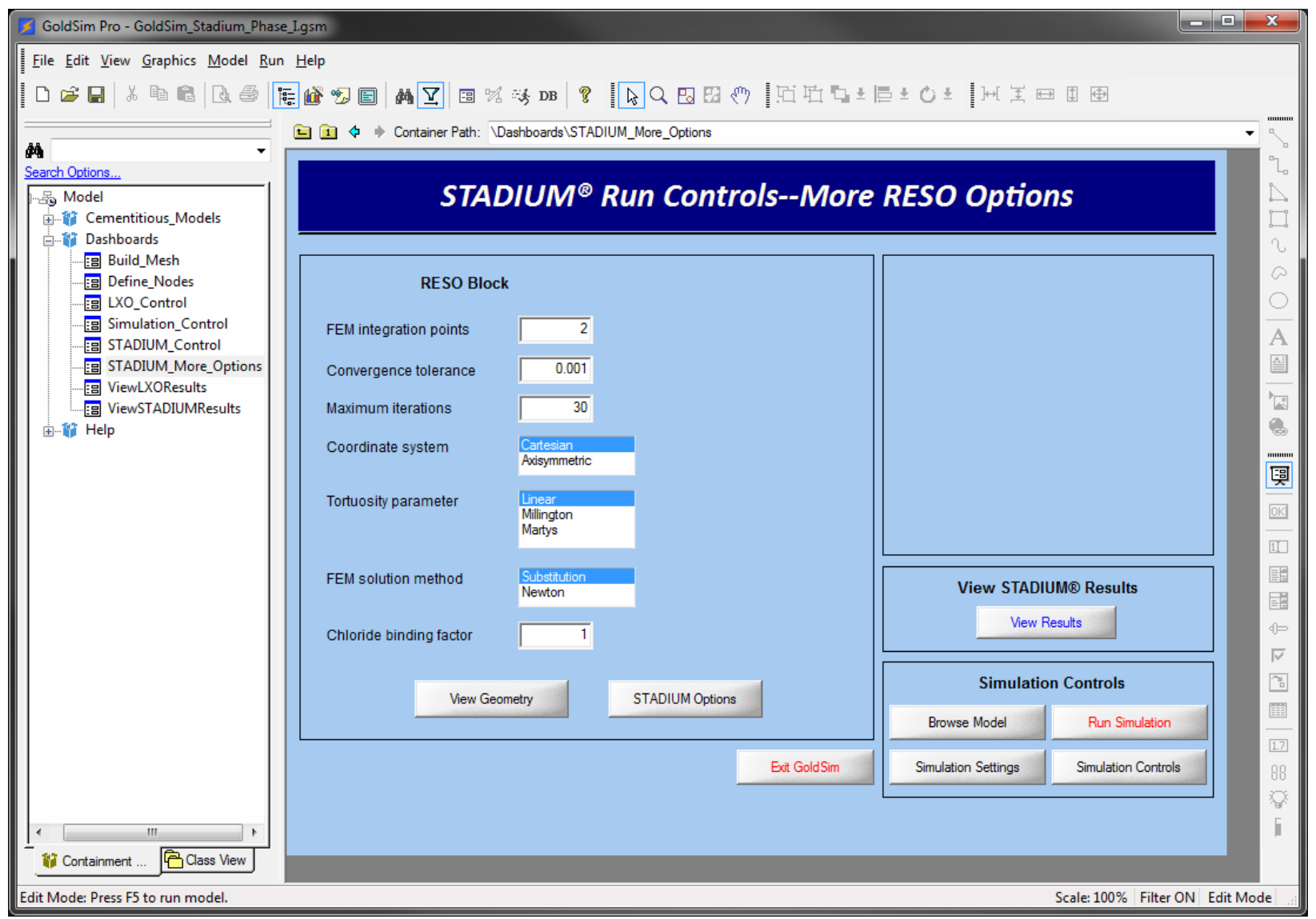

Figure 4-14. Additional STADIUM ${ }^{\circledR}$ simulation control dashboard.

Below the General Run Settings portion of the dashboard shown in Figure 4-13, two buttons are provided that allow the user to view the STADIUM ${ }^{\circledR}$ input and output. Clicking the View Results button opens the Dashboard shown in Figure 4-15 that allows the user to view graphs of STADIUM® results for a particular mineral or chemical. These graphs are generated using the built-in GoldSim plotting functions. Results available for plotting are those transferred back to GoldSim from the STADIUM ${ }^{\circledR}$ output files through the DLL interface. An example plot is shown in Figure 4-16 where the concentration of chlorine at each computational node is plotted. In this example, the plot is for 100 years into the simulation of a two layer system where the interface between the layers is located at node 50. GoldSim plotting capabilities are primarily designed to produce time history graphs. As shown in Figure 4-16, plots of special distributions, which will be of significant interest for evaluating the performance of cementitious materials, can be created but the results are not of the highest quality. The Phase I dashboard controls can be used to create a quick plot of the results and better quality graphs produced by working with the computational results outside of the interface. As a Phase II enhancement, improved plotting capabilities will be provided through the code interface. 


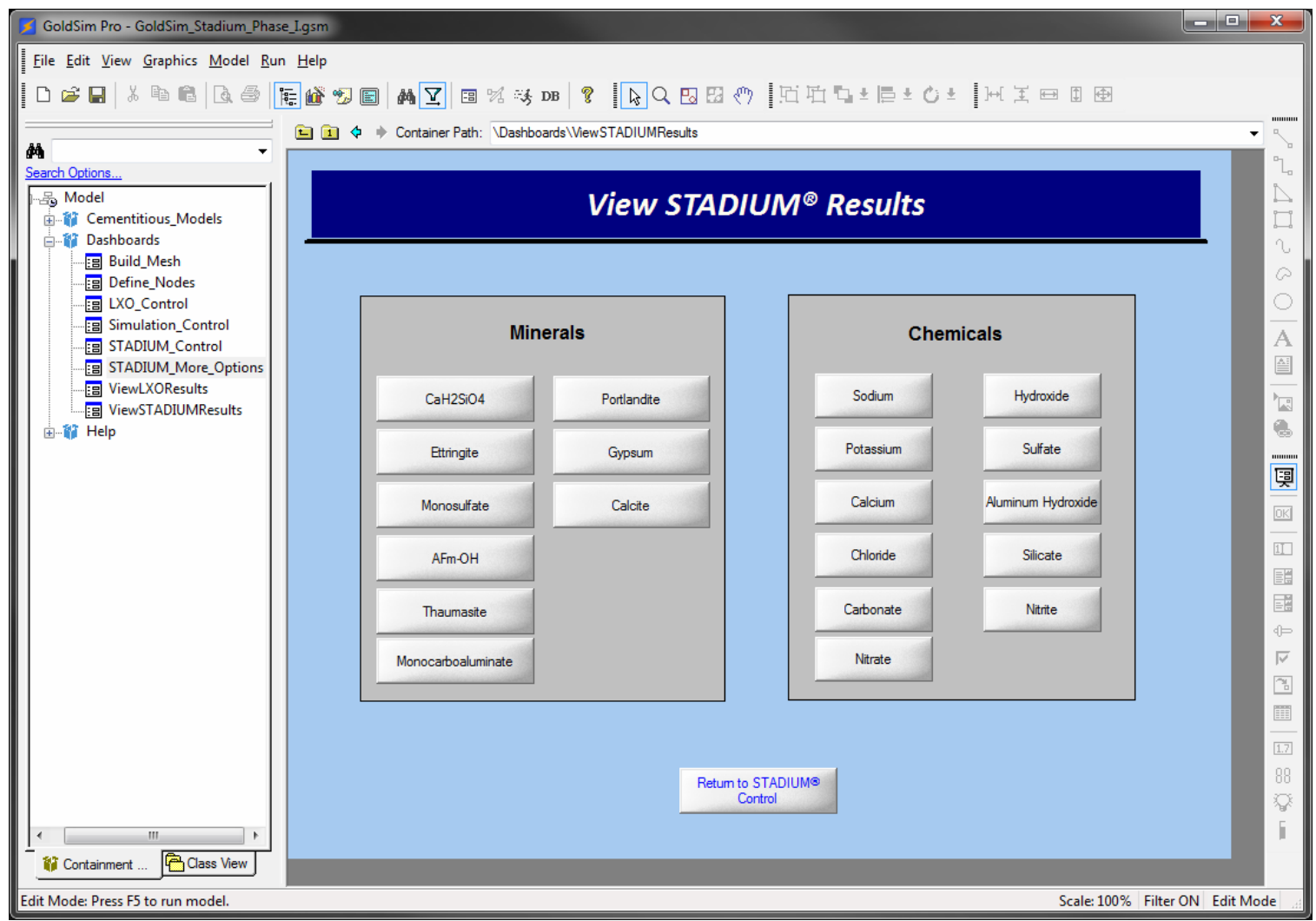

Figure 4-15. Dashboard for selecting a plot of STADIUM ${ }^{\circledR}$ results.

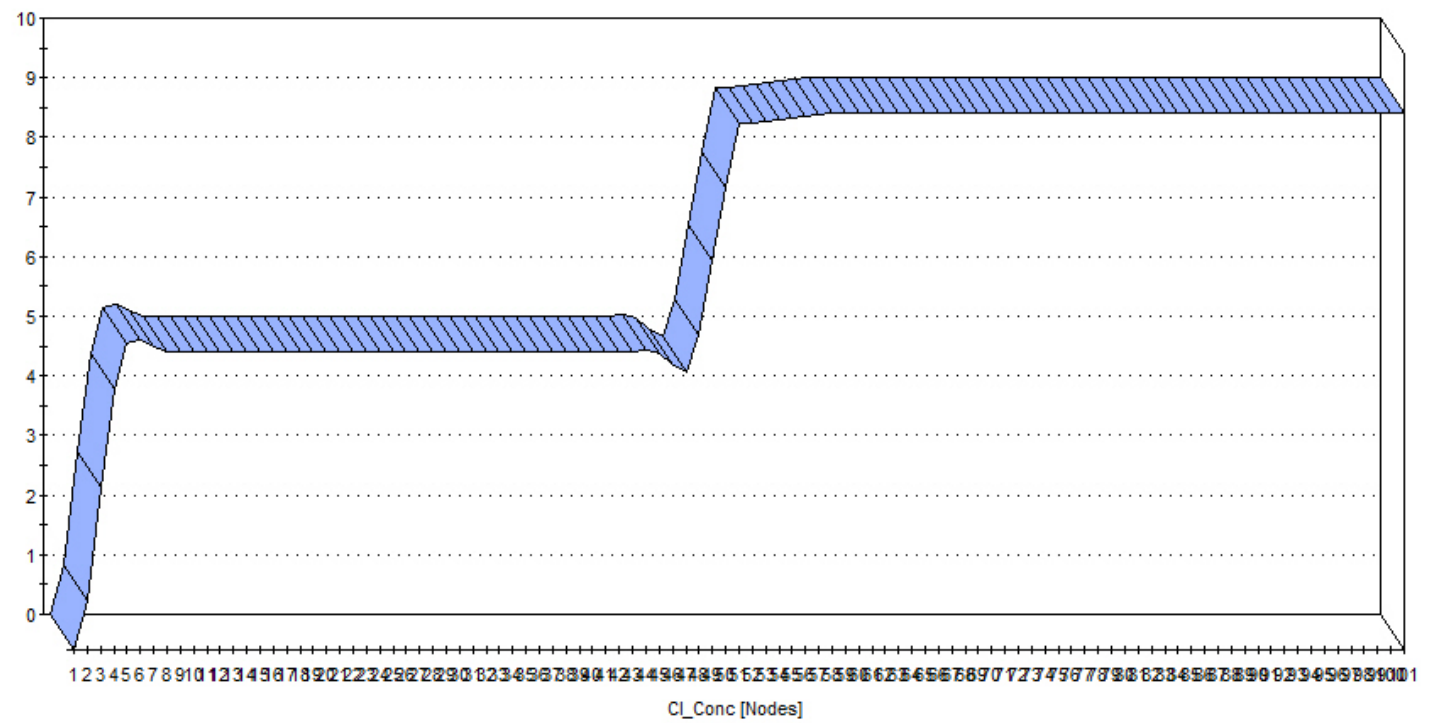

Figure 4-16. Example GoldSim results display plot for chloride. 


\subsubsection{LeachXS ${ }^{\text {TM }}$ /ORCHESTRA}

Clicking the LeachXS/ORCHESTRA button on the simulation control dashboard shown in Figure 4-9 opens the LeachXS ${ }^{\mathrm{TM}} / \mathrm{ORCHESTRA}$ run controls dashboard shown in Figure 4-17. The LeachXS ${ }^{\mathrm{TM}} / \mathrm{ORCHESTRA}$ control dashboard is similar to the STADIUM ${ }^{\circledR}$ run controls dashboard described in the previous section. Using the group of inputs labeled "Scenario Options" on the left hand side of the dashboard, the user selects whether a two or three layer system is being modeled by checking the appropriate option box. The materials present in each layer are selected from a list of available materials (see Section 4.1.2) and the layer thicknesses in meters are entered. In the final input box for each layer, the user specifies the standard deviation applied to the initial compositions for use in probabilistic calculations. For probabilistic calculations, it is assumed that the nominal compositions provided in the materials property spreadsheets are mean values of normal distributions with the standard deviations specified by the concentration RSD entries.

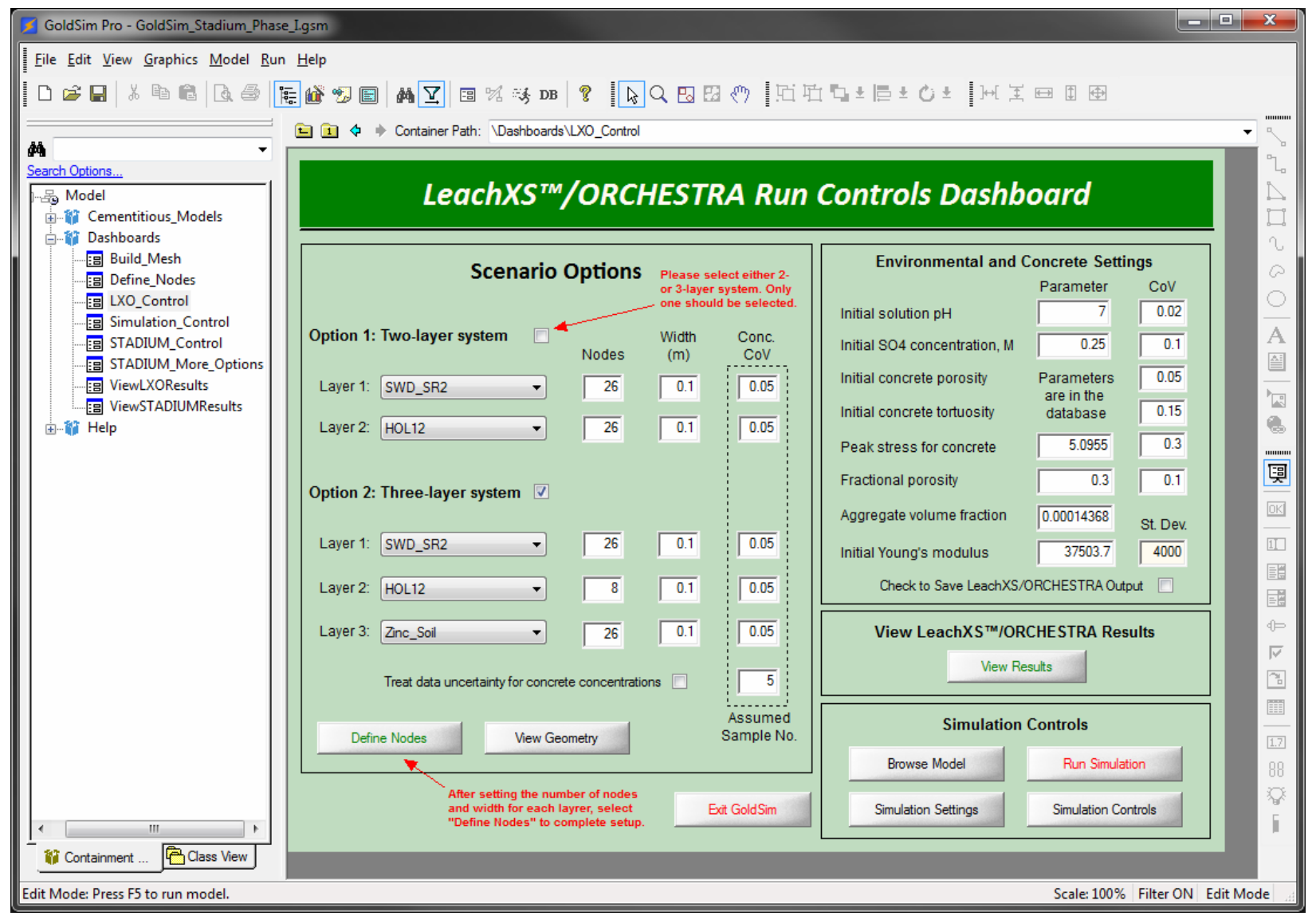

Figure 4-17. LeachXS ${ }^{\mathrm{TM}}$ /ORCHESTRA run controls dashboard.

The section of the LeachXS"M/ORCHESTRA run controls dashboard labeled "Environmental and Concrete Settings" contains a set of controls that allow the user to enter the external $\mathrm{pH}$ and sulfate concentration. Some parameters related to the concrete layer (if part of the system) can also be set using these controls. Below these 
controls resides a check box where the user selects whether or not to save the output from the LeachXSTM/ORCHESTRA calculations. When the Save option is checked, the integration software will create files saving output from each realization during a stochastic simulation as noted in Section 4.1.3 above.

Below the "Environmental and Concrete Settings" portion of the dashboard shown in Figure 4-17, the View Results button can be selected to open the Dashboard shown in Figure 4-18 that allows the user to view graphs of the LeachXSTM/ORCHESTRA results for a particular chemical or mineral. These graphs are generated using the GoldSim plotting functions using the results transferred back to GoldSim from the LeachXSTM/ORCHESTRA output files through the DLL interface. The Phase I dashboard controls can be used to create a quick plot of the results and better quality graphs produced by working with the computational results outside of the interface. As a Phase II enhancement, improved plotting capabilities will be provided through the code interface.

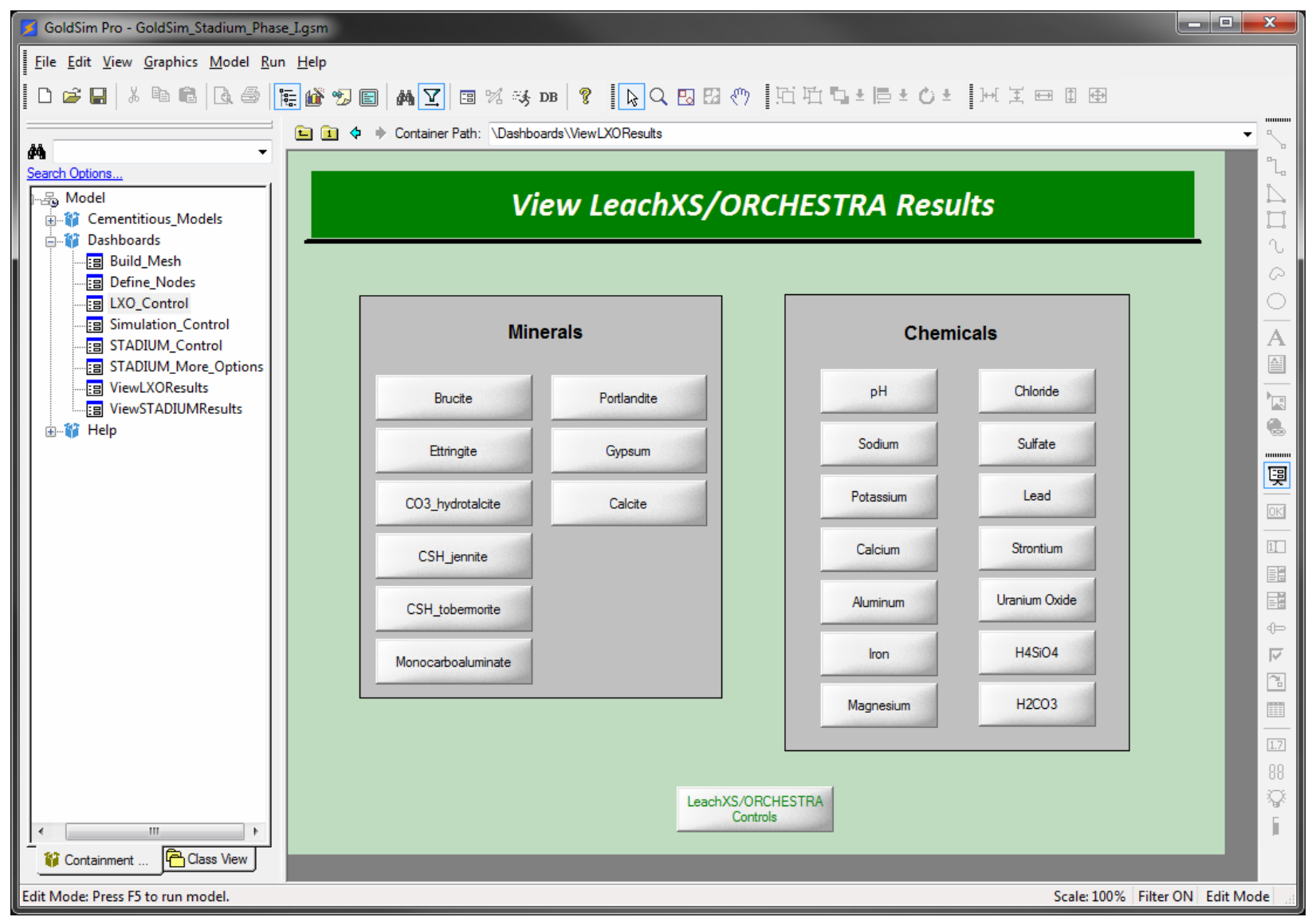

Figure 4-18. Dashboard for selecting a plot of LeachXS ${ }^{\mathrm{TM}} / \mathrm{ORCHESTRA}$ results.

\subsubsection{Help}

Returning to the top-level GoldSim dashboard shown in Figure 4-8, the final user option is clicking on the Help button which opens the Help container. The contents of the Help container are displayed in Figure 4-19. 
Each of the subcontainers shown contains material that provides a limited amount of information on the indicated subject. The Help information will be expanded and more completely developed during the next phase of the code integration work.

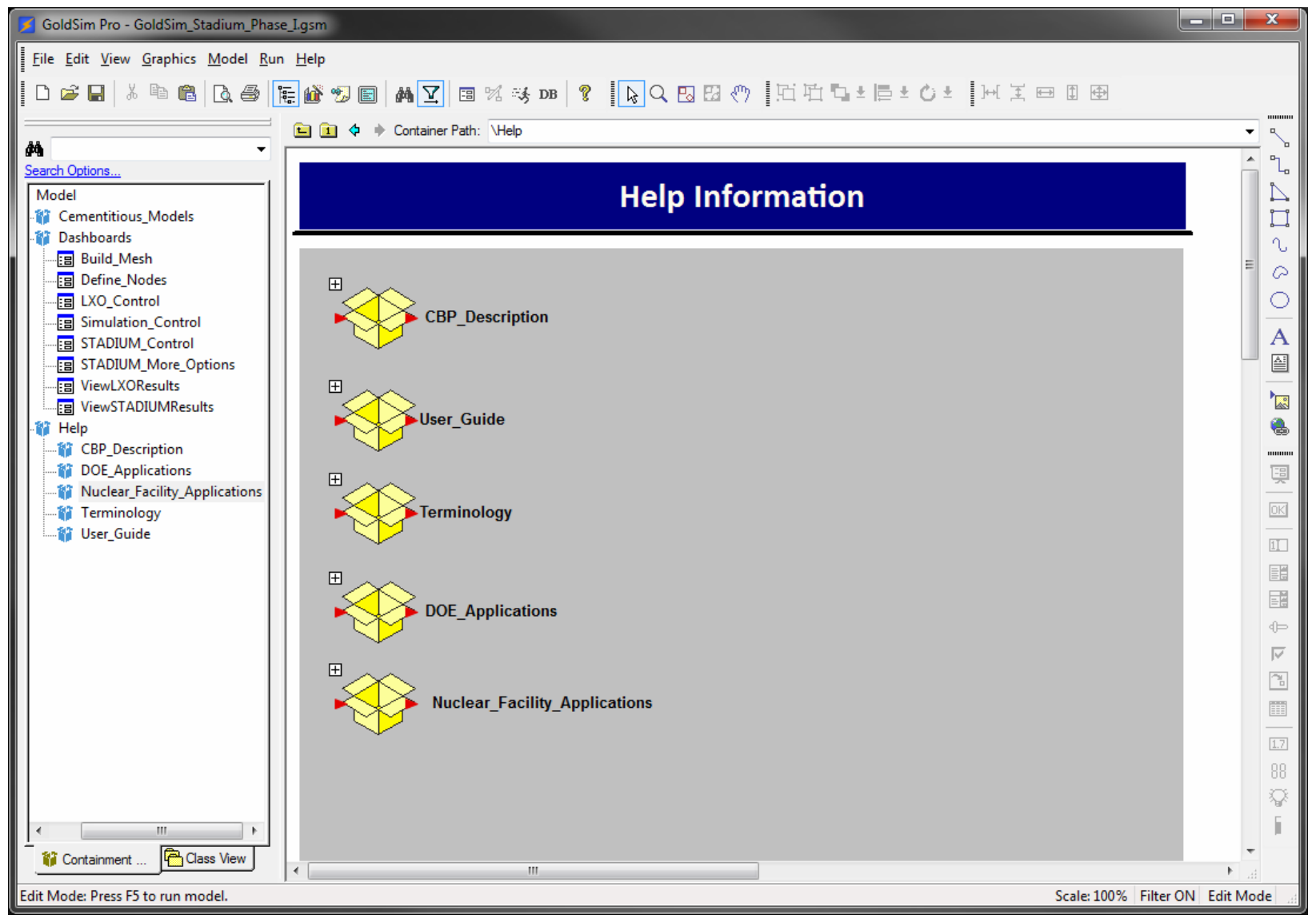

Figure 4-19. Contents of the Help container.

\subsection{GoldSim Model Functionality}

Opening the Cementitious Models container shown in Figure 4-8 takes the user to the top level of the actual GoldSim model. The graphical display of the model in GoldSim is shown in Figure 4-20. The GoldSim model collects the simulation settings specified using the dashboard controls described above, defines material properties for the simulation, runs the selected simulation code through the DLL interface, and transfers selected results from the simulation back to the GoldSim model environment for subsequent analysis. 


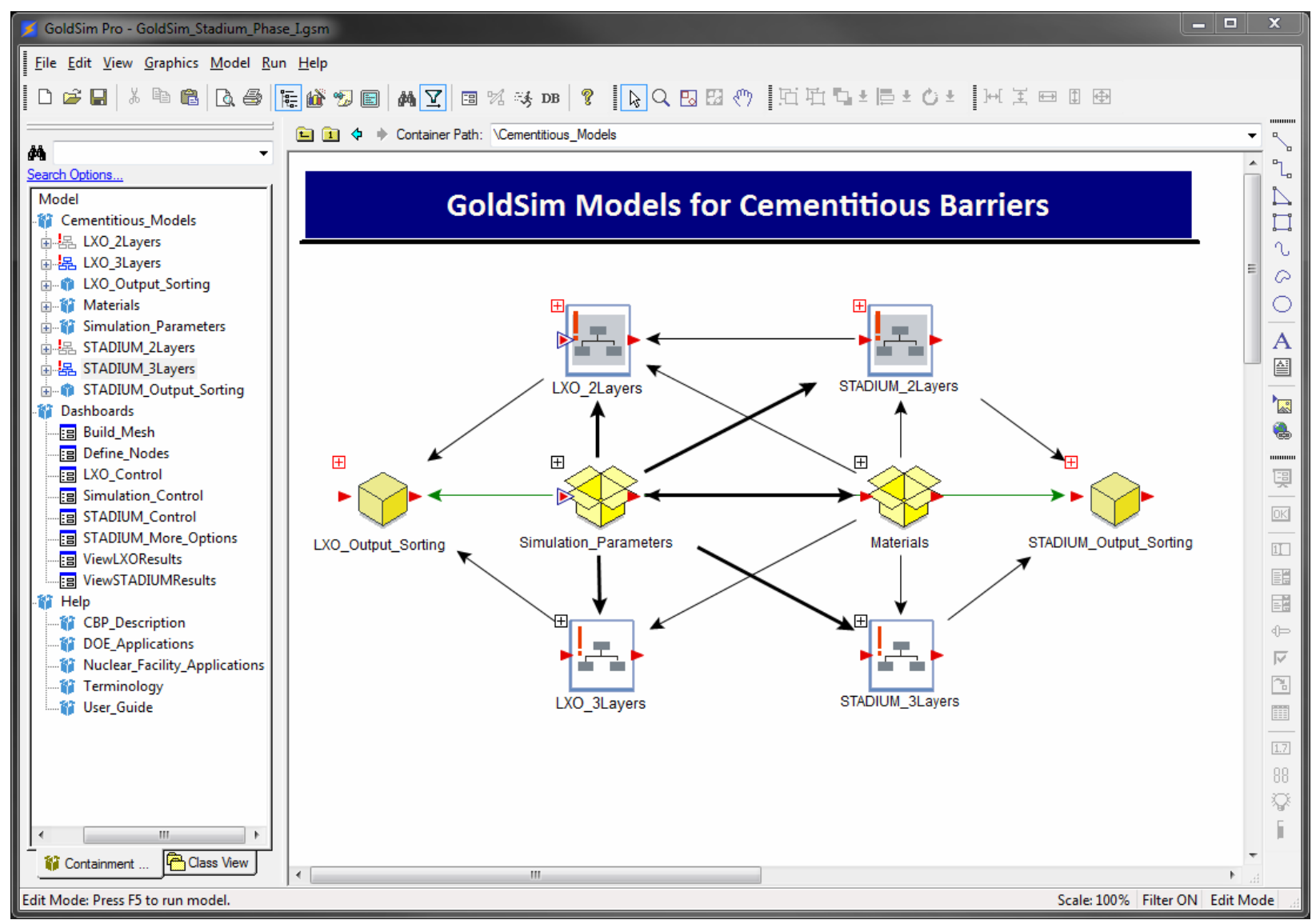

Figure 4-20. Top-level GoldSim model.

The simulation parameters entered through the dashboards are stored in GoldSim data elements within the Simulation_Parameters container. The contents of the Simulation_Parameters container are shown in Figure 4-21. This container also has a link to the Microsoft Excel spreadsheet STADIUM_Summary where a summary of the input parameters used for STADIUM ${ }^{\circledR}$ simulations are saved; the LeachXS ${ }^{\text {TM} / O R C H E S T R A ~}$ input parameters are defined directly in GoldSim elements. The sub-container Conditions checks that certain conditions needed for successful GoldSim model execution are satisfied. For example, this container has functions that check that either two or three layers have been specified and that different materials have been specified for each layer. If these conditions are not met, warning messages are displayed to the user identifying the problem and the necessary correction. 


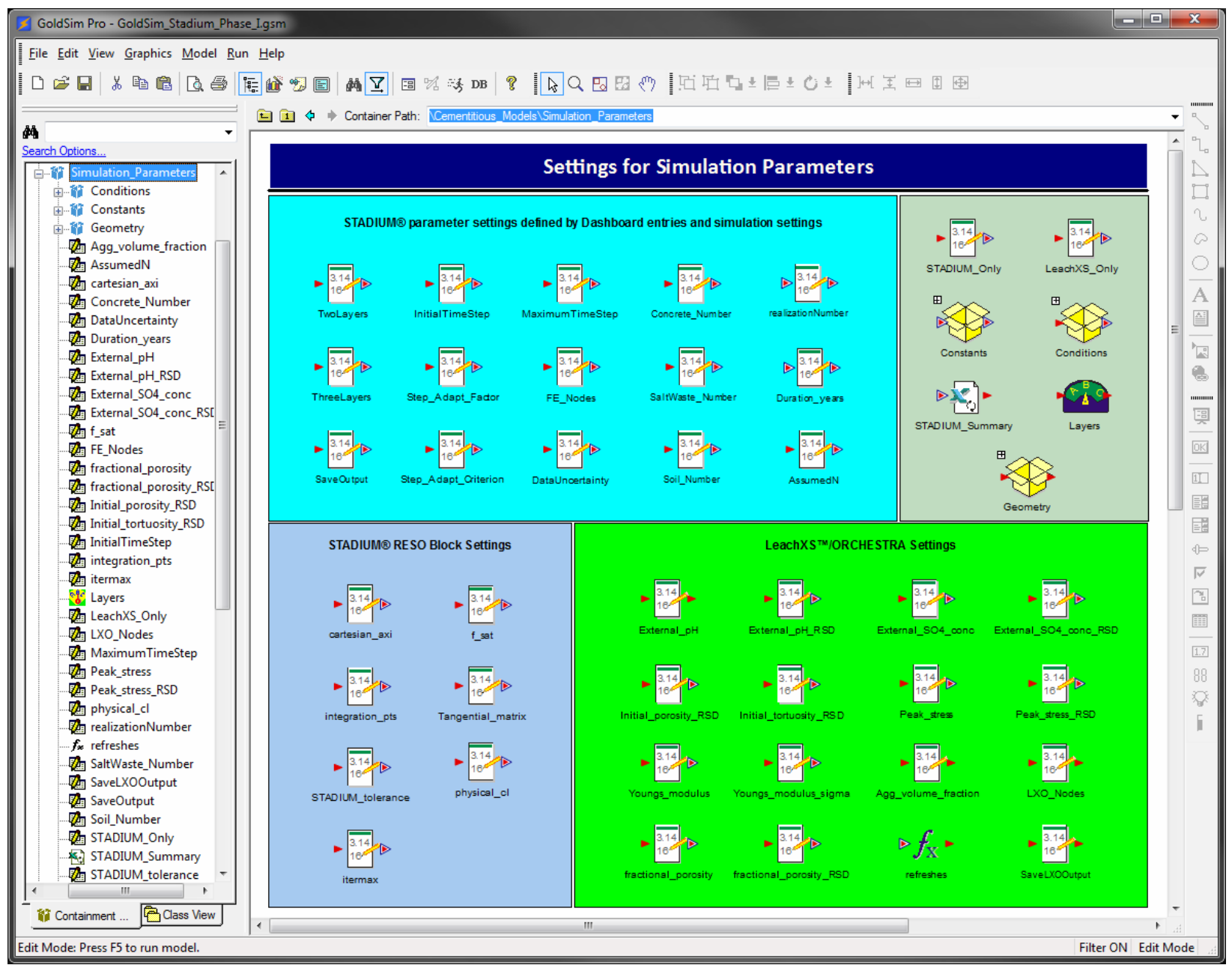

Figure 4-21. Contents of Simulation_Parameters container.

The contents of the Materials container are shown in Figure 4-22. Functions in this container define the material compositions and properties used in the model simulation. Three material types are defined: SaltWaste, Concrete and Soil. For STADIUM® simulations, the species list consists of the ions: $\mathrm{Ca}, \mathrm{OH}, \mathrm{Na}$, $\mathrm{K}, \mathrm{SO} 4, \mathrm{AlO} 4 \mathrm{H} 4, \mathrm{Cl}, \mathrm{H} 2 \mathrm{SiO} 4, \mathrm{CO} 3, \mathrm{NO} 3$, and $\mathrm{NO} 2$ as well as nine minerals: Portlandite, $\mathrm{CaH} 2 \mathrm{SiO} 4$, Ettringite, Monosulfate, AFmOH, Thaumasite, Calcite, Monocarboaluminate, and Gypsum. The species list and material types are the same as those used in the STADIUM® Task 7 case studies (SIMCO 2010). For LeachXSTM/ORCHESTRA simulations, the ions included Al, Ca, H2CO3, Fe, Mg, Na, H4SiO4, SO4, OH, K, $\mathrm{Cl}, \mathrm{NO} 3, \mathrm{NO} 2$, and $\mathrm{H}$ and the minerals included Portlandite, $\mathrm{CSH} \_$jennite, $\mathrm{CSH}$ _tobermorite, Ettringite, Brucite, CO3_hydrotalcite, Calcite, Monocarboaluminate, and Gypsum. The species list and material types are among those described in the LeachXSTM/ORCHESTRA Task 7 case studies (Meeussen et al. 2010). Material properties available in the Phase I code integration model are listed in Appendix B. 


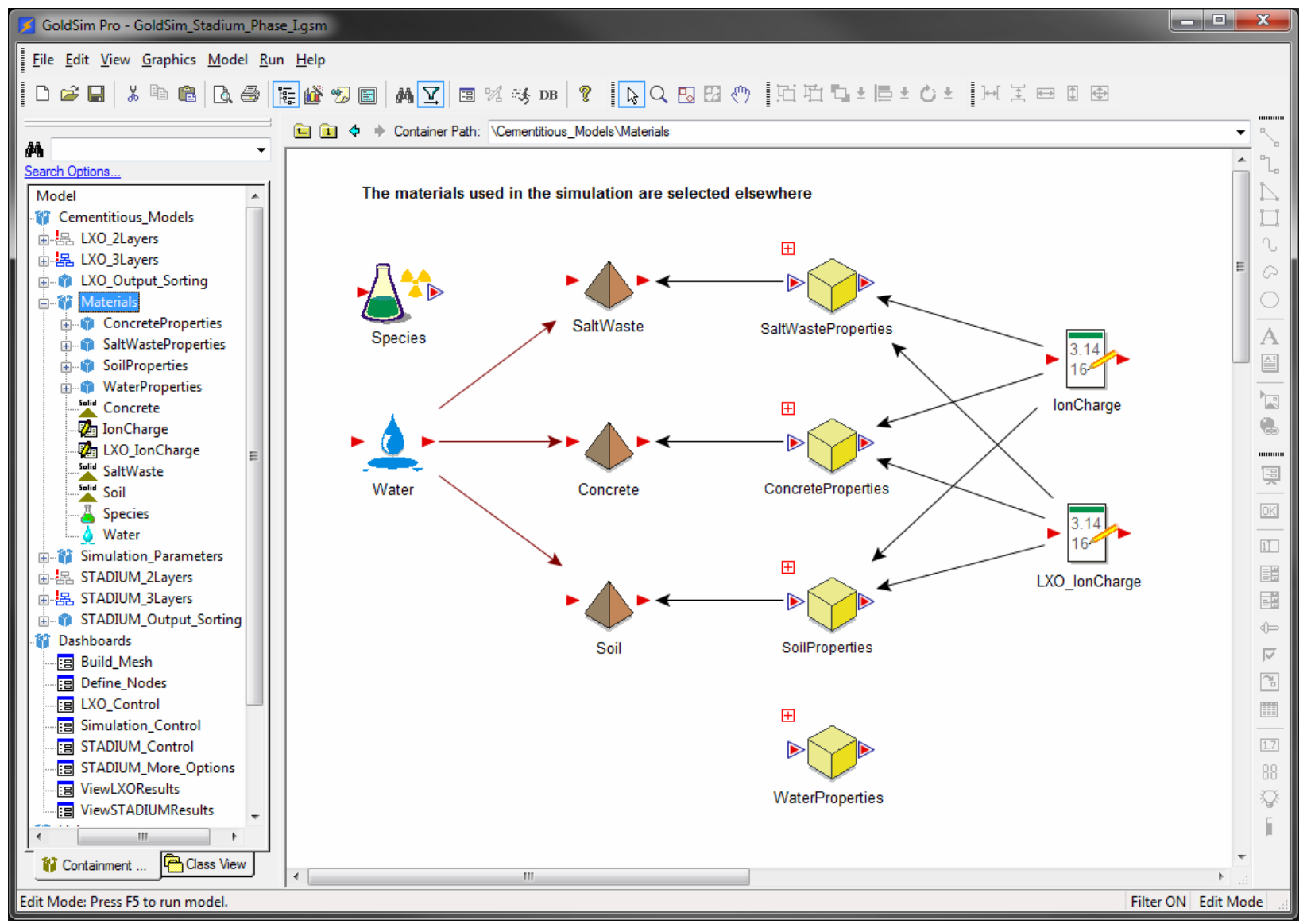

Figure 4-22. Contents of Materials container.

The containers SaltWasteProperties, ConcreteProperties and SoilProperties perform the same functions that help define the material properties; whereas, the WaterProperties container defines the initial external solution information. As an example, the contents of container ConcreteProperties are show in Figure 4-23. The physical properties, chemical and mineral compositions of the concrete are stored in Microsoft Excel workbook Concrete_Data in the Materials folder (see Figure 4-4). The GoldSim function Concrete_Input provides a link to the workbook and extracts the data from the spreadsheet for the selected material into variables that GoldSim can access. Properties for various types of concrete are stored in the workbook. The concrete type is selected as shown in Figure 4-13 and the type number points to the spreadsheet that is read. 


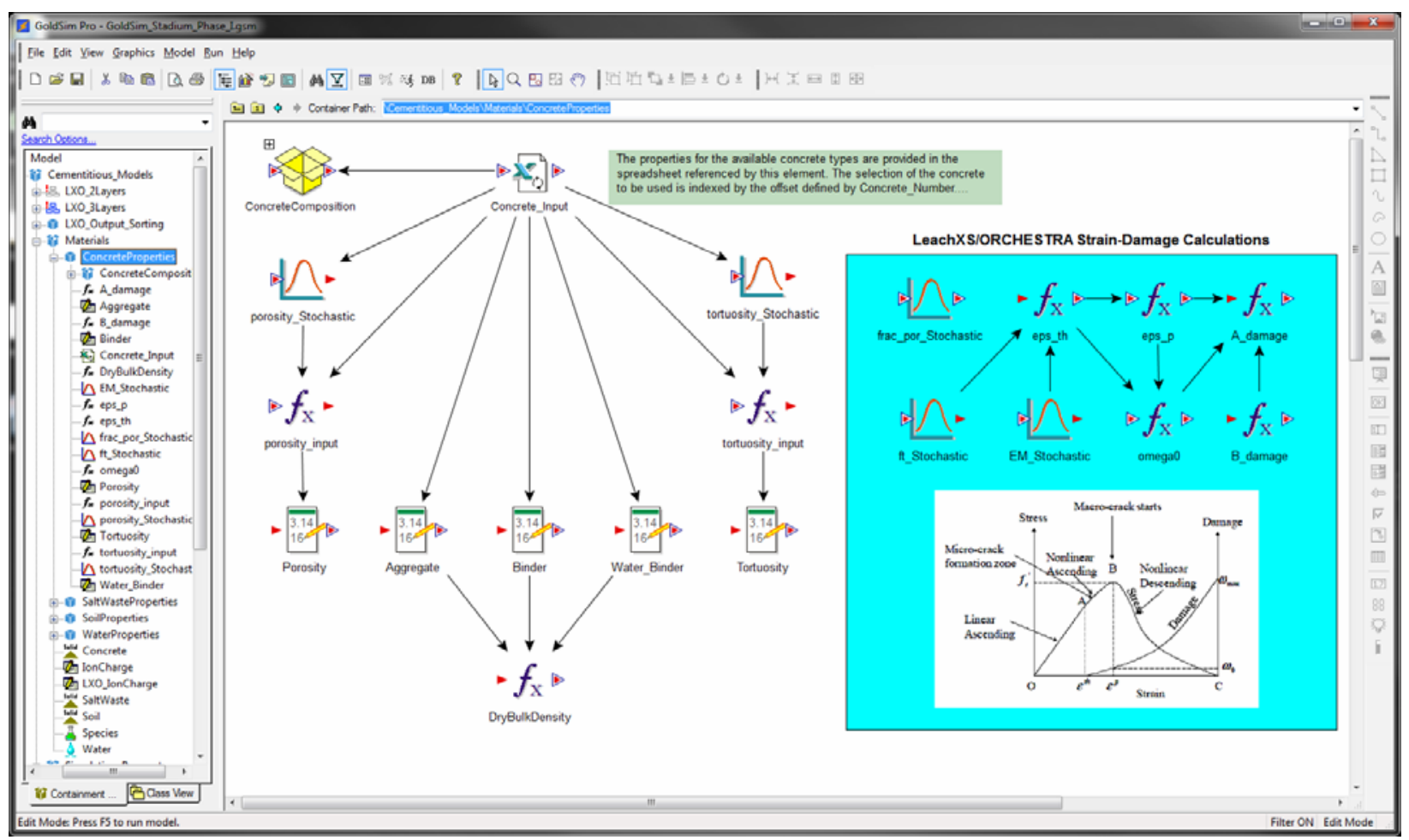

Figure 4-23. Contents of ConcreteProperties container.

The container ConcreteComposition processes the input chemical and mineral composition for probabilistic calculations and ensures charge balance. For LeachXSTM/ORCHESTRA, the inputs needed for damage estimates are computed in this container. The contents of container ConcreteComposition are shown in Figure 4-24. The nominal compositions stored in the Microsoft Excel workbook are assumed to represent the mean values of normal distributions of possible compositions. The standard deviation of the distribution is the Concentration $\mathrm{CoV}$ value entered using the dashboard shown in Figure 4-13. For STADIUM $®$ calculations, the net charge on the concrete ions is calculated, and the composition adjusted by changing the sodium ion concentration to achieve electroneutrality. A final adjustment is made to the ion and mineral compositions to set any concentrations less than $0.001 \mathrm{mmol} / \mathrm{L}$ for ions and less than $0.001 \mathrm{~g} / \mathrm{kg}$ for minerals to zero. STADIUM ${ }^{\circledR}$ calculations with material compositions having very small concentrations of chemicals or minerals appeared to convergence slowly. Electroneutrality is achieved for LeachXS simulations internally, by adjusting the amount of protons until total charge of the system becomes neutral. 


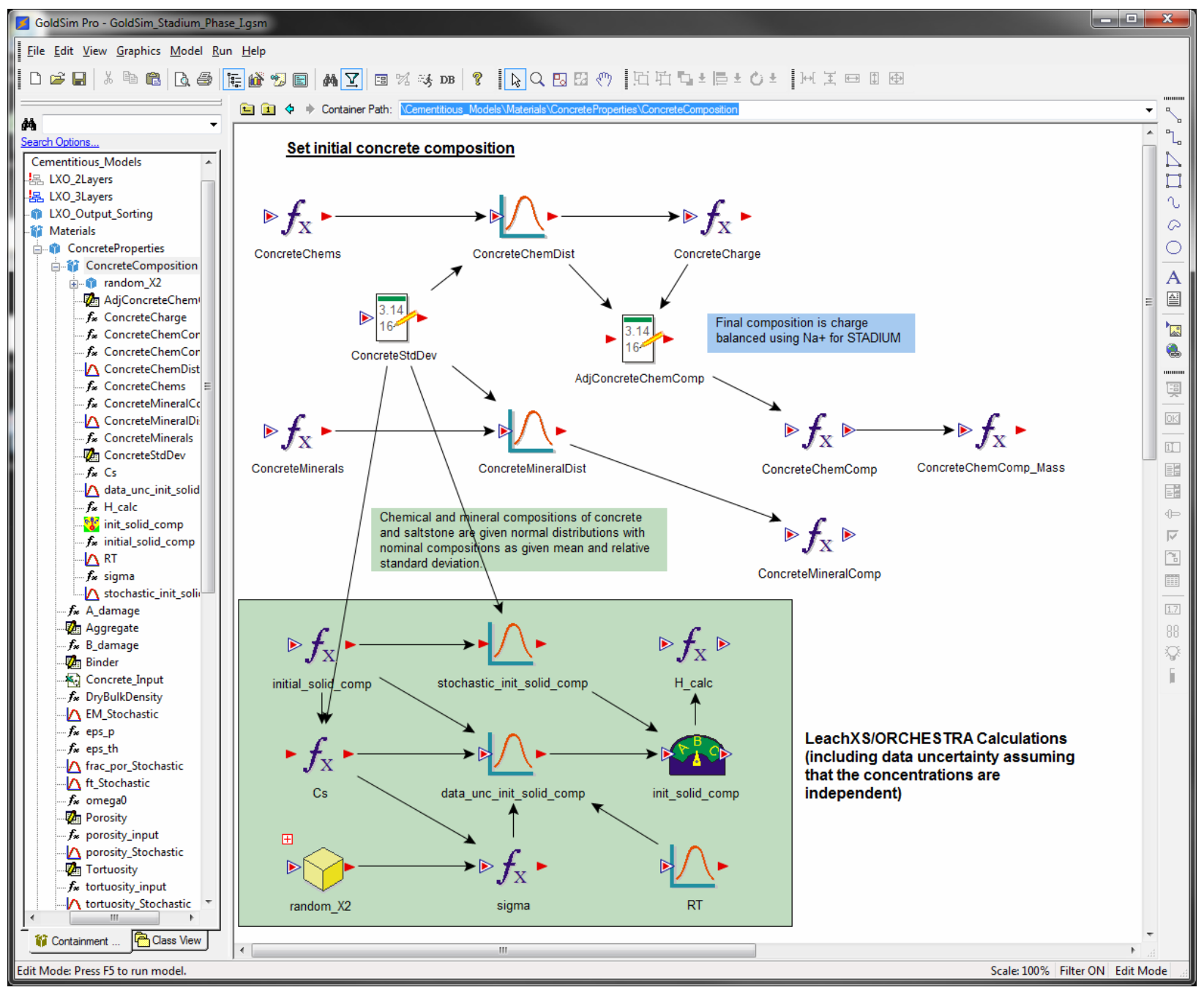

Figure 4-24. Contents of ConcreteComposition container.

Returning to the top-level GoldSim model shown in Figure 4-20, the four containers LXO_2Layers, LXO_3Layers, STADIUM_2Layers and STADIUM_3Layers contain the GoldSim links to the corresponding Dynamic-link Libraries (DLLs) shown in Figure 4-3. For example, the contents of the STADIUM_2Layers container are shown in Figure 4-25. The container Input_Collection first collects the physical property data into a dimensionless array. This operation simplifies the required DLL . dat instructions so that the physical properties can be passed with a single command instead of having separate commands for each property. The DLL function provides a link to the external DLL and defines the input and output variables that are passed between GoldSim and the appropriate DLL. Contents of the Input_Collection container are shown in Figure 4-26. The switch functions are defined to arrange the properties in the same order as the material regions specified in Figure 4-13. 


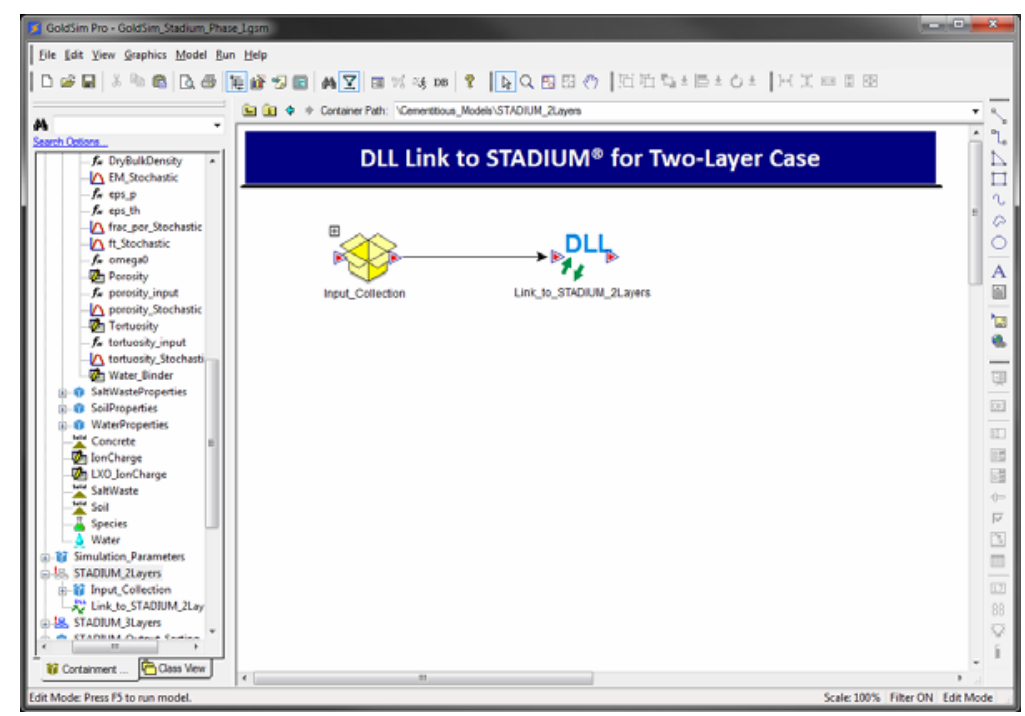

Figure 4-25. Contents of STADIUM_2Layers container.

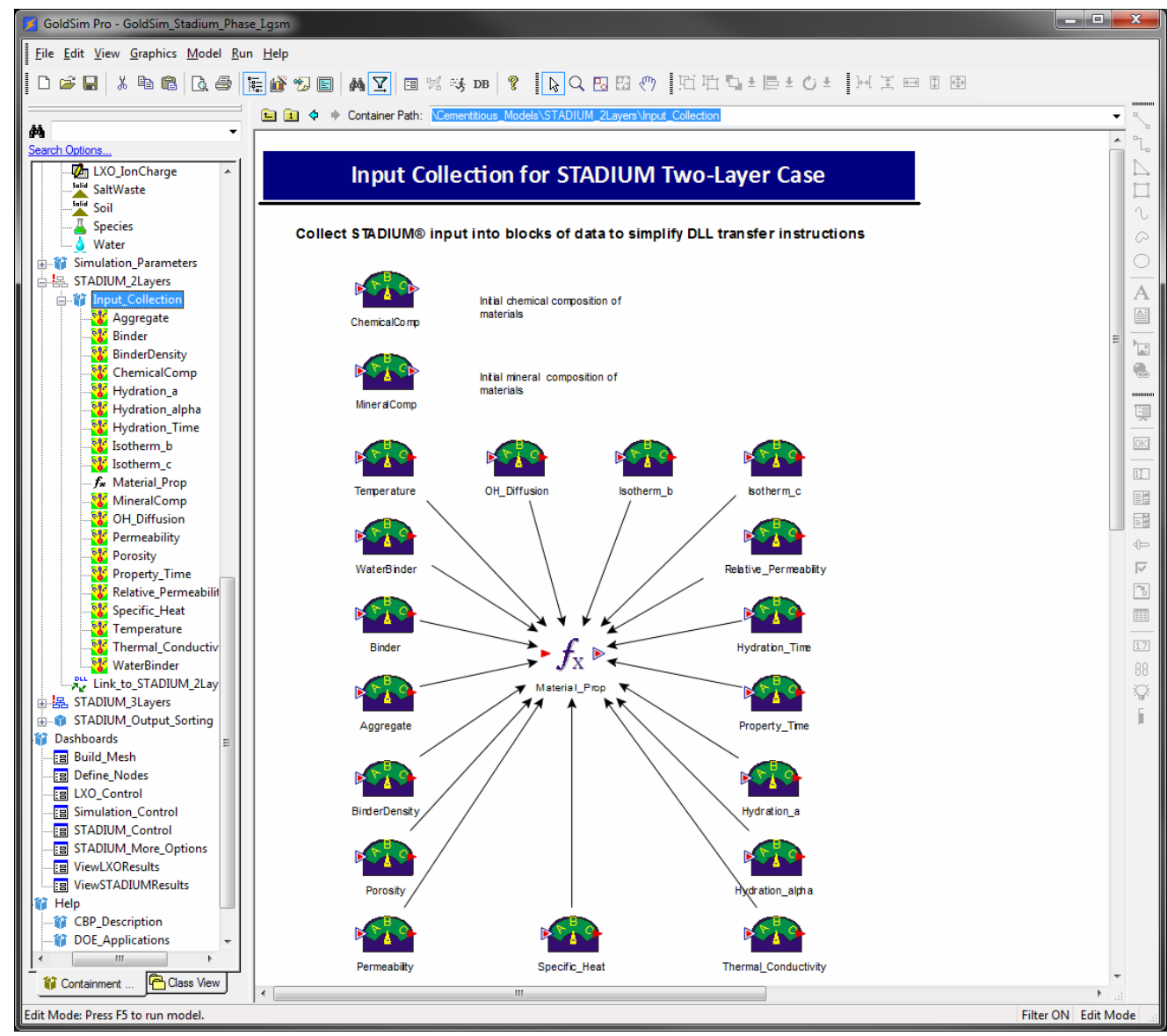

Figure 4-26. Contents of Input_Collection container. 
The contents of the last container in the top-level GoldSim model, STADIUM_Output_Sorting, are shown in Figure 4-27. This container extracts the chemical and mineral compositions from the vector of results transferred through the DLL to GoldSim and provides simple plots of the results. An example of the plots provided is shown in Figure 4-16. In this example, results at 100 years were read from the STADIUM ${ }^{\circledR}$ output file and chemical and mineral compositions are plotted at each node to give a spatial picture of the concentration profile. There are corresponding containers for the 3-layer STADIUM ${ }^{\circledR}$ and LeachXS ${ }^{\text {TM} / O R C H E S T R A ~ m o d e l s . ~}$

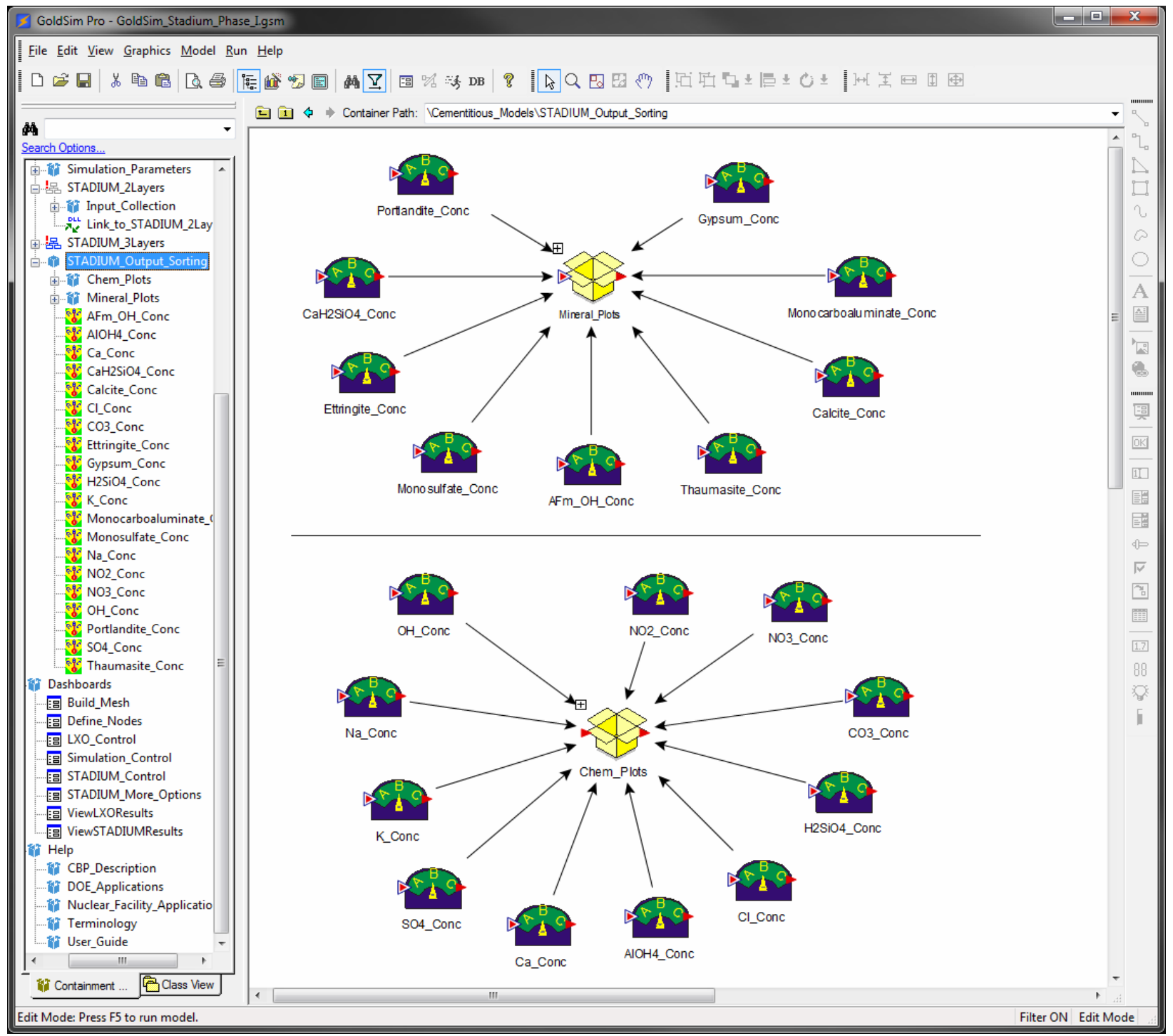

Figure 4-27. Contents of STADIUM_Output_Sorting container. 


\section{EXAMPLE CALCULATIONS}

Example calculations using the CBP STADIUM ${ }^{\circledR}$ partner code are provided to demonstrate the code interfacing possible within the GoldSim framework and the use of GoldSim to perform probabilistic calculations with the partner codes. The example simulations described here are taken from CBP Task 7 (SIMCO 2010) intended to demonstrate the capabilities of the current versions of the partner codes for typical problems of interest to the CBP. These examples evaluate the leaching of material from SRS Saltstone waste form through a concrete barrier into the environment and the durability of the concrete barrier over time. A single case is used to demonstrate the code interfacing capabilities for the STADIUM ${ }^{\circledR}$ partner code while more extensive results are available in the CBP Task 7 reports (SIMCO 2010, Meeussen et al. 2010).

As a test of the GoldSim code integration software and the associated DLL interface, two runs were made using the STADIUM ${ }^{\circledR}$ code. The first run was a deterministic calculation duplicating the STADIUM ${ }^{\circledR}$ Case_01 simulation made as part of CBP Task 7 (SIMCO 2010). The second run was a 50 realization Monte Carlo simulation also using the Task 7 Case_01 STADIUM ${ }^{\circledR}$ simulation. The Case_01 simulation was selected for these tests because it used the smallest mesh of any of the STADIUM ${ }^{\circledR}$ Task 7 cases and presumably would run in the least amount of time. Each STADIUM ${ }^{\circledR}$ run simulated 10,000 years of operation.

The selected test case modeled a one-dimensional, two-layer system consisting of $50 \mathrm{~cm}$ of SRS Saltstone and $20 \mathrm{~cm}$ of concrete. Each material was assigned 50 nodes. The mesh for the STADIUM ${ }^{\circledR}$ calculation was generated using the Mesh2d Fortran code that is included as a part of the GoldSim code integration software (Section 4.2.2). Using the XMesh. dat input file shown in Figure 5-1, the code generated coordinate and element files that are required for the STADIUM ${ }^{\circledR}$ calculations with parameters identical to those provided in the SIMCO Technologies, Inc. example. 


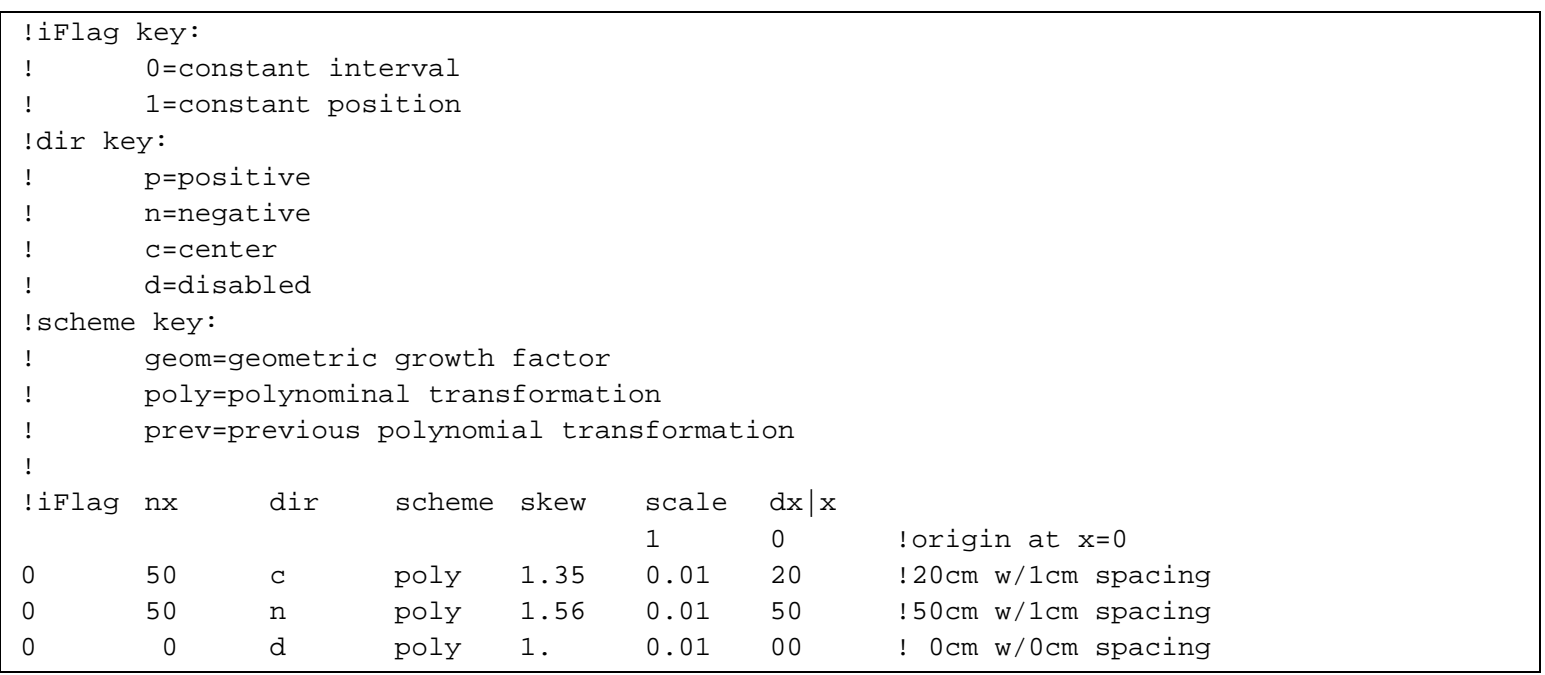

Figure 5-1. Input file used to generate the one-dimensional STADIUM® mesh for test cases.

The input file that provided instructions to the DLL interface between GoldSim and STADIUM ${ }^{\circledR}$ is shown in Figure 5-2. The PUT command is used to write chemical and mineral compositions, material properties, and some calculation parameters to the STADIUM ${ }^{\circledR}$ input file. The RPL command places the coordinate and element file names into the input. The EXE command runs the STADIUM ${ }^{\circledR}$ code. The GET command extracts chemical and mineral compositions after 100 years in the simulation from the STADIUM ${ }^{\circledR}$ output for transfer back to GoldSim. The LOG command keeps a record of the values sent to and received from GoldSim from execution of the DLL.

Selected results from the Case_01 deterministic calculation are shown in Figure 5-3 and Figure 5-4. These results were contained in the normal STADIUM $®$ output file and processed outside of the GoldSim interface. For comparison purposes, these results have been plotted in the same format as the results shown in the Task 7 report demonstrating STADIUM ${ }^{\circledR}$ capabilities (SIMCO 2010). A direct comparison of the output file from the GoldSim calculation to the Case_01 output supplied by SIMCO showed that results from the two calculations were identical. The deterministic calculations required 11.2 hours to run using a $2.13 \mathrm{GHz}$ Intel Xeon processor. 


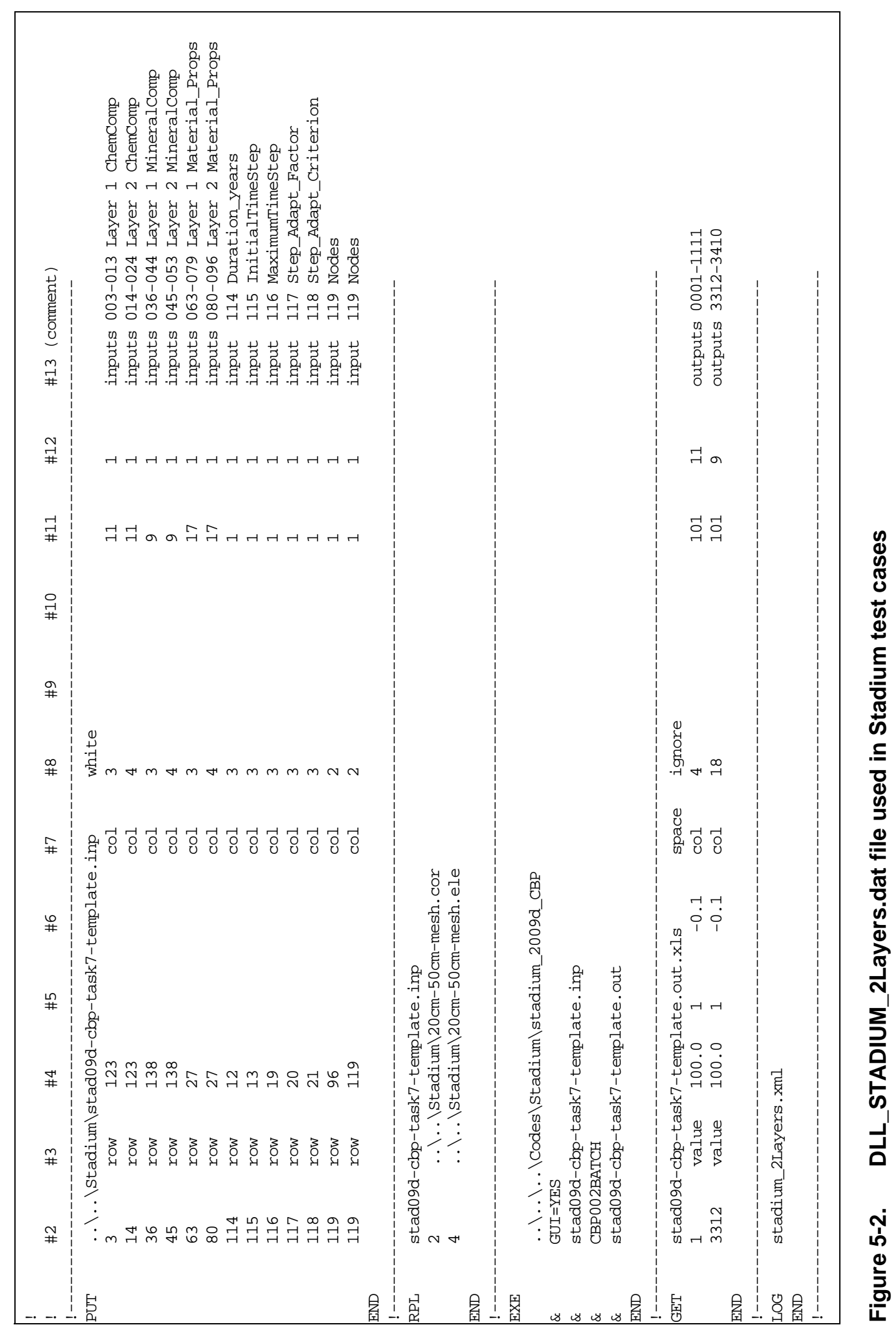




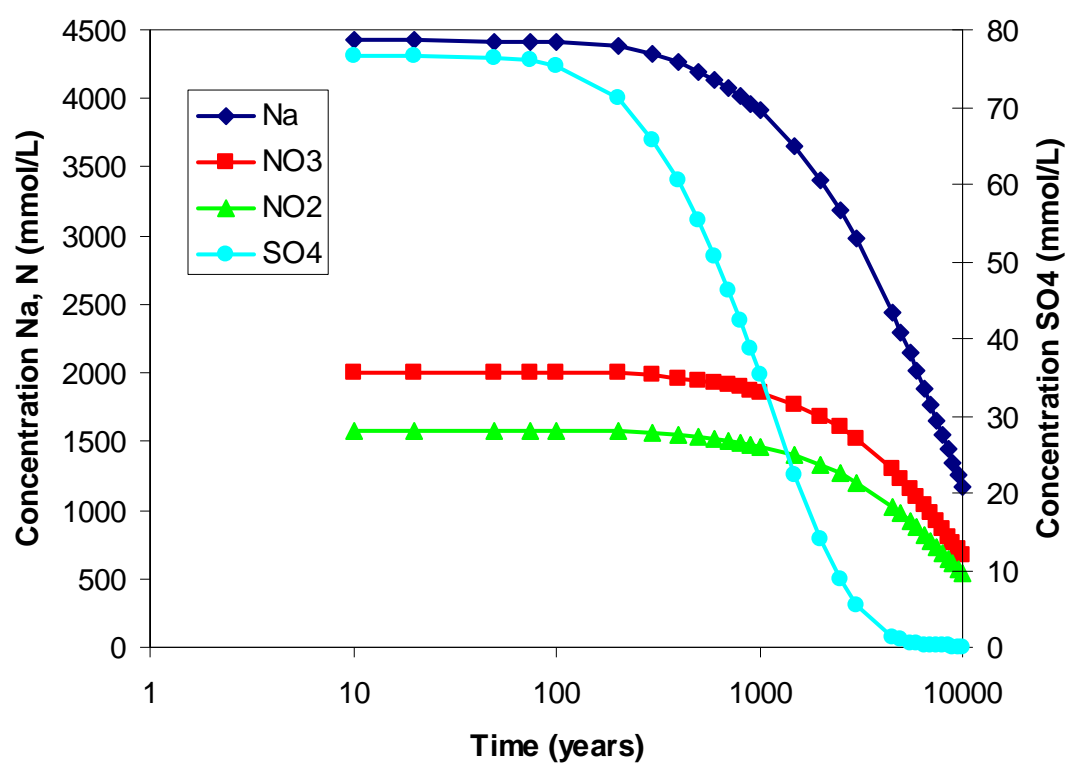

Figure 5-3. Ion concentrations at end of Saltstone domain

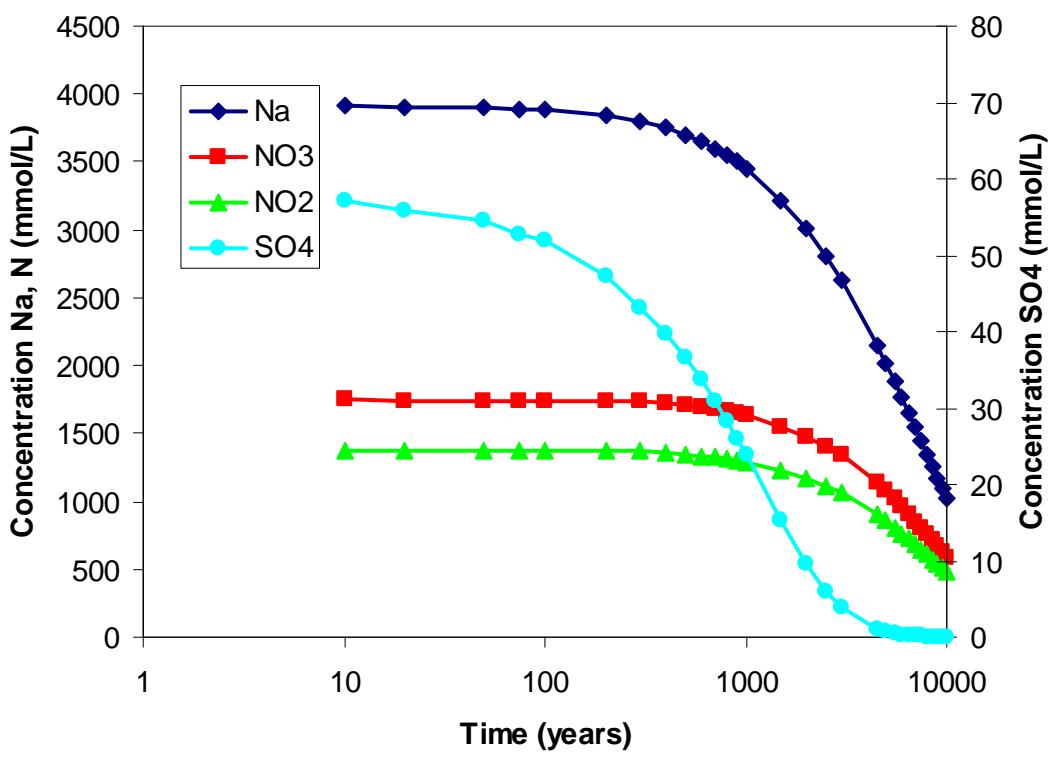

Figure 5-4. Ion concentrations at Saltstone-concrete interface

Having established that the GoldSim code integration software is able to reproduce a single STADIUM ${ }^{\circledR}$ calculation, a Monte Carlo calculation was made for 50 random realizations of the Case_01 simulation to demonstrate this capability of the GoldSim code integration software. The GoldSim model currently has random distributions only on the initial Saltstone and concrete chemical and mineral compositions. For test purposes, it was assumed that the compositions would have a normal distribution with a relative standard deviation of $5 \%$ of the mean concentration. The concentrations given in the Case_01 input were assumed to be the mean values. GoldSim randomly varied each chemical and mineral concentration separately. 
Some results from the Monte Carlo calculations are shown in Figure 5-5 through Figure 5-9. These results were extracted from the normal STADIUM ${ }^{\circledR}$ output files and plotted outside of the GoldSim interface. Figure 5-5 through Figure 5-7 plot concentrations of nitrate, calcium and sulfate, respectively, at the Saltstoneconcrete interface for all 50 realizations over 10,000 years. Figure 5-8 and Figure 5-9 plot the concentrations of nitrate and sodium, respectively, at the end of the Saltstone region for all 50 realizations over 10,000 years. Results from the deterministic case are plotted on each figure as the thicker black curve. It would be expected that the deterministic case would fall close to the midpoint of the 50 realizations, and this is seen to be the case. Fifty realizations are not enough to obtain good statistics for determining the true distribution of possible outcomes for this scenario. This trial calculation was instead intended to provide a demonstration of the GoldSim code integration software capabilities.

The 50 realizations were run on a workstation with eight Intel Xeon CPU's that took advantage of GoldSim's distributed processing capabilities to run four realizations simultaneously. Calculation times for the individual realizations varied from 8.0 to 15.6 hours and the entire Monte Carlo run took just over six days to complete. The calculation provided a good demonstration of the robustness of the code integration system and its ability to perform long calculations without encountering problems. When using the distributed processing capability, GoldSim automatically creates the remote processes that will run on individual CPU's and copies required files to folders for each process. However, GoldSim can only recognize files that are directly linked to the GoldSim model. For example, GoldSim placed copies of the DLL into each remote process folder but it could not know that the DLL would read the DLL. dat file and the instructions would call for operations on other files. Any files not directly linked to GoldSim were manually copied to each remote process folder ${ }^{4}$.

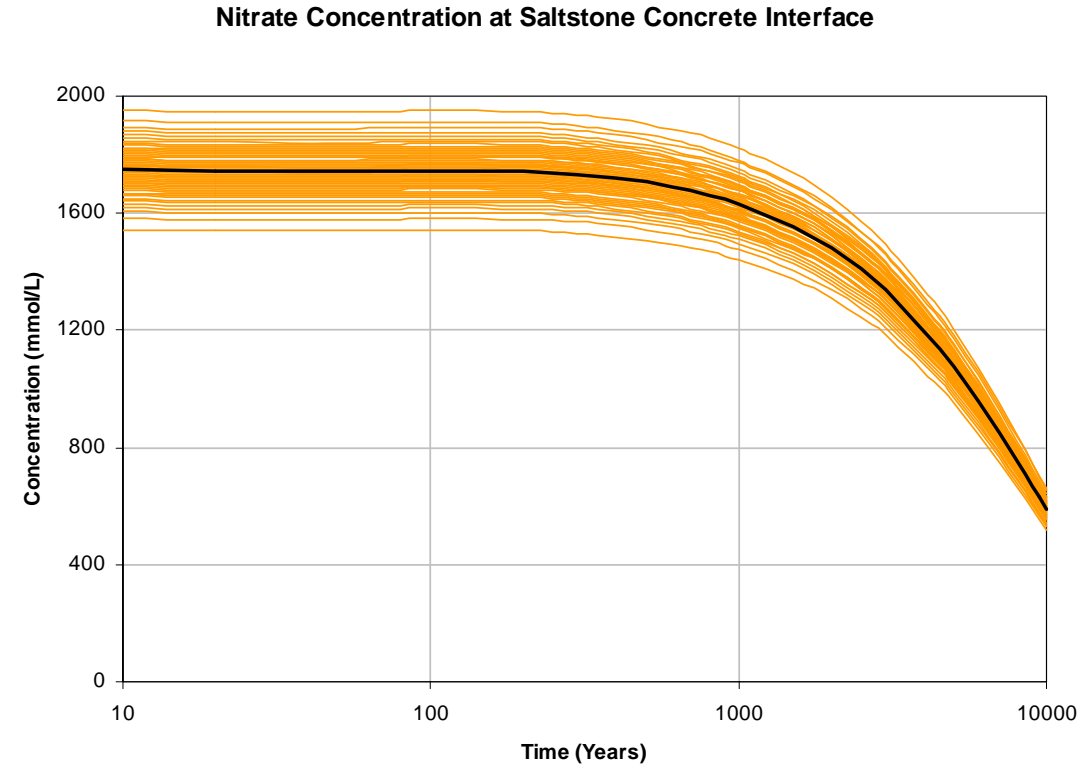

Figure 5-5. Nitrate concentration at Saltstone-concrete interface from deterministic calculation and $\mathbf{5 0}$ Monte Carlo realizations

4 In the Phase II code integration model, GoldSim file elements (GTG 2010b) will be used to assure that necessary support files are passed to remote process folders when using the GoldSim Distributed Processing Module. 
Calcium Concentration at Saltstone Concrete Interface

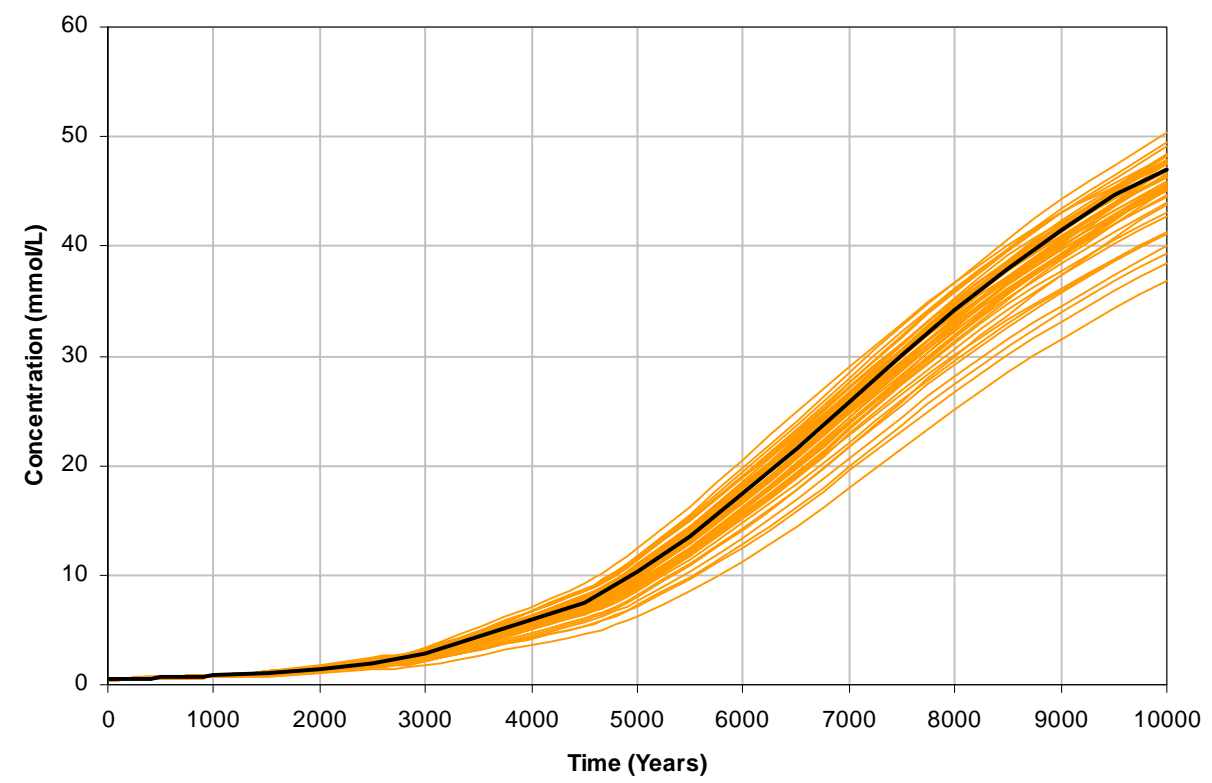

Figure 5-6. Calcium concentration at Saltstone-concrete interface from deterministic calculation and $\mathbf{5 0}$ Monte Carlo realizations

Sulfate Concentration at Saltstone Concrete Interface

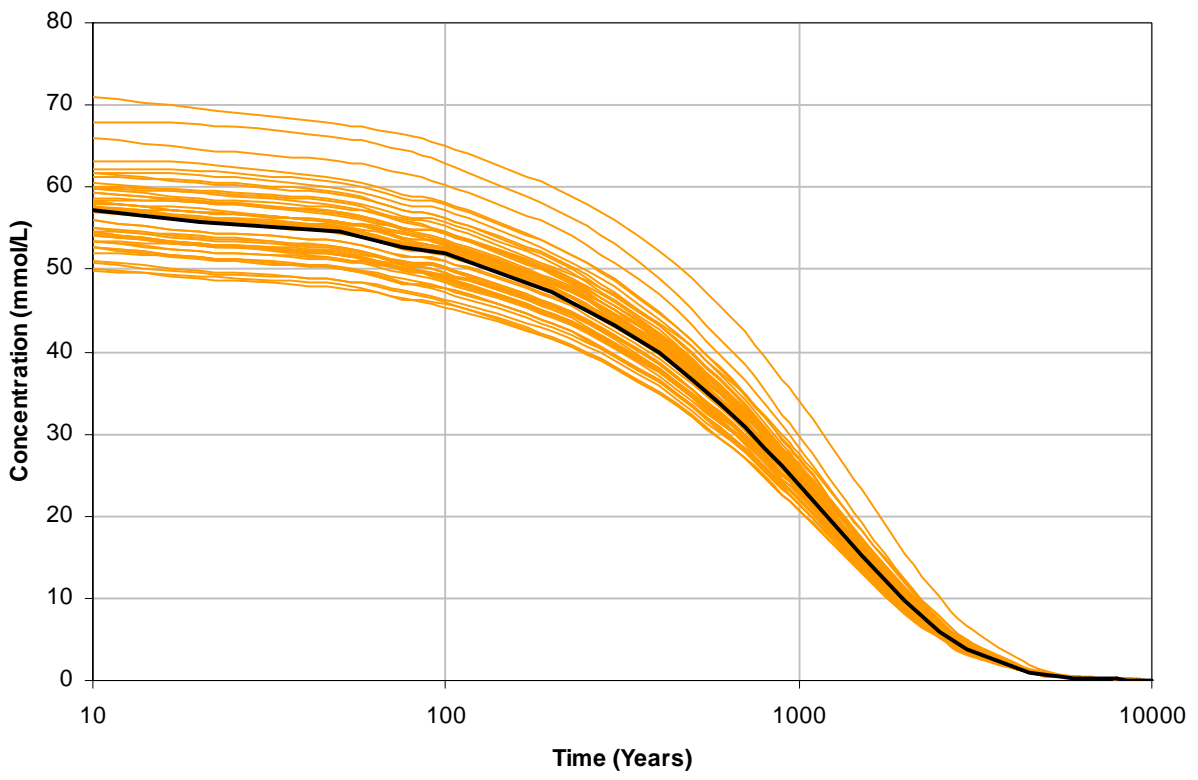

Figure 5-7.Sulfate concentration at Saltstone-concrete interface from deterministic calculation and $\mathbf{5 0}$ Monte Carlo realizations 


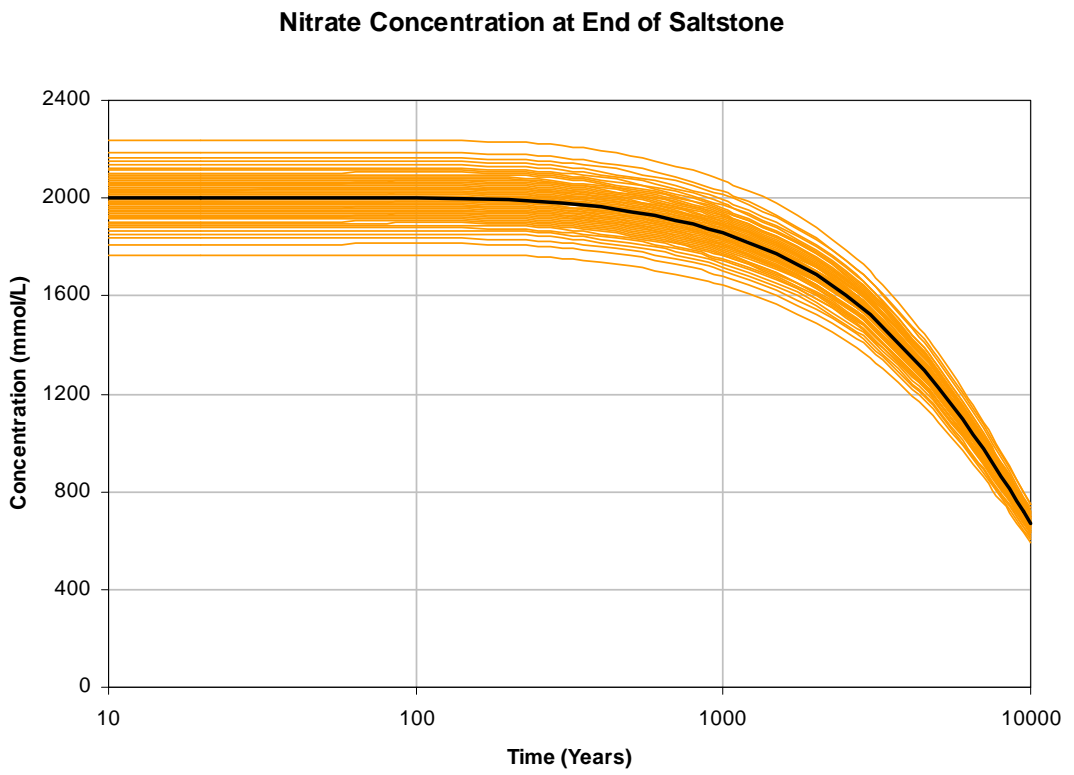

Figure 5-8. Nitrate concentration at end of Saltstone domain from deterministic calculation and 50 Monte Carlo realizations

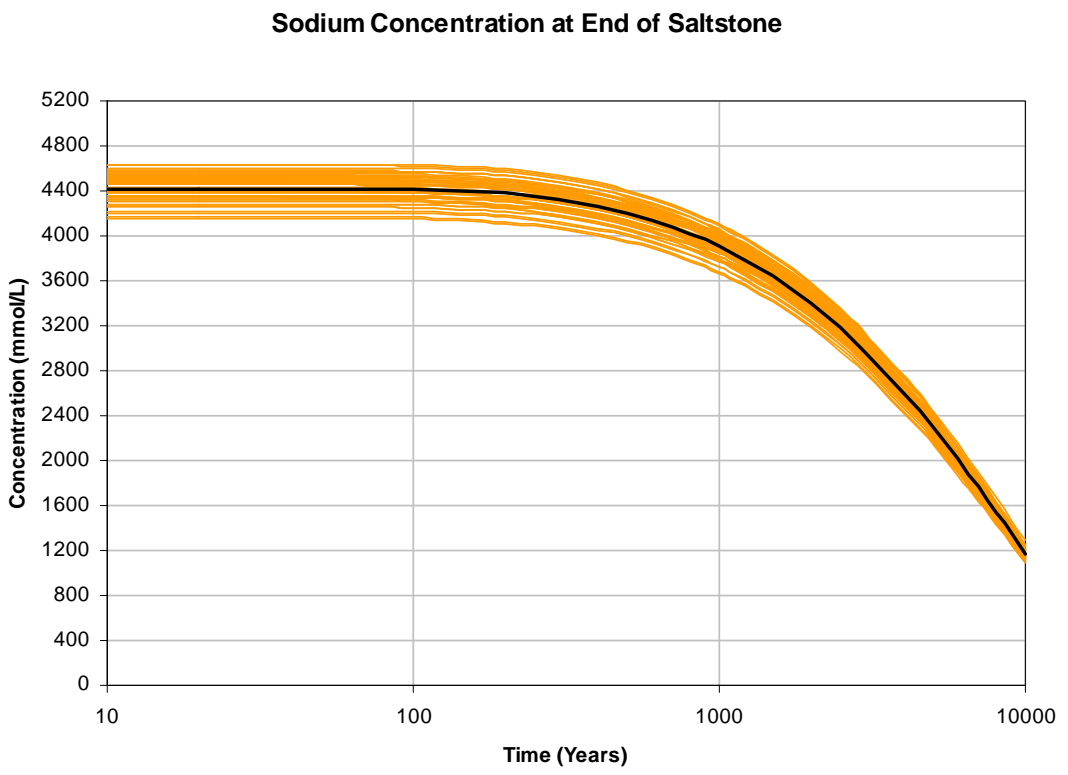

Figure 5-9.Sodium concentration at end of Saltstone domain from deterministic calculation and 50 Monte Carlo realizations

Further tests of the GoldSim code integration platform and the associated DLL interface were made calling the LeachXSTM/ORCHESTRA partner code. These runs were more focused on uncertainty evaluation of a threelayer model as described in the ECN Task 7 report (Meeussen et al. 2010). A typical realization as illustrated in Figure 5-10 required approximately 3.5 hours to simulate 300 days (i.e., the simulation time from the original ECN example) using GoldSim Version 10.5 on a workstation with dual 6-core Xeon ${ }^{\circledR}$ processors and 
$24 \mathrm{~GB}$ of main memory. Because these tests were focused on uncertainty analysis, the scenario and simulation results will be described in detail in the companion CBP uncertainty analysis report to be released.

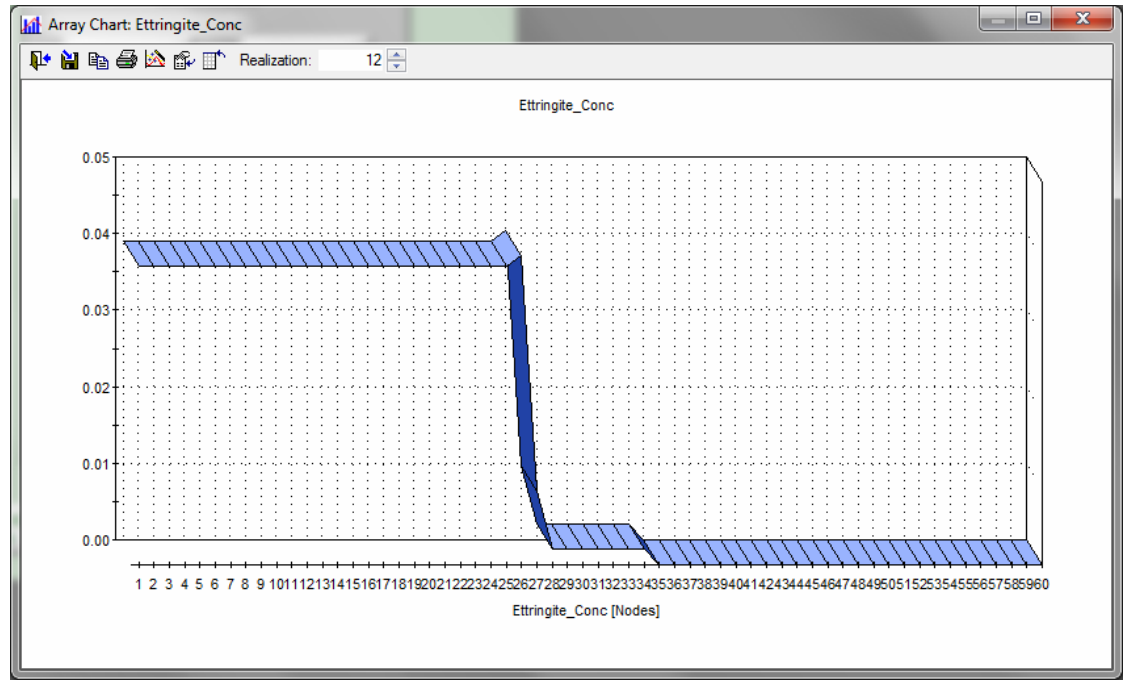

Figure 5-10. Ettringite concentration (mols / L) computed by LeachXS ${ }^{\mathrm{TM}} / \mathrm{ORCHESTRA}$ for the nodes in a 3-layer system for single realization. The results for a single realization can be displayed using the built-in GoldSim Array View Element.

\section{CONCLUSIONS}

The Phase I CBP code integration work has developed a feasible integration methodology and demonstrated its applicability with the LeachXS ${ }^{\mathrm{TM}} / \mathrm{ORCHESTRA}$ and STADIUM ${ }^{\circledR} \operatorname{codes}^{5}$. The code integration was implemented using the GoldSim software and a generalized DLL to interface with other codes. GoldSim, using the DLL interface, provides a workable integration platform and allows the user to perform probabilistic or deterministic simulations with the partner CBP codes.

As shown in Section 4, the user can work entirely within the GoldSim interface to modify input to the linked CBP codes, run simulations using these codes and view the results. The user is able to select the materials used in the simulation from the limited set of possible materials shown in Appendix B and modify material properties and initial compositions within the framework of the code integration software. The integration software also gives the user control over simulation numerics without working directly with the codes. GoldSim simulation controls can be used to run deterministic or Monte Carlo simulations. The GoldSim interface also offers the capability of creating and viewing the computational grid for the STADIUM ${ }^{\circledR}$ as explained in Appendix A. For this initial phase of CBP code integration, operation of the partner codes is not coupled. Methods to view simulation results are also somewhat limited within the integrated code framework.

5 A detailed description of the STADIUM ${ }^{\circledR}$ evaluation is provided in Section 5 of this report, and the LeachXSTM/ORCHESTRA example will be described in a companion report (to be issued) describing the evaluation of uncertainty using the GoldSim framework. 
At present, simulation results are best viewed by accessing the results outside of the code integration software. These issues will be addressed in the second phase of the code integration effort described in the following Section. The methods and software developed as part of the Phase I code integration effort can be directly applied to other external codes.

\subsection{Software Use}

The code integration tool described in Section 4 was developed as part of the Cementitious Barriers Partnership collaboration supported by the United States Department of Energy (US DOE) Office of Waste Processing. Development of the code integration software was a joint project between researchers at Vanderbilt University and the Savannah River National Laboratory (SRNL). It is ultimately intended that this software should be available to users beyond the CBP project. The code integration tool interfaces with software that is in some cases freely available and in other cases proprietary. In either case, the integration software developers are not free to distribute third party software for use. Therefore, at this time, to use the code integration tool, a prospective user would need to take the following steps.

1. The code integration software is available from Vanderbilt University and the Savannah River National Laboratory to members of the CBP project. Copywriting and licensing for release to distribution outside of the CBP have not yet been determined. The software includes the Mesh2d grid generator.

2. The Windows based GoldSim Player can be obtained from the GoldSim Technology Group as a free download from www.goldsim.com. The prospective user must fill out a request form.

3. ORCHESTRA is available as a free download from the Energy Research Centre of the Netherlands (ECN) at http://www.meeussen.nl/orchestra/. ORCHESTRA is Java-based software compatible with the Java6 Runtime Environment.

4. STADIUM ${ }^{\circledR}$ is proprietary software that can be licensed from SIMCO Technologies Inc. of Quebec City in Quebec, Canada. The CBP project used a special version of STADIUM® that did not include access to the GUI normally supplied with the code. Code integration software users outside of the CBP would need to arrange with SIMCO to license this version of STADIUM ${ }^{\circledR}$.

5. Tecplot Viewer is available as a free download from www.tecplottalk.com/addons/viewer/. The user agrees to accept Tecplot's license agreement.

6. Gnuplot is open source freeware available for download from a link on www.gnuplot.info.

\section{PHASE II CODE INTEGRATION PLAN}

Figure 7-1 shows a schematic diagram of the planned Phase II CBP code integration framework. Solid arrows show the existing Phase I framework. Dashed arrows indicate additional capabilities planned for Phase II. 


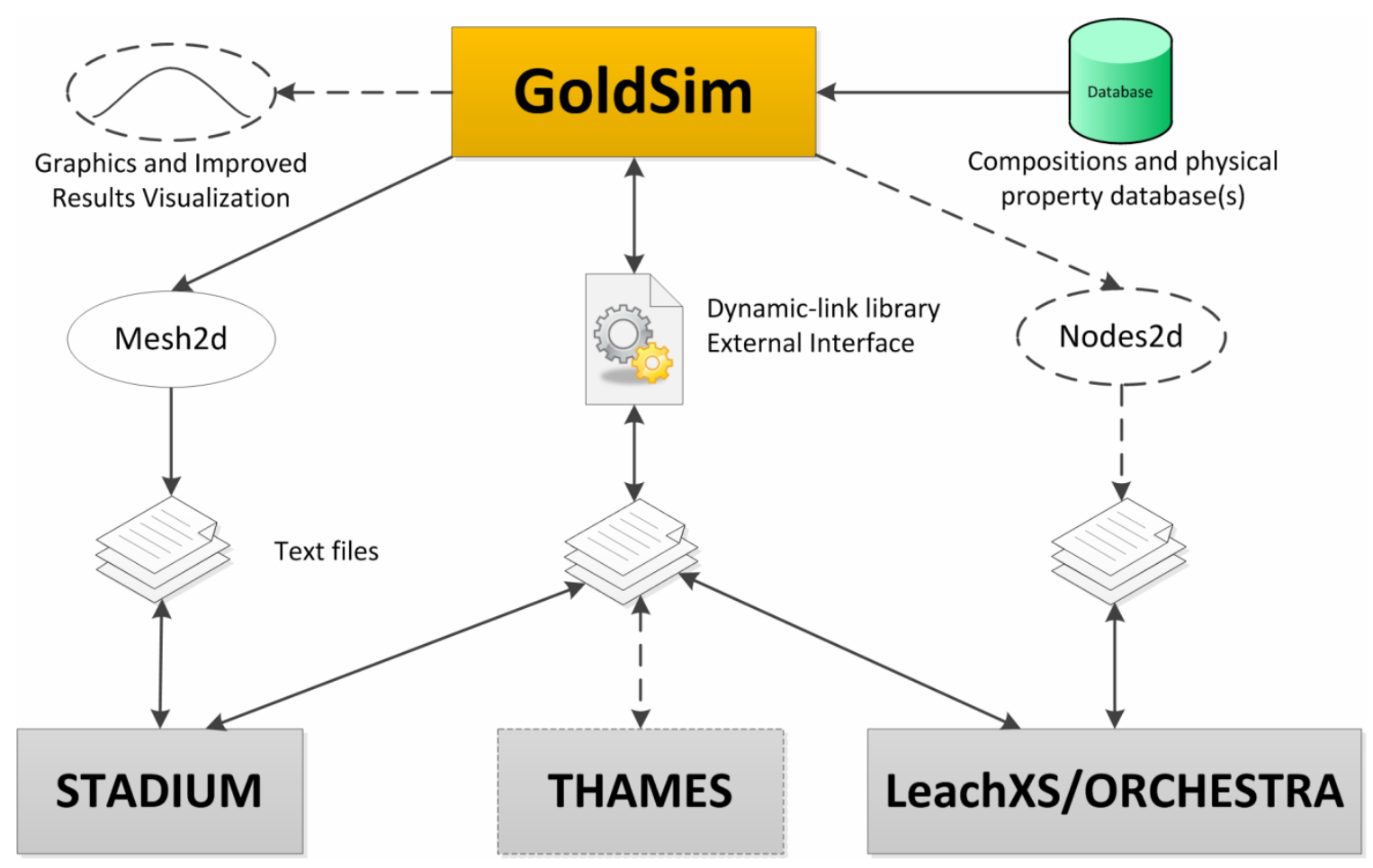

Figure 7-1. Proposed Phase II CPB code integration framework.

Items that will be addressed in Phase II of the CBP code integration include:

- Improvements to the DLL interface such as enhanced error trapping. The DLL interface is currently well developed for linking to external codes having the primary input and output in text files. It is expected that this approach will be adequate for the needs of the CBP project. However, minor improvements to the interface will be made as needed.

- Improved data visualization capabilities by including a direct interface from GoldSim to plotting software. The Phase I code provides the capability of visualizing the computational mesh using a selection of readily available graphics software. Simulation results can be viewed using the GoldSim graphics but this approach is somewhat limited. GoldSim would typically be applied for transient analysis and has good capabilities for displaying results as a function of time. However, if it is desired to display the results spatially GoldSim plotting is limited. Most of the Phase I results presented in this report were plotted outside of the GoldSim integration model. In Phase II the methodology used to display the mesh will be extended to the display of simulation results possibly by using another DLL interface.

- Development of a database of material properties that will be linked to GoldSim and thereby available for use in the CBP codes. The database would include physical properties for waste materials, cementitious materials and soils.

- Interfacing GoldSim to the THAMES code from NIST.

- Coupling between the CBP partner code calculations. 


\section{REFERENCES}

Brown, KG \& Flach, GP 2009a, CBP Software Summaries for LeachXS ${ }^{\text {TM} / O R C H E S T R A, ~ S T A D I U M ®, ~}$ THAMES, and GoldSim, CBP-TR-2009-003, Rev. 0, Vanderbilt University/CRESP and Savannah River National Laboratory; Cementitious Barriers Partnership, Nashville, TN and Aiken, SC. Available from: http://cementbarriers.org/reports.html.

Brown, KG \& Flach, GP 2009b, Detailed Description of the GoldSim Integrating Platform Selected for the CBP Project, CBP-TR-2009-003, Rev. 0, Vanderbilt University/CRESP and Savannah River National Laboratory; Cementitious Barriers Partnership, Nashville, TN and Aiken, SC. Available from: http://cementbarriers.org/reports.html.

Eary, T 2007, 'Example 3: Direct Linkage between GoldSim and PHREEQC through a "DLL" Element', [Online] http://www.goldsim.com/, p. 13 pp. Available from: http://www.goldsim.com/ [July 2007].

ECN 2007, LeachXS User Manual, Energy research centre of The Netherlands, Denmark. Available from: www.leaching.org [September 1, 2009].

GTG 2010a, "GoldSim User's Guide: Probabilistic Simulation Environment (Volume 1 of 2)," Version 10.5 (December 2010) edn, 2 vols, GoldSim Technology Group, Issaquah, WA..

GTG 2010b, "GoldSim User's Guide: Probabilistic Simulation Environment (Volume 2 of 2)," Version 10.5 (December 2010) edn, 2 vols, GoldSim Technology Group, Issaquah, WA.

Mattie, PD, Knowlton, RG \& Arnold, BW 2007, “A User's Guide to the GoldSim/BLT-MS Integrated Software Package: A Low-Level Radioactive Waste Disposal Performance Assessment Model," Report No. SAND2007-1354, Sandia National Laboratories, Albuquerque, NM.

Meeussen, JCL 2003, "ORCHESTRA: An Object-Oriented Framework for Implementing Chemical Equilibrium Models,” Environmental Science \& Technology, vol. 37, no. 6, pp. 1175-1182.

Meeussen, JCL, van der Sloot, HA, Kosson, DS \& Sarkar, S 2010, "Demonstration of LeachXSTM/ORCHESTRA Capabilities by Simulating Constituent Release from a Cementitious Waste Form in a Reinforced Concrete Vault," CBP-TR-2010-0007-C1, Rev. 0, Energy Research Centre of the Netherlands and Vanderbilt University/CRESP; Cementitious Barriers Partnership, Petten, The Netherlands and Nashville, TN. Available from: http://cementbarriers.org/reports.html.

SIMCO 2008, "Software for Transport and Degradation in Unsaturated Materials (STADIUM)", Version 2.8 User Guide, September 2008, SIMCO Technologies, Inc., Available from:

http://www.mslexperts.com/slm/stadium_help/index.html [February 6, 2009].

SIMCO 2010, "Demonstration of STADIUM ${ }^{\circledR}$ for the Performance Assessment of Cementitious Structures," CBP-TR-2010-0007-C3, Rev. 0, SIMCO Technologies Inc.; Cementitious Barriers Partnership, Quebec, Canada. Available from: http://cementbarriers.org/reports.html. 
Smith III, FG, Flach, G \& Brown, KG 2010, “CBP Code Integration GoldSim DLL Interface,” CBP-TR-2010009-2, Rev. 0, Savannah River National Laboratory and Vanderbilt University/CRESP; Cementitious Barriers Partnership, Aiken, SC and Nashville, TN. Available from: http://cementbarriers.org/reports.html. 


\section{APPENDIX A \\ GRID GENERATOR DESIGN AND USE}




\section{DESIGN OVERVIEW}

Mesh2d is a Fortran90 program designed to generate two-dimensional structured grids of the form [x(i),y(i,j)] where $[x, y]$ are grid coordinates identified by indices $(i, j)$. The $x(i)$ coordinates alone can be used to specify a one-dimensional grid, such as for the STADIUM ${ }^{\circledR}$ and Orchestra examples described in this report. Because the $\mathrm{x}$-coordinates vary only with the $\mathrm{i}$ index, a two-dimensional grid is composed in part of straight vertical lines. However, the nominally horizontal $y\left(i, j_{0}\right)$ coordinates along index $i$ are permitted to undulate or otherwise vary. Mesh2d also assigns an integer material type to each grid cell, $m$ typ $(i, j)$, in a user-specified manner. The complete grid is specified through three separate input files defining the $x(i), y(i, j)$, and mtyp(i,j) variations.

The overall mesh is constructed from grid zones that are typically then subdivided into a collection of smaller grid cells. The grid zones usually correspond to distinct materials or larger-scale geometric shapes. The structured grid zones are identified through uppercase indices (I,J). Subdivision of zonal regions into grid cells can be done uniformly, or non-uniformly using either a polynomial or geometric skewing algorithm. Grid cells may be concentrated backward, forward, or toward both ends. Figure A-1 illustrates the above concepts in the context of a simple four zone grid.

For non-uniform grid cell distribution, the original polynomial skewing algorithm implemented in Mesh2d is fundamentally defined by

$$
\eta=\left\{\begin{array}{cc}
\xi^{\mathrm{s}} & \text { negative } \\
1-(1-\xi)^{\mathrm{s}} & \text { positive } \\
(3-2 \mathrm{~s}) \xi+6(\mathrm{~s}-1) \xi^{2}+4(1-\mathrm{s}) \xi^{3} & \text { central }
\end{array}\right.
$$

where $\xi$ is the normalized distance across the grid zone (ranging from 0 to 1 ), $\eta$ is the transformed (skewed) position, and $\mathrm{s}$ is the skewing parameter. "Negative" skewing concentrates grid cells in the negative direction (backward), and "Positive" has the opposite effect. "Central" skewing pushes grid cells away from the center. To avoid excessive skewing, $\mathrm{s} \leq 2$ should be chosen for negative or positive skewing or $\mathrm{s} \leq 1.5$ for central skewing. Figure A-2 illustrates the three polynomials defined by Equation (1) for $s=1.5$. The figure also shows an example of negative skewing for three grid points initially placed at $\xi=0.25,0.50$ and 0.75 . The transformed coordinates become $\eta=0.125,0.354$ and 0.650 .

The revised, and generally preferred, polynomial skewing algorithm retains the negative and positive skewing algorithm indicated by Equation (1) but uses a different central skewing approach defined by

$$
\eta=\left\{\begin{array}{cc}
\frac{(2 \xi)^{s}}{2} & \xi \leq 0.5 \\
1-\frac{(2-2 \xi)^{s}}{2} & \xi>0.5
\end{array}\right.
$$


Thus the revised polynomial approach uses the negative skewing algorithm over the first half of the zone and the positive algorithm over the second half. This approach has the advantage that the skewing parameter (s) has the same meaning and limit $(<2)$ for negative, positive, and central skewing. The previous polynomial algorithm is identified by the demoted label "prev" (previous) whereas the revised approach is labeled "poly" in user inputs to Mesh2d.

In addition to the two polynomial-based skewing schemes, non-uniform gridding may be specified through a geometric growth factor. Skewing in the negative direction is specified through the recursive relationship

$$
\Delta \eta_{\mathrm{i}}=\mathrm{s} \Delta \eta_{\mathrm{i}-1}
$$

and positive skewing by

$$
\Delta \eta_{\mathrm{i}}=\Delta \eta_{\mathrm{i}-1} / \mathrm{s}
$$

Central skewing is performed by using negative skewing over the first half of the zone and positive skewing over the second half, similar to the revised polynomial scheme. Both even and odd numbers of grid cells are permitted, and the starting cell size is determined by interval length and a specified total number of cells. When the number of subdivisions is odd, the middle cell spanning the two halves of the zone has the same size as the two adjoining cells.

Material type assignments can be specified through index ranges for grid zones $(I, J)$ or cells $(i, j)$, or through trapezoids with vertical sides or general polygons defined in terms of $(\mathrm{x}, \mathrm{y})$ coordinates. Integers used to identify material type can take on arbitrary values and be assigned in any order.

Mesh2d produces grid coordinate, material type, and visualization files in multiple formats and coordinate systems. The software currently supported are the PORFLOW and STADIUM® computational codes, and the Tecplot, VisIt, Paraview, and Gnuplot plotting software. Cartesian and cylindrical coordinate systems are supported for PORFLOW. 


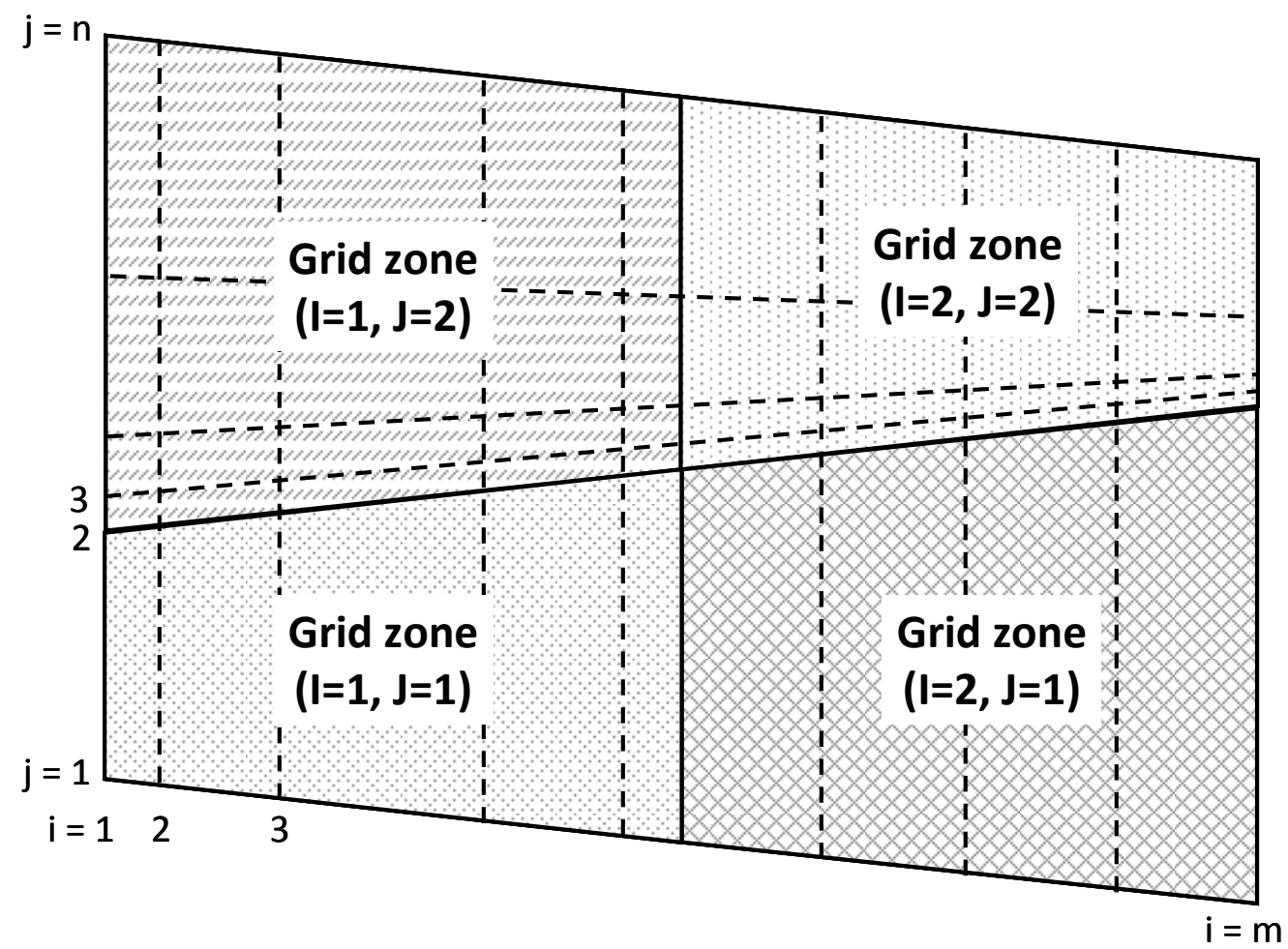

Figure A-1. Grid zones subdivided in various ways.

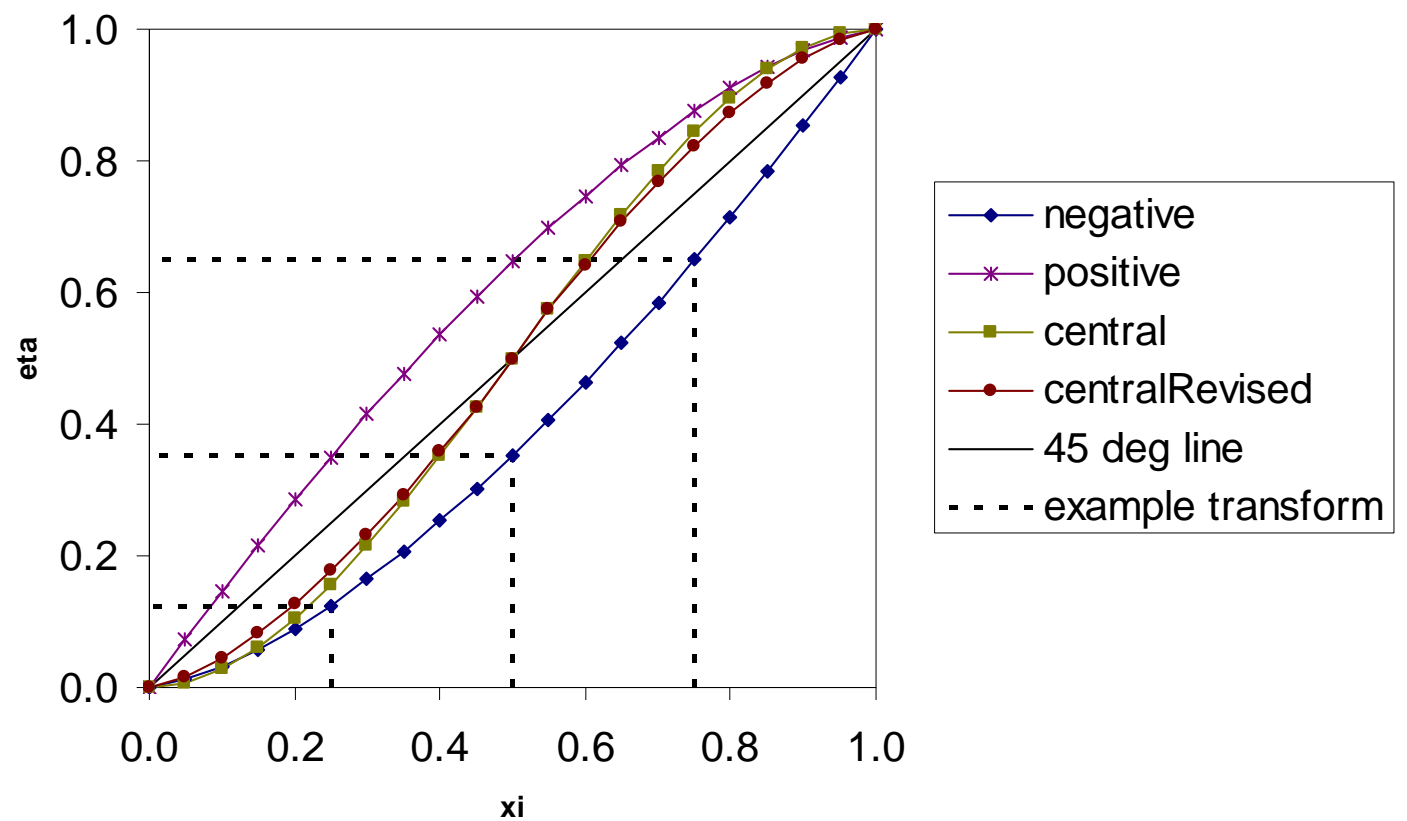

Figure A-2. Polynomial grid skewing defined by Equations (1) and (2) for $s=1.5$. 


\section{User specifications}

The top-tier input to Mesh2d is a superfile containing only filenames and high-level option specifications, in the order indicated by Table A-1. The input file containing the $\mathrm{x}(\mathrm{i})$ grid specifications can be assigned an arbitrary name, but is conventionally called $x$ Mesh.dat. Similarly, yMesh.dat and mtypMesh.dat are the traditional names for the $y(i, j)$ and mtyp $(i, j)$ specifications. These conventional names will be used for convenience in the remaining discussion.

The formats of XMesh. dat, yMesh. dat and mtypMesh. dat are defined in Tables A-2 through A-4. All three files may contain empty lines and/or comment lines denoted by an exclamation point in column 1, as any such lines are discarded during input processing. Material type specifications in mtypMesh. dat overwrite any prior specifications.

Table A-1. Superfile format.

\begin{tabular}{|l|l|}
\hline \multicolumn{1}{|c|}{ Input } & \multicolumn{1}{c|}{ Description } \\
\hline e.g. XMesh.dat & Input file containing x(i) grid specifications \\
\hline e.g. $y$ Mesh.dat & Input file containing y(i,j) grid specifications \\
\hline $\begin{array}{l}\text { e.g. } \\
\text { mtypMesh.dat }\end{array}$ & Input file containing mtyp(i,j) grid specifications \\
\hline xyz or xrt & Cartesian (xyz) or cylindrical (xrt) coordinates for PORFLOW \\
\hline & \\
\hline e.g. Mesh2d.log & Log file \\
\hline e.g. Mesh2d.dat & PORFLOW high-level grid specification statements \\
\hline e.g. COOR.dat & PORFLOW coordinates file \\
\hline e.g. TYPE.dat & PORFLOW material type file \\
\hline e.g. Stadium.cor & Stadium coordinate file \\
\hline e.g. Stadium.ele & Stadium element connectivity and material file \\
\hline e.g. Mesh2d.tec & Tecplot graphics file containing grid data points \\
\hline e.g. Geometry.tec & $\begin{array}{l}\text { Tecplot graphics file containing "TextGeom" geometries outlining grid zones and material } \\
\text { boundaries }\end{array}$ \\
\hline e.g. polygon.tec & $\begin{array}{l}\text { Tecplot graphics file containing "TextGeom" geometries for polygons (if used) to define } \\
\text { materials }\end{array}$ \\
\hline e.g. Mesh2d.vts & VTK graphics file suitable for VisIt and Paraview plotting software \\
\hline e.g. Mesh2d.gnu & Gnuplot graphics file \\
\hline
\end{tabular}


Table A-2. File format for specifying the $x(i)$ grid coordinates.

\begin{tabular}{|c|c|}
\hline Line & Format \\
\hline Line 0 & scale \\
\hline Line $\mathrm{I}, \mathrm{I}=1 \rightarrow \mathrm{M}$ & $\begin{array}{l}\text { iFlag } \mathrm{nx} \text { dir scheme skew scale } \mathrm{dx} \mid \mathrm{x} \\
\text { (one line per each of } \mathrm{M} \text { grid zones in the } \mathrm{x} \text {-direction) }\end{array}$ \\
\hline Input & Description \\
\hline iFlag & $\begin{array}{l}\text { Mode flag (integer }=0 \text { or } 1): \\
0=\text { Interval size specification for grid zone in field } 7(\mathrm{dx}) \\
1=\text { End position of grid zone specification in field } 7(\mathrm{x})\end{array}$ \\
\hline $\mathrm{nx}$ & Number of grid cells within the grid zone (integer $\geq 1$ ) \\
\hline dir & $\begin{array}{l}\text { Skewing direction (character): } \\
n=\text { negative } \\
p=\text { positive } \\
c=\text { central } \\
d=\text { disabled (uniform gridding) }\end{array}$ \\
\hline scheme & $\begin{array}{l}\text { Skewing scheme ( } 4 \text { character string): } \\
\text { prev = (previous) polynomial skewing scheme defined by Equation (1) } \\
\text { poly = polynomial skewing scheme defined by Equations (1) and (2) } \\
\text { geom = geometric skewing scheme defined by Equations (3) and (4) }\end{array}$ \\
\hline skew & Skewing parameter, s, in Equations $(1)$ through $(4)($ real < 2.0) \\
\hline scale & $\begin{array}{l}\text { Multiplier to } \mathrm{dx} \mid \mathrm{x} \text { typically used for units conversions (real }>0.0 \text { ), } \\
\text { e.g., scale }=30.48 \text { to convert } \mathrm{dx} \mid \mathrm{x} \text { in feet to centimeters for grid coordinates. }\end{array}$ \\
\hline $\begin{array}{l}\mathrm{x} 0 \\
\mathrm{dx} \mid \mathrm{x}\end{array}$ & $\begin{array}{l}\text { Line } 0 \text { : The origin of the } x \text { coordinate system }(x 0) \text { (real) } \\
\text { Line } I>0 \text { : The size }(d x) \text { or ending position }(x) \text { of grid zone } I(\text { real, } d x>0.0)\end{array}$ \\
\hline
\end{tabular}


Table A-3. File format for specifying the $y(i, j)$ grid coordinates.

\begin{tabular}{|c|c|}
\hline Line & Format \\
\hline Line 0 & $\mathrm{y} 0 \mid \mathrm{nPts}$ \\
\hline $\begin{array}{l}\text { Line } 0.1 \\
\ldots 0 . n P t s\end{array}$ & $\begin{array}{l}\mathrm{x} \quad \mathrm{y}(\mathrm{if} \text { iFlag }=1) \\
\ldots(\mathrm{nPts} \text { instances })\end{array}$ \\
\hline $\begin{array}{l}\text { Line } \mathrm{J}, \\
\mathrm{J}=1 \rightarrow \mathrm{N}\end{array}$ & $\begin{array}{l}\text { iFlag ny dir scheme skew scale dy|y|nPts } \\
\text { (one line per each of } \mathrm{N} \text { grid zones in the y-direction) }\end{array}$ \\
\hline $\begin{array}{l}\text { Line J.1 } \\
\ldots \text { J.nPts }\end{array}$ & $\begin{array}{ll}\mathrm{x} & \text { dy|y (if iFlag }=2 \mid 3) \\
\ldots & (\mathrm{nPts} \text { instances })\end{array}$ \\
\hline Input & Description \\
\hline iFlag & $\begin{array}{l}\text { Mode flag (integer }=0 \text { to } 3 \text { ): } \\
\text { For Line } 0 \\
0=\text { Fixed baseline for grid in field } 3(\mathrm{y} 0) \\
1=\text { Variable baseline for grid in field } 3 \text { (nPts) } \\
\text { For Line } \mathrm{J}, \\
0=\text { Fixed interval size specification for grid zone in field } 7(\mathrm{dy}) \\
1=\text { Fixed end position of grid zone specification in field } 7(\mathrm{y}) \\
2=\text { Variable interval size specification for grid zone in field } 7(\mathrm{nPts}) \\
3=\text { Variable end position of grid zone specification in field } 7(\mathrm{nPts})\end{array}$ \\
\hline ny & Number of grid cells within the grid zone (integer $\geq 1$ ) \\
\hline dir & $\begin{array}{l}\text { Skewing direction (character): } \\
n=\text { negative } \\
p=\text { positive } \\
c=\text { central } \\
d=\text { disabled (uniform gridding) }\end{array}$ \\
\hline scheme & $\begin{array}{l}\text { Skewing scheme (4 character string): } \\
\text { prev = (previous) polynomial skewing scheme defined by Equation (1) } \\
\text { poly = polynomial skewing scheme defined by Equations (1) and (2) } \\
\text { geom = geometric skewing scheme defined by Equations (3) and (4) }\end{array}$ \\
\hline skew & Skewing parameter, s, in Equations $(1)$ through $(4)($ real < 2.0) \\
\hline scale & $\begin{array}{l}\text { Multiplier to dy|y typically used for units conversions (real }>0.0) \text {, } \\
\text { e.g., scale }=30.48 \text { to convert dy|y in feet to centimeters for grid coordinates. The scaling factor } \\
\text { is also applied to any x values specified (e.g. iFlag }=2 \mid 3 \text { ). }\end{array}$ \\
\hline $\begin{array}{l}\mathrm{y} 0 \mid \mathrm{nPts} \\
\mathrm{dy}|\mathrm{y}| \mathrm{nPts}\end{array}$ & $\begin{array}{l}\text { Line } 0 \text { : The origin of the } y \text { coordinate system }(y 0)(\text { real }) \\
\text { Line } i>0 \text { and iFlag }=0 \mid 1: \text { The size }(\text { dy) or ending position }(y) \text { of grid zone } J(\text { real, dy }>0.0) \\
\text { Line } i>0 \text { and iFlag }=2 \mid 3 \text { : The number of }(x, \text { dy } \mid y) \text { pairs to follow (integer }>0)\end{array}$ \\
\hline $\begin{array}{ll}\mathrm{x} & \mathrm{dy} \mid \mathrm{y}\end{array}$ & For iFlag $=2 \mid 3,(x$, dy $\mid y)$ pairs, $n$ Pts in total, one pair per line \\
\hline
\end{tabular}


Table A-4. File format for specifying the mtyp(i,j) material assignments.

\begin{tabular}{|c|c|}
\hline Line & Format \\
\hline Line $\mathrm{K}$ & iFlag im|xm ip|xp jm|ymm jp|ypm mZone \\
\hline $\begin{array}{l}\text { Line K.2 } \\
\text { if iFlag =2 }\end{array}$ & ymp \\
\hline $\begin{array}{l}\text { Line K.2 } \\
\text { if iFlag }=3\end{array}$ & polygon (filename) \\
\hline $\begin{array}{l}\text { repeat as } \\
\text { needed }\end{array}$ & \\
\hline Input & Description \\
\hline iFlag & $\begin{array}{l}\text { Mode flag (integer }=0 \text { to } 3) \text { : } \\
0=\text { Material zone specified using grid zone indices }(I, J) \\
1=\text { Material zone specified using grid element indices }(i, j) \\
2=\text { Material zone specified by trapezoid with vertical sides using }(x, y) \text { points } \\
3=\text { Material zone specified by general polygon using }(x, y) \text { points }\end{array}$ \\
\hline $\mathrm{im} \mid \mathrm{xm}$ & $\begin{array}{l}\text { iFlag }=0,1: \text { starting zone }(\mathrm{I}) \text { or element }(\mathrm{i}) \text { index in } \mathrm{x} \text {-direction (integer) } \\
\mathrm{iFlag}=2: \text { left or } \mathrm{x} \text { - coordinate of trapezoid (real) } \\
\mathrm{iFlag}=3: \text { read but ignored }\end{array}$ \\
\hline ip|xp & $\begin{array}{l}\text { iFlag }=0,1: \text { ending zone }(\mathrm{I}) \text { or element }(\mathrm{i}) \text { index in } \mathrm{x} \text {-direction (integer) } \\
\mathrm{iFlag}=2: \text { right or } \mathrm{x}+\text { coordinate of trapezoid (real) } \\
\mathrm{iFlag}=3: \text { read but ignored }\end{array}$ \\
\hline $\mathrm{jm} \mid \mathrm{ymm}$ & $\begin{array}{l}\text { iFlag }=0,1: \text { starting zone }(\mathrm{J}) \text { or element }(\mathrm{j}) \text { index in } \mathrm{y} \text {-direction (integer) } \\
\mathrm{iFlag}=2: \text { lower left y coordinate of trapezoid (real) } \\
\mathrm{iFlag}=3: \text { read but ignored }\end{array}$ \\
\hline jp|ypm & $\begin{array}{l}\mathrm{iFlag}=0,1: \text { ending zone }(\mathrm{J}) \text { or element }(\mathrm{j}) \text { index in } \mathrm{y} \text {-direction (integer) } \\
\mathrm{iFlag}=2: \text { lower right y coordinate of trapezoid (real) } \\
\mathrm{iFlag}=3: \text { read but ignored }\end{array}$ \\
\hline mZone & Material type identification number (arbitary integer) \\
\hline ymp & iFlag $=2:$ upper left y coordinate of trapezoid (real) \\
\hline урp & iFlag $=2:$ upper right y coordinate of trapezoid (real) \\
\hline polygon & $\begin{array}{l}\text { iFlag }=3 \text { : filename of polygon with }(\mathrm{x}, \mathrm{y}) \text { vertices. Empty lines and lines with 'P', '\#' or a blank } \\
\text { in column } 1 \text { are ignored. The first vertex is repeated to close the polygon, e.g., } \\
(\mathrm{x} 1, \mathrm{y} 1) \\
(\mathrm{x} 2, \mathrm{y} 2) \\
\ldots \\
(\mathrm{x} 1, \mathrm{y} 1)\end{array}$ \\
\hline
\end{tabular}

\section{Example grid}

Figure A-3 illustrates an example two-dimensional grid and material type assignment that utilizes many of the grid specification options described above. Tables A-5 through A-9 list the contents of the Mesh2d input files 
used to generate the example mesh. The plot was generated from the Tecplot output files Mesh2d . tec, Geometry. tec and polygon. tec named in superfile Mesh2d. sup (Table A-5).

In the $\mathrm{x}$-direction the grid is composed of 4 zones, each subdivided into 5 elements or cells (Table A-6). The uniform gridding is accomplished in the first zone by disabling skewing $(\mathrm{dir}=\mathrm{d})$. The same effect can be achieved by setting the skewing parameter to 1.0. Non-uniform gridding is applied to the remaining three zones using negative, central and positive polynomial skewing in succession. Scaling is used to convert user inputs in inches and feet to centimeters for grid coordinates.

The grid is also composed of 4 zones in the y-direction (Table A-7). A variable baseline is defined through interpolation and extrapolation using two points. Linear interpolation is used between points and flat line extrapolation before and after the endpoints. Geometric skewing with a growth factor of 1.5 is specified for all zones, but skewing is disabled in the first zone. Note that the first zone is not subdivided $(\mathrm{nx}=1)$.

Every grid cell is initially assigned a material type number of 1 (active line 1 of mtypMesh . dat, Table A-8). The next 15 active lines, assign sequential material type numbers to each of the grid zones, thus overwriting the initial assignment. The final active lines overwrite the prior material type assignments using selection by cell indices, a trapezoid, and a general polygon. The polygon points are listed in Table A-9. In Figure A-3, the trapezoid is depicted in blue and the polygon in green. 


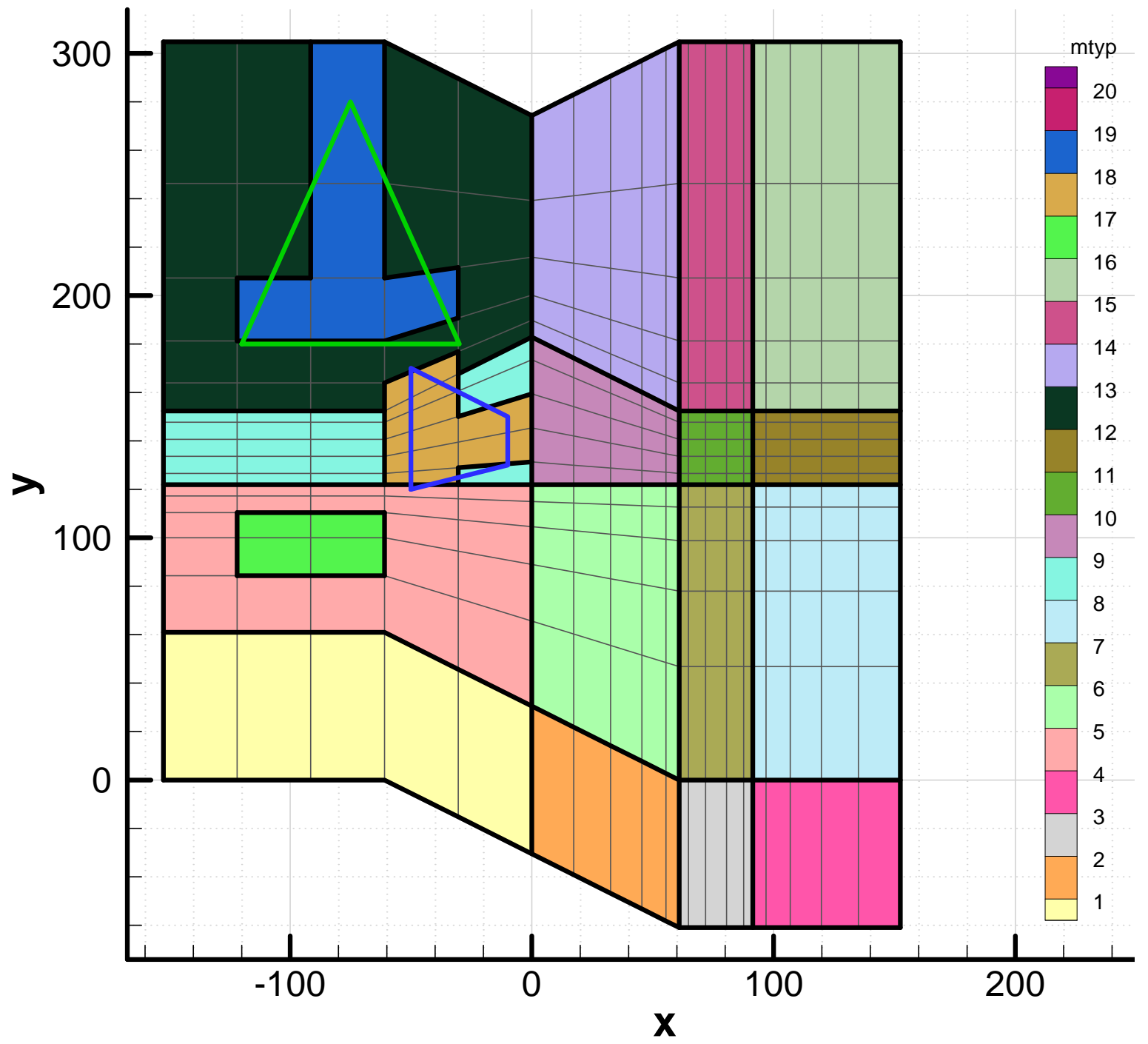

Figure A-3. Example two-dimensional grid generated by Mesh2d. 
Table A-5. superfile for example two-dimensional mesh.

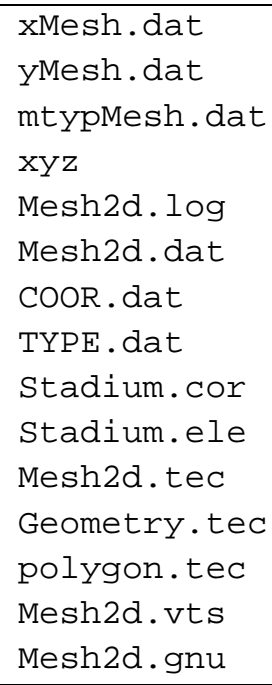

Table A-6. xMesh.dat file for example two-dimensional mesh.

\begin{tabular}{|c|c|c|c|c|c|c|c|}
\hline \multicolumn{8}{|c|}{ ! iflag key: } \\
\hline ! & \multicolumn{7}{|c|}{$\Theta=$ constant interval } \\
\hline$!$ & \multicolumn{7}{|c|}{$1=$ constant position } \\
\hline & \multicolumn{7}{|c|}{ key: } \\
\hline$!$ & \multicolumn{7}{|c|}{$p=p o s i t i v e$} \\
\hline$!$ & \multicolumn{7}{|c|}{$\mathrm{n}=$ negative } \\
\hline ! & \multicolumn{7}{|c|}{$c=$ center } \\
\hline ! & \multicolumn{7}{|c|}{$\mathrm{d}=$ disabled } \\
\hline \multicolumn{8}{|c|}{ !scheme key: } \\
\hline$!$ & \multicolumn{7}{|c|}{ geom=geometric growth factor } \\
\hline$!$ & \multicolumn{7}{|c|}{ poly=polynominal transformation } \\
\hline$!$ & \multicolumn{7}{|c|}{ prev=previous polynomial transformation } \\
\hline ! & & & & & & & \\
\hline \multirow{2}{*}{\multicolumn{2}{|c|}{ ! iflag }} & $\mathrm{nx}$ & dir & sch & & skew & scale $\mathrm{dx} \mid \mathrm{x}$ \\
\hline & & & & & 30.48 & -5 & 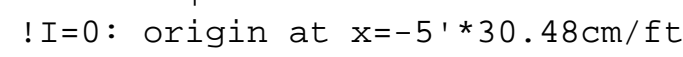 \\
\hline 1 & 5 & d & prev & 1.5 & 30.48 & $\odot$ & !I=1: step to $x=0^{\prime} * 30.48 \mathrm{~cm} / \mathrm{ft}$ \\
\hline$\odot$ & 5 & $\mathrm{p}$ & poly & 1.5 & 30.48 & 2 & $! \mathrm{I}=2:$ add $\mathrm{dx}=2^{\prime} * 30.48 \mathrm{~cm} / \mathrm{ft}$ \\
\hline$\odot$ & 5 & c & poly & 1.5 & 2.54 & 12 & ! I=3: add $d x=12 " * 2.54 \mathrm{~cm} /$ in \\
\hline$\odot$ & 5 & $\mathrm{n}$ & poly & 1.5 & 30.48 & 2 & $! \mathrm{I}=4:$ add $\mathrm{dx}=2^{\prime *} 30.48 \mathrm{~cm} / \mathrm{ft}$ \\
\hline
\end{tabular}




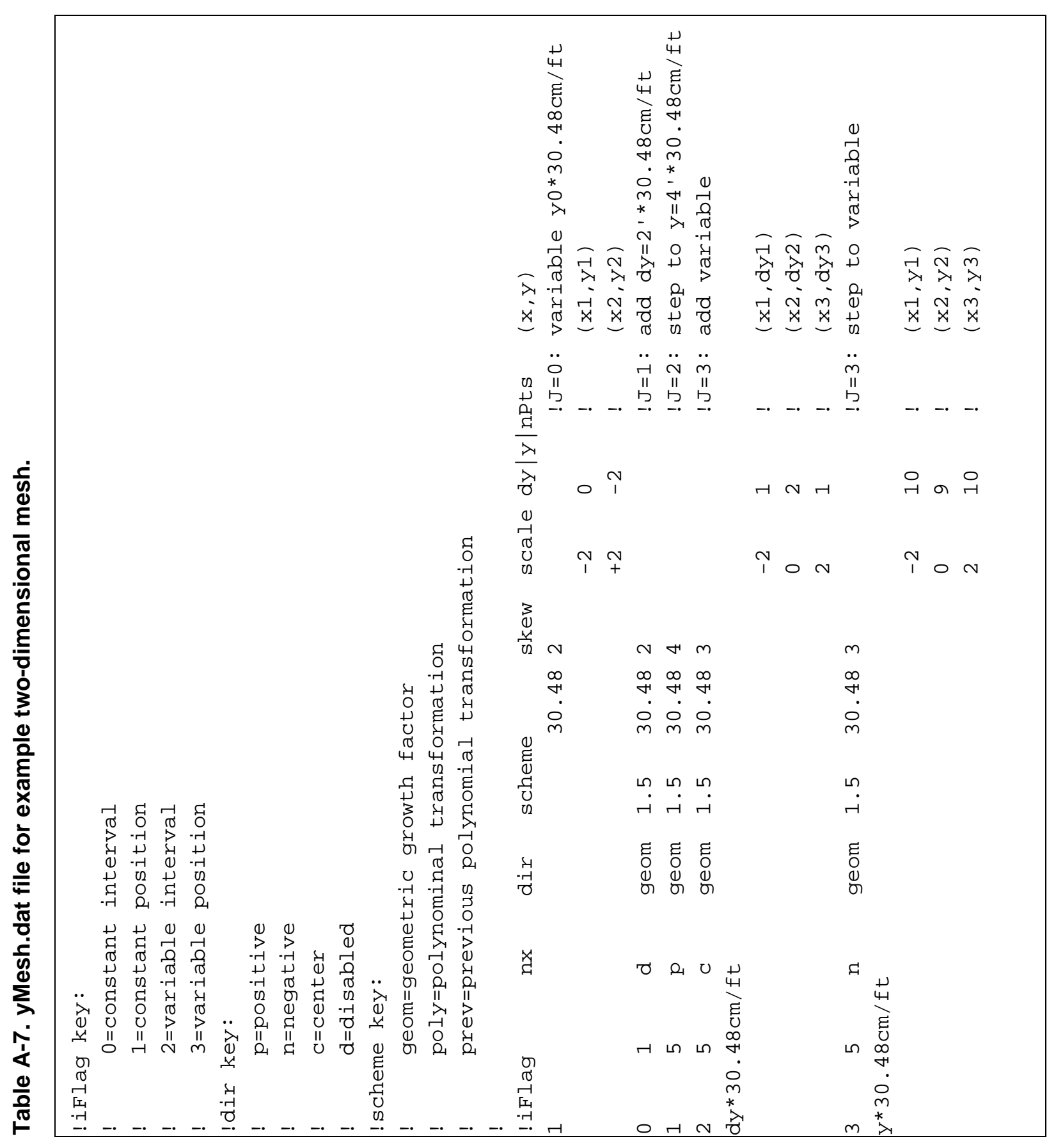


Table A-8. mtypMesh.dat file for example two-dimensional mesh.

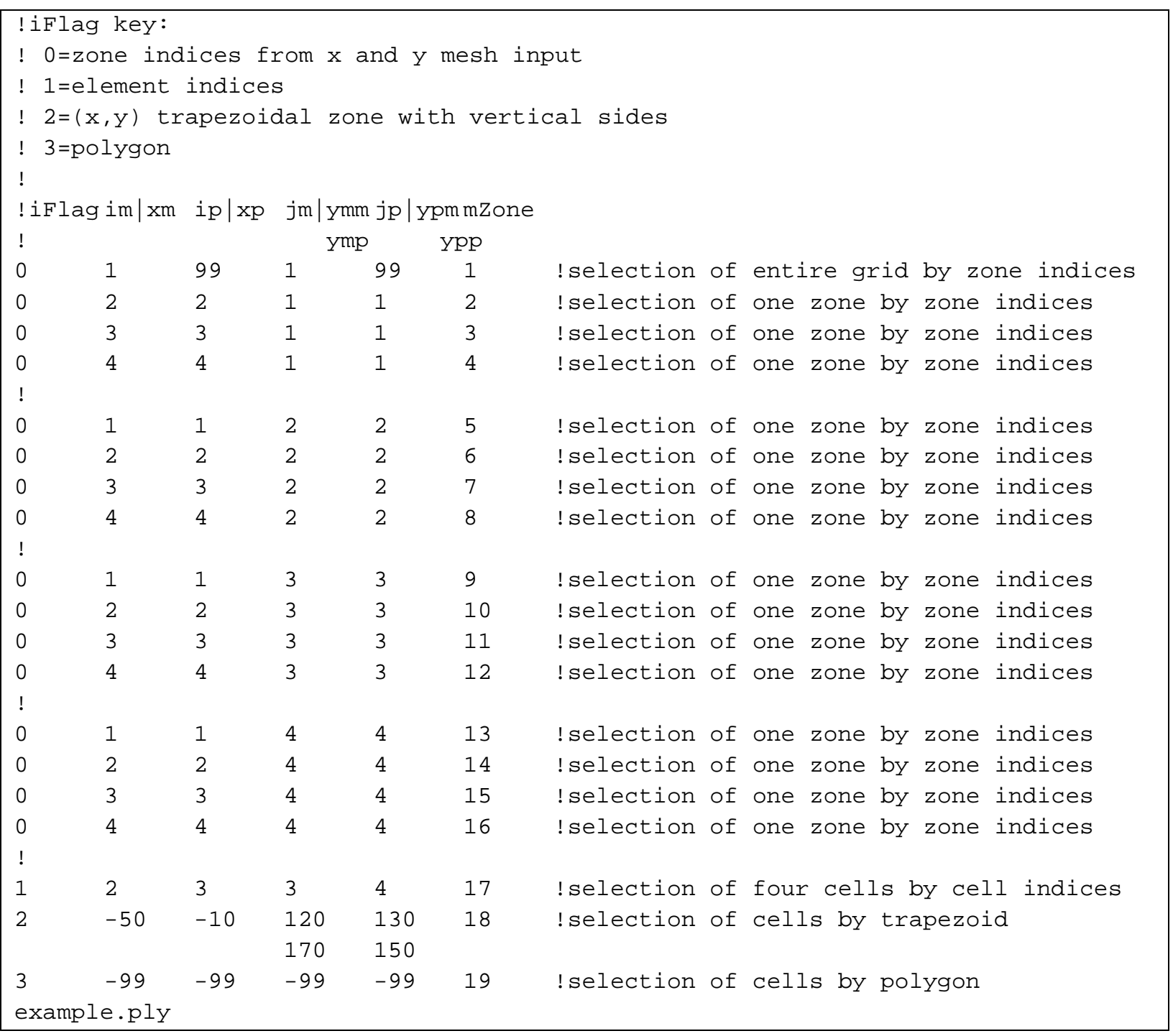

Table A-9. example.ply file referenced in mtypMesh.dat for example two-dimensional mesh.

\begin{tabular}{|ll|}
\hline \multicolumn{2}{l}{ Polygon file } \\
-120 & 180 \\
-30 & 180 \\
-75 & 280 \\
-120 & 180 \\
\hline
\end{tabular}




\section{APPENDIX B}

\section{MATERIAL PROPERTY DATA}




\begin{tabular}{|c|c|c|c|}
\hline Chemicals (mmol/L) & Concrete & Chemicals (mmol/L) & Concrete \\
\hline $\mathrm{OH}$ & 400.00 & $\mathrm{OH}$ & 449.00 \\
\hline $\mathrm{Na}$ & 282.10 & $\mathrm{Na}$ & 215.00 \\
\hline K & 138.00 & $\mathrm{~K}$ & 234.00 \\
\hline $\mathrm{SO} 4$ & 8.00 & $\mathrm{SO} 4$ & 1.00 \\
\hline $\mathrm{Ca}$ & 0.50 & $\mathrm{Ca}$ & 1.00 \\
\hline $\mathrm{AlO} 4 \mathrm{H} 4$ & 0.10 & $\mathrm{AlO} 4 \mathrm{H} 4$ & 0.00 \\
\hline $\mathrm{Cl}$ & 5.00 & $\mathrm{Cl}$ & 0.00 \\
\hline $\mathrm{H} 2 \mathrm{SiO} 4$ & 0.00 & $\mathrm{H} 2 \mathrm{SiO} 4$ & 0.00 \\
\hline $\mathrm{CO} 3$ & 0.00 & $\mathrm{CO} 3$ & 0.00 \\
\hline NO3 & 0.00 & NO3 & 0.00 \\
\hline NO2 & 0.00 & NO2 & 0.00 \\
\hline Minerals (g/kg) & Concrete & Minerals (g/kg) & Concrete \\
\hline Portlandite & 13.60 & Portlandite & 29.20 \\
\hline $\mathrm{CaH} 2 \mathrm{SiO} 4$ & 37.90 & $\mathrm{CaH} 2 \mathrm{SiO} 4$ & 75.10 \\
\hline Ettringite & 0.00 & Ettringite & 0.00 \\
\hline Monosulfate & 19.40 & Monosulfate & 29.80 \\
\hline $\mathrm{AFmOH}$ & 14.80 & AFmOH & 7.30 \\
\hline Thaumasite & 0.00 & Thaumasite & 0.00 \\
\hline Calcite & 0.00 & Calcite & 0.00 \\
\hline Monocarboaluminate & 0.00 & Monocarboaluminate & 0.00 \\
\hline Gypsum & 0.00 & Gypsum & 0.00 \\
\hline Properties & Concrete & Properties & Concrete \\
\hline Temperature, C & 23 & Temperature, $\mathrm{C}$ & 23 \\
\hline Water/Binder Ratio & 0.38 & Water/Binder Ratio & 0.38 \\
\hline Binder, $\mathrm{kg} / \mathrm{m}^{3}$ & 405 & Binder, $\mathrm{kg} / \mathrm{m}^{3}$ & 424 \\
\hline Aggregates, $\mathrm{kg} / \mathrm{m}^{3}$ & 1659 & Aggregates, $\mathrm{kg} / \mathrm{m}^{3}$ & 1787 \\
\hline Binder Density, $\mathrm{kg} / \mathrm{m}^{3}$ & 2885 & Binder Density, $\mathrm{kg} / \mathrm{m}^{3}$ & 3158.4 \\
\hline Porosity & 0.135 & Porosity & 0.12 \\
\hline Permeability, $\mathrm{m}^{2}$ & $1.80 \mathrm{E}-21$ & Permeability, $\mathrm{m}^{2}$ & $1.80 \mathrm{E}-21$ \\
\hline OH Diffusion Coefficient, $\mathrm{m}^{2} / \mathrm{s}$ & $1.40 \mathrm{E}-11$ & OH Diffusion Coefficient, $\mathrm{m}^{2} / \mathrm{s}$ & 3.67E-11 \\
\hline Isotherm Parameter $\square$ & -25.928 & Isotherm Parameter $\cong$ & -25.928 \\
\hline Isotherm Parameter $\square$ & 0.4285 & Isotherm Parameter $\cong$ & 0.4285 \\
\hline Relative Permeability & 18 & Relative Permeability & 18 \\
\hline Initial Hydration, days & 28 & Initial Hydration, days & 28 \\
\hline Reference Time, days & 28 & Reference Time, days & 28 \\
\hline Hydration Parameter a & 0.8 & Hydration Parameter a & 1 \\
\hline Hydration Parameter $\square \oplus 1 / \mathrm{s}$ & 0.015 & Hydration Parameter $\cong \Uparrow 1 / s$ & 0 \\
\hline Thermal Conductivity, W/m/C & 2 & Thermal Conductivity, W/m/C & 2 \\
\hline Specific Heat, J/kg/C & 1000 & Specific Heat, J/kg/C & 1000 \\
\hline Tortuosity & 0.3 & Tortuosity & 0.3 \\
\hline
\end{tabular}

Table B1. Type 1 and Type 2 Concrete properties. 


\begin{tabular}{|c|c|c|c|}
\hline Chemicals (mmol/L) & Saltstone & Chemicals (mmol/L) & Saltstone \\
\hline $\mathrm{OH}$ & 670.08 & $\mathrm{OH}$ & 766.40 \\
\hline $\mathrm{Na}$ & 4420.00 & $\mathrm{Na}$ & 4420.00 \\
\hline $\mathrm{K}$ & 120.00 & $\mathrm{~K}$ & 120.00 \\
\hline $\mathrm{SO} 4$ & 130.70 & $\mathrm{SO} 4$ & 82.00 \\
\hline $\mathrm{Ca}$ & 0.41 & $\mathrm{Ca}$ & 0.30 \\
\hline $\mathrm{AlO} 4 \mathrm{H} 4$ & 0.14 & $\mathrm{AlO} 4 \mathrm{H} 4$ & 0.40 \\
\hline $\mathrm{Cl}$ & 9.00 & $\mathrm{Cl}$ & 9.00 \\
\hline $\mathrm{H} 2 \mathrm{SiO} 4$ & 9.70 & $\mathrm{H} 2 \mathrm{SiO} 4$ & 12.50 \\
\hline $\mathrm{CO} 3$ & 2.90 & $\mathrm{CO} 3$ & 0.40 \\
\hline NO3 & 2000.00 & NO3 & 2000.00 \\
\hline NO2 & 1575.00 & NO2 & 1575.00 \\
\hline Minerals (g/kg) & Saltstone & Minerals $(\mathrm{g} / \mathrm{kg})$ & Saltstone \\
\hline Portlandite & 41.90 & Portlandite & 34.30 \\
\hline $\mathrm{CaH} 2 \mathrm{SiO} 4$ & 103.30 & $\mathrm{CaH} 2 \mathrm{SiO} 4$ & 86.40 \\
\hline Ettringite & 28.60 & Ettringite & 30.10 \\
\hline Monosulfate & 0.00 & Monosulfate & 11.30 \\
\hline AFmOH & 0.00 & $\mathrm{AFmOH}$ & 0.00 \\
\hline Thaumasite & 0.00 & Thaumasite & 0.00 \\
\hline Calcite & 4.80 & Calcite & 0.00 \\
\hline Monocarboaluminate & 11.00 & Monocarboaluminate & 39.20 \\
\hline Gypsum & 0.00 & Gypsum & 0.00 \\
\hline Properties & Saltstone & Properties & Saltstone \\
\hline Temperature, C & 23 & Temperature, $\mathrm{C}$ & 23 \\
\hline Water/Binder Ratio & 0.595 & Water/Binder Ratio & 0.595 \\
\hline Binder, $\mathrm{kg} / \mathrm{m}^{3}$ & 930 & Binder, $\mathrm{kg} / \mathrm{m}^{3}$ & 930 \\
\hline Aggregates, $\mathrm{kg} / \mathrm{m}^{3}$ & 0 & Aggregates, $\mathrm{kg} / \mathrm{m}^{3}$ & 0 \\
\hline Binder Density, $\mathrm{kg} / \mathrm{m}^{3}$ & 2603.5 & Binder Density, $\mathrm{kg} / \mathrm{m}^{3}$ & 2603.5 \\
\hline Porosity & 0.65 & Porosity & 0.65 \\
\hline Permeability, $\mathrm{m}^{2}$ & $4.00 \mathrm{E}-19$ & Permeability, $\mathrm{m}^{2}$ & $4.00 \mathrm{E}-19$ \\
\hline $\mathrm{OH}$ Diffusion Coefficient, $\mathrm{m}^{2} / \mathrm{s}$ & $7.50 \mathrm{E}-11$ & OH Diffusion Coefficient, $\mathrm{m}^{2} / \mathrm{s}$ & 7.50E-11 \\
\hline Isotherm Parameter ${ }^{\circ}$ & -6.4651 & Isotherm Parameter $\cong$ & -6.4651 \\
\hline Isotherm Parameter ${ }^{\circ}$ & 1.7825 & Isotherm Parameter $\cong$ & 1.7825 \\
\hline Relative Permeability & 18 & Relative Permeability & 18 \\
\hline Initial Hydration, days & 28 & Initial Hydration, days & 28 \\
\hline Reference Time, days & 28 & Reference Time, days & 28 \\
\hline Hydration Parameter a & 0.3 & Hydration Parameter a & 0.3 \\
\hline Hydration Parameter ${ }^{\circ} \mathrm{Y} 1 / \mathrm{s}$ & 0.003 & Hydration Parameter $\cong 81 / \mathrm{s}$ & 0.003 \\
\hline Thermal Conductivity, W/m/C & 2 & Thermal Conductivity, W/m/C & 2 \\
\hline Specific Heat, J/kg/C & 1000 & Specific Heat, J/kg/C & 1000 \\
\hline Tortuosity & 0.3 & Tortuosity & 0.3 \\
\hline
\end{tabular}

Table B2. Type 1 and Type 2 Saltstone properties. 


\begin{tabular}{|c|c|}
\hline Chemicals (mmol/L) & Soil \\
\hline $\mathrm{OH}$ & 0.5 \\
\hline $\mathrm{Na}$ & 0.25 \\
\hline K & 0.25 \\
\hline SO4 & 0 \\
\hline $\mathrm{Ca}$ & 0 \\
\hline $\mathrm{AlO} 4 \mathrm{H} 4$ & 0 \\
\hline $\mathrm{Cl}$ & 0 \\
\hline $\mathrm{H} 2 \mathrm{SiO} 4$ & 0 \\
\hline $\mathrm{CO} 3$ & 0 \\
\hline NO3 & 0 \\
\hline NO2 & 0 \\
\hline Minerals (g/kg) & Soil \\
\hline Portlandite & 1.00E-10 \\
\hline $\mathrm{CaH} 2 \mathrm{SiO} 4$ & 0 \\
\hline Ettringite & 0 \\
\hline Monosulfate & 0 \\
\hline AFmOH & 0 \\
\hline Thaumasite & 0 \\
\hline Calcite & 0 \\
\hline Monocarboaluminate & 0 \\
\hline Gypsum & 0 \\
\hline Properties & Soil \\
\hline Temperature, C & 23 \\
\hline Water/Binder Ratio & 0 \\
\hline Binder, $\mathrm{kg} / \mathrm{m}^{3}$ & 1291.5 \\
\hline Aggregates, $\mathrm{kg} / \mathrm{m}^{3}$ & 1358.5 \\
\hline Binder Density, $\mathrm{kg} / \mathrm{m}^{3}$ & 3150 \\
\hline Porosity & 0.35 \\
\hline Permeability, $\mathrm{m}^{2}$ & $5.00 \mathrm{E}-11$ \\
\hline OH Diffusion Coefficient, $\mathrm{m}^{2} / \mathrm{s}$ & 5.27E-10 \\
\hline Isotherm Parameter $\square$ & -29 \\
\hline Isotherm Parameter $\square$ & 1.25 \\
\hline Relative Permeability & 18 \\
\hline Initial Hydration, days & 28 \\
\hline Reference Time, days & 28 \\
\hline Hydration Parameter a & 1 \\
\hline Hydration Parameter $\square \not \varnothing 1 / s$ & 0 \\
\hline Thermal Conductivity, W/m/C & 2 \\
\hline Specific Heat, $\mathrm{J} / \mathrm{kg} / \mathrm{C}$ & 1000 \\
\hline Tortuosity & 0.3 \\
\hline
\end{tabular}

Table B3. Soil properties. 



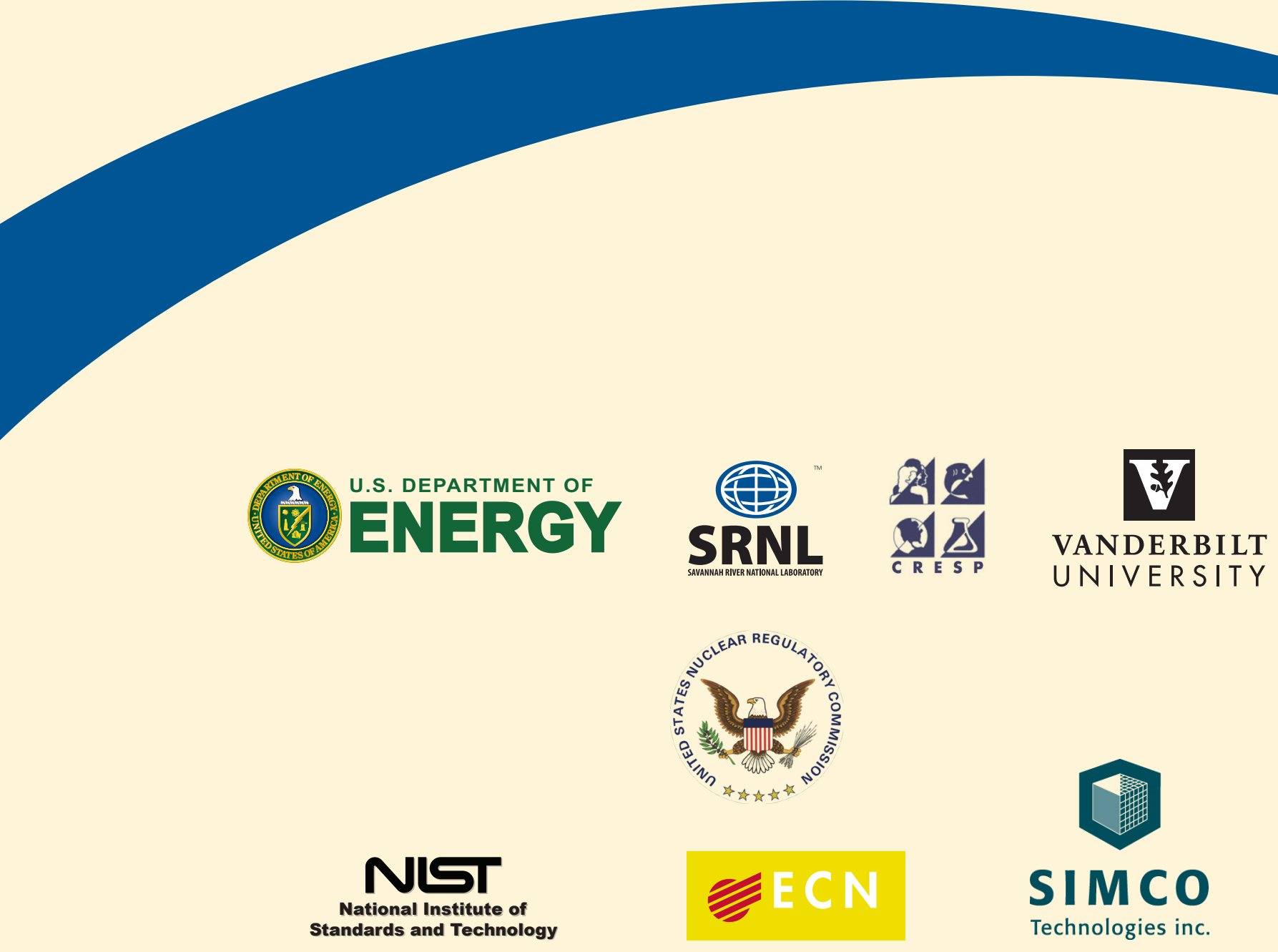

